Portland State University

PDXScholar

Summer 7-20-2018

\title{
The Intersections of Good Intentions, Criminality, and Anti-Carceral Feminist Logic: a Qualitative Study that Explores Sex Trades Content in Social Work Education
}

Meg Rose Panichelli

Portland State University

Follow this and additional works at: https://pdxscholar.library.pdx.edu/open_access_etds

Part of the Feminist, Gender, and Sexuality Studies Commons, and the Social Work Commons Let us know how access to this document benefits you.

\section{Recommended Citation}

Panichelli, Meg Rose, "The Intersections of Good Intentions, Criminality, and Anti-Carceral Feminist Logic: a Qualitative Study that Explores Sex Trades Content in Social Work Education" (2018). Dissertations and Theses. Paper 4512.

https://doi.org/10.15760/etd.6396

This Dissertation is brought to you for free and open access. It has been accepted for inclusion in Dissertations and Theses by an authorized administrator of PDXScholar. Please contact us if we can make this document more accessible: pdxscholar@pdx.edu. 
The Intersections of Good Intentions, Criminality, and Anti-Carceral Feminist Logic: A Qualitative Study That Explores Sex Trades Content in Social Work Education

Meg Rose Panichelli

A dissertation submitted in partial fulfillment of the requirements for the degree of

Doctor of Philosophy

in

Social Work and Social Research

Dissertation Committee:

Stéphanie Wahab, Chair

Ben Anderson-Nathe

Gita Mehrotra

Eric Mankowski

Portland State University

2018 
C 2018 Meg Rose Panichelli 


\begin{abstract}
This study uses anti-carceral feminist logic to explore the cultural meanings, criminal implications, and neoliberal influence that shape the landscape of social work education about the sex trades in the United States and transnationally. "What are social work instructors teaching students about the sex trades in coursework?" is the question that directs the study, which uses a feminist qualitative methodology inclusive of intersectional feminist epistemology as well as direct content analysis. To answer this question, I analyzed 20 social work course syllabi from sex trade related courses across the contiguous United States and interviewed 20 social work instructors from 14 different states.
\end{abstract}

Study findings show that course content represents people in the sex trades primarily as victimized cisgender women and girls with a significant focus on sex trafficking, especially within the Global South. While there is some course content that portrays sex trade workers as having complex and autonomous experiences, this material is limited to courses that have "sex" or "sexuality" in the title (i.e. "sex trafficking" or "sexuality and social work" courses). Furthermore, course content that represents the intersectional experiences and impact of systemic violence encountered by trans women of color and LGBTQ+ people is underrepresented in the sample--confined to two course syllabi and visibly absent from remaining syllabi. The sample indicates the prevalence of carceral approaches to the sex trades with an unexamined and racially-biased emphasis upon rescue and/or incarceration. This project provides significant implications for social work education about the necessity of an anti-carceral feminist, intersectional, and consequently, an anti-oppressive approach to teaching about the sex trades. 


\section{Dedication}

Adrienne, my teenage witch sister and sex work training partner, how do I even count the ways. Your critical insight on community building, accountability, systems of power, feminism, social work, and sex trade has been such a major contribution to my thinking, research, teaching, writing, dreaming, and loving during my time in $\mathrm{PhD}$

land. Thank you for being you, for seeing me, and for learning and growing with me. I have to dedicate this dissertation to you, because you helped me think it and write it without even knowing. 


\section{Acknowledgements}

Deb Ortega, years ago at breakfast you told me that as a white queer feminist who claims to be committed to social change I had a duty to write, and that I must use my knowledge to contribute to critical feminist scholarship. With the guidance and feedback of a rockstar committee, family, friends, and colleagues I am now at the point where my dissertation is complete. First, Dr. Lee and Thet Mar Win, your support of my progress as a teacher, researcher, student, and scholar has been invaluable. Thank you for your encouraging responses to programmatic and logistical needs along the way. I am additionally indebted to the social work faculty around the country who provided their time, syllabi, knowledge, and passion, without any material compensation to talk with me about the sex trades.

Furthermore, I could not have asked for a more outstanding dissertation committee. It has been the ultimate privilege to receive mentorship from Stéphanie Wahab as my dissertation chair. I am grateful that she believed in me even when I doubted my abilities often. Thank you for sharing your time, kindness, and critical feedback with me. Ben Anderson-Nathe, thank you for...well everything. Your pushback and insight on my writing, your open door, my first teaching adventures, and your nonjudgmental intellect are just a few. gita Mehrotra, I am grateful for the labor of care you extended to meet about dissertating, research, teaching, the job market, and life circumstances. Your insight and feedback on drafts were invaluable and helped me look beyond the page. Thank you for helping me feel as though I belonged no matter how often I stumbled over my words to try and communicate intellectually. Lastly, thank you 
Eric Mankowski for serving as my OGS rep and providing encouragement for my dissertation vision.

Throughout my Undgergraduate degree in Women's Studies and my Master of Social Work program, I developed a "dream team" of mentors who were instrumental in making a career in academia feel accessible and enjoyable. Thank you Page Buck for teaching me about subjugated knowledges. Darla Coffey I will remain appreciative of our powerful conversations during superversion. Nadine Bean, thank for your mentorship on my first qualitative research project. JB, your role as my first mentor which grew into friendship over the last 16 years helped to nurture my queer feminist identity, dreams, and goals. It was your Lesbian Studies class where I first encountered the impact of a professor who loved learning, teaching, and inspiring activism. Lisa Huebner, thank you for teaching about emotional labor and intersectionality, and for your feminist mentorship. Adale, thank you for your friendship, humor, and endless feedback on my writing.

Finally, my sweet family and friends, (Lee, Aidan, Sloan, Mom \& Dad Watts, Traci, Tina, and Amy and families, and Jenna, Jesse, Dad, Dawn, Michelle, Zoe, Cassie, the E's, GL, Beka, Rian, Saron, and Luc). Steph and Lisa, thank you for \#community, and thoughts about cultivating empathy. Lee Watts, my magical, generous, and creative partner who not only believed me in and told me so everyday, but who took on the bulk of weekend parenting so that I could write, you have my endless gratitude. Sloan, your birth, joy, and growth in the world serves as a reminder everyday of what is possible and to keep dreaming radical visions for the future. Sister, thank you for your love and kindness even during the toughest times one could go through. Thank you to my dad, for 
teaching me never to give up on my dreams even when I'm the shortest one on the team and self-doubt creeps in.

Finally, to all of the radical intersectional-anticarceral-queer-trans-feministscholar-activists-educators and organizations whose work and knowledge has taught me how I must strive to live, love, and work in this world: (just to name a few) Angela Davis, Emi Koyama, Kimberlé Crenshaw, bell hooks, Chandra Talpade Mohanty, Amber Hollibaugh, Beth Richie, Andrea Ritchie, Nancy Naples, PJ Starr, Dean Spade, Alexandra Lutnick, TGI Justice Project, Young Women's Empowerment Project, Project SAFE, Sex Workers Project, INCITE! and so many others. I also just want to name my gratitude for the 2012 NWSA Atlanta Conference where Dr. Analouise Keating and Dr. Gloria González-Lopéz brought many people together in the spirit of Gloria Anzaldúa to share and embrace her impact on our lives. To Gloria Anzaldúa for, "now let us shift...the path of conocimiento...inner work, public acts" so that I could survive grad school—and beyond. 


\title{
TABLE OF CONTENTS
}

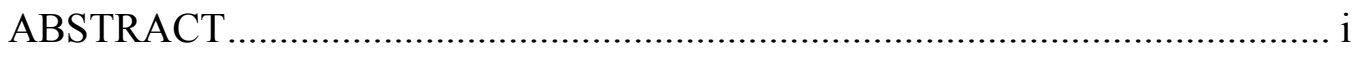

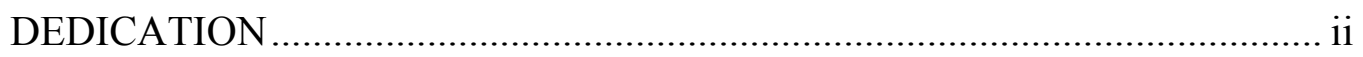

ACKNOWLEDGEMENTS ........................................................................ ii

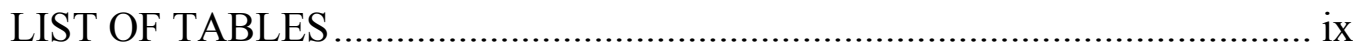

\section{CHAPTER}

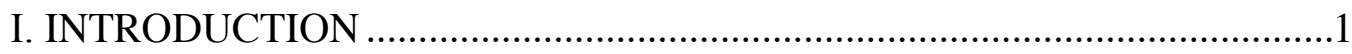

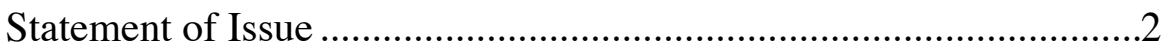

Language, Terms, and Definitions ....................................................13

Significance of Study for Social Work ……………………….........17

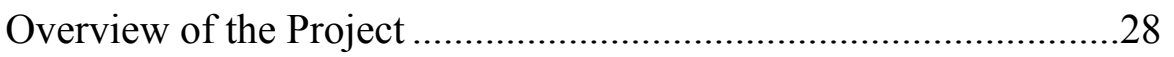

Social Work Education as Site for Inquiry .......................................29

II. LIT REVIEW \& THEORETICAL FRAMEWORK ……………..................33

Rescuing Fallen Women: A History of Carceral Feminism in

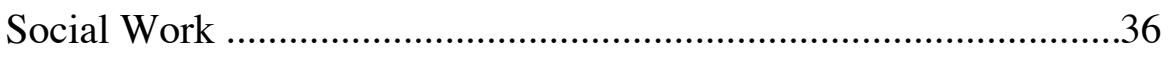

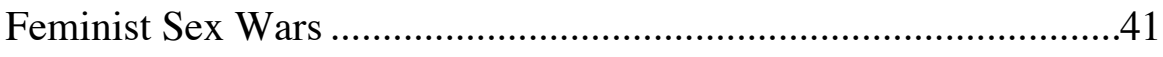

Radical Feminists vs. Sex Radical Feminists ....................................43

What is Carceral Feminism? ............................................................46

Carceral Feminisms in Policy ..........................................................51

Critique of Carceral Feminisms and Rescue Social Work................65

Theoretical Framework: Anti-carceral Feminism ……………..........76

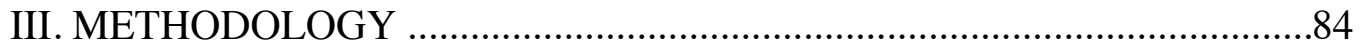

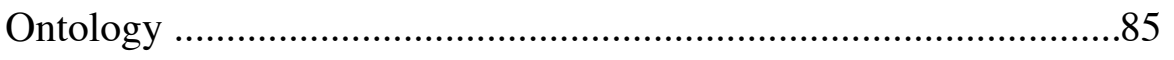

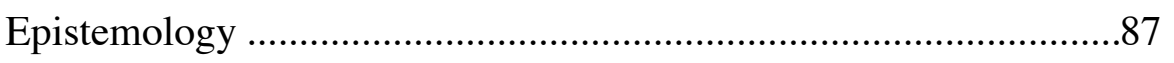


Feminist Epistemologies in this Project......................................90

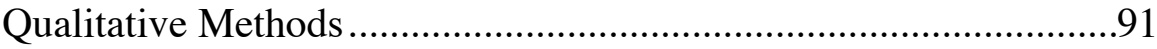

Feminist Methods in Qualitative Research ..................................93

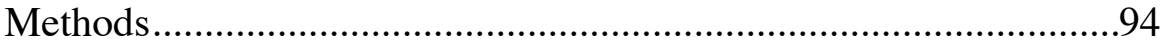

Research Question .................................................................96

Sampling and Recruitment...................................................97

Data Analysis: Content Analysis of Data ..................................102

Demonstrating Rigor/Quality in Content Analysis .......................109

Ethical Issues in Feminist Research .........................................118

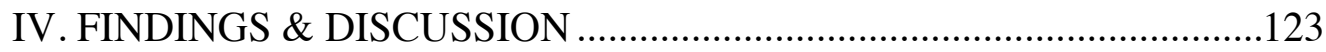

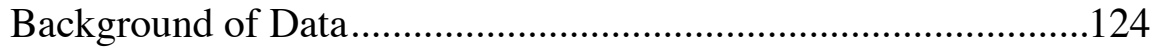

Experiences of People in the Sex Trades Represented

in Courses ................................................................................127

Representations of the $3^{\text {rd }}$ parties Who Facilitate Sex Trade.........147

People in the Sex Trades Have Complex Experiences..................158

Good Intentions and Carceral Feminisms ...................................164

Instructors Socialize Students to Grasp the Experiences of

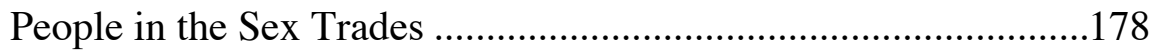

Conclusion....................................................................204

V. ANALYSIS \& IMPLICATIONS ....................................................206

The Anti-carceral Feminist Politics of Using Racialized

Imagery to Teach about Sex Trade..............................................208

Use an Intersectional Lens to Examine Concepts and Values About Sex(uality) .....................................................212

The Exclusion of Trans Women of Color (TWOC) and Lesbian, Gay, Bisexual, Transgender, and Queer (LGBTQ) People ...........214 
Cultivating Empathy for "Good Victims".

Impact of Feminist Imperialism on Cisgender Women

and Girls in the Global South

Rescue Work is Paramount .......................................................218

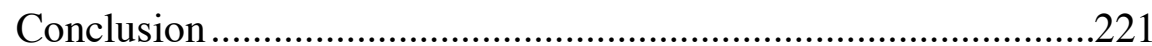

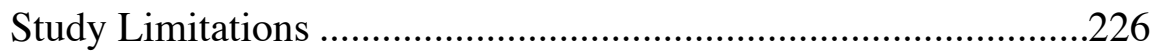

Future Directions for Social Work ..........................................228

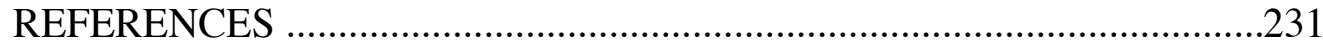

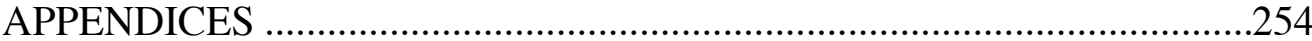

Appendix A: Template for analyzing syllabi ...........................254

Appendix B: Recruitment Letter to Faculty to share syllabi and/or be interviewed ................................................255

Appendix C: Original Interview Guide ...................................256

Appendix D: Revised Interview Guide ...................................257

Appendix E: Raw Data for organizing and coding content...........258 


\section{LIST OF TABLES}

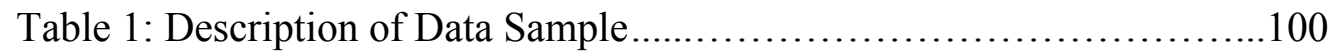

Table 2: Cisgender women and girls as victims of "bad cisgender men .......134

Table 3: Women in the Global South are particularly vulnerable to SE .......141

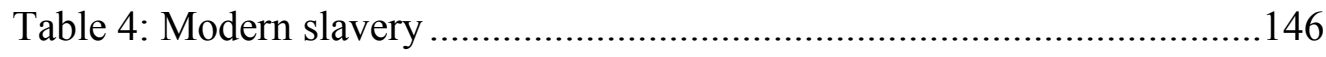

Table 5: Representations of the $3^{\text {rd }}$ Parties who facilitate sex trade ..............153

Table 6: (sub-theme) The subjectivity of human rights .............................158

Table 7: People in the sex trades have complex experiences ........................160

Table 8: (sub-theme) LGBTQ people in the sex trades ..............................163

Table 9: Interventions intended to address trauma ..................................170

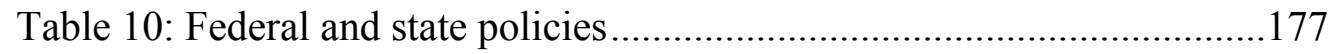

Table 11: "Vigilante Rescue" will help end global sex trade ......................181

Table 12: (sub-theme) Feminist abolitionism ..........................................185

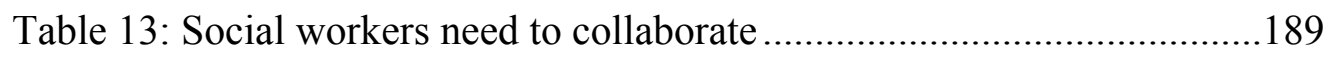

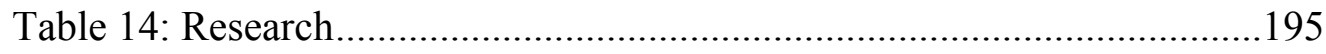

Table 15: Talk about sex..............................................................200

Table 16: Interrogate structural violence ................................................203 


\section{Chapter I: Introduction}

We have a problem. The following Black women, Latesha Clay ${ }^{1}$, Alisha Walker ${ }^{2}$, Monica Jones $^{3}$, Marissa Alexander ${ }^{4}$, Bresha Meadows ${ }^{5}$ represent just a small number of the countless victims of carceral feminist policies and practices. The above women are all criminalized by policies aimed at combatting gender-based violence and protecting survivors of violence. This group consists of sex workers, sex worker activists, women of color, trans women, domestic violence survivors, trafficked youth (as defined by the law), poor women, women who have been imprisoned, criminalized, and deemed by a judge or jurors to be guilty of committing a crime. However, these same women are targeted by oppression based on their intersectional marginalized identities as they navigate micro, mezzo, and macro systems. The many identities that these women share are among groups that social workers have deemed vulnerable (NASW, 2008). Although working to meet the needs of oppressed individuals, families, and communities is at the heart of social work values, some social workers have embraced advocacy and intervention efforts that lead to further violence, trauma, and harm in the lives of people who work in the sex trades.

\footnotetext{
${ }^{1}$ Latesha Clay is a 15 year-old African-American woman from Kent County, Michigan, who posted an ad on the internet offering sex with a teenager, and when her client showed up, two other people with her pointed a gun at the client and made the client withdraw money from ATM. Clay was sentenced to 9 years in prison, which the judge said was the lower-end of the sentence (Agar, 2016).

${ }^{2}$ Alisha Walker is an African-American sex worker in Chicago, who was sentenced to 15 years in prison for the death of Alan Filan, a client, when she defended herself after being confronted by Filan when she wouldn't provide unprotected sex. He ended up dying, and she was charged with $2^{\text {nd }}$-degree murder. ${ }^{3}$ Monica Jones, a phoenix-based sex worker activist arrested on a manifesting prostitution charge. She is a Black Trans woman and is a recent graduate of the Arizona State University School of Social Work.

${ }^{4}$ Marissa Alexander in an African-American woman from Florida who was arrested after firing a warning shot in the sky to scare off her abuser.

${ }^{5}$ Bresha Meadows is a, " 14 year old girl who is charged with aggravated murder with a gun for killing her father. She shot her father while defending her mother during a domestic violence incident. Born into a nightmare of domestic abuse, she and her family were subject to domestic violence for over 20 years at the hands of her father" (www.breshameadows.com).
} 
In this project, I look to social work education as the site of inquiry, because I am deeply concerned about interventions institutionalized in the field of social work that focus on "rescue" as a strategy for helping. By looking to social work education, I question what is taught related to the sex trades and ultimately to understand the landscape of education that informs social workers about their roles in working with the sex trades across micro, mezzo, and macro practice. Further, I engage the sex trades content used for instruction in social work education through the lens of anti-carceral feminist logic because it centers intersectionality, alternatives to criminalization for sex trade workers, and aligns with a vision of social justice that seeks to dismantle oppression through all social institutions.

\section{Statement of Issue}

It is essential to frame the issues that inform this study as intersectional, because the problem facing the women whose names begin this chapter, is based on the convergence of race, class, gender, and sexuality which frame them as criminals and not victims, workers, or survivors. As Black women, perceptions of their sexuality have been shaped by images that portray them as "wild" and "animalistic" and unable to be tamed (Collins, 2005, p. 28). If racial stereotypes mark these women as always on the prowl and sexually promiscuous, they are also viewed as unable to be victimized (since they are always ready to be sexual) and therefore, if involved in illegal behavior are easily seen as criminals (Collins, 2005; Richie, 2012). In particular, women who trade sex for money defy hegemonic femininity by virtue of being sexually active rather than chaste. Such defiance marks them as social, sexual, and gender deviants. A critical feminist analysis suggests that these women are criminalized as a result of intersectional oppression in 
their lives, and for the ways that they deviate from dominant white western gender normativity.

The women named at the beginning of this chapter have been severely impacted by legislation that was passed with the intention of helping women who are survivors of violence. As sex workers and survivors of domestic violence, they share common experiences of systemic oppression, and although the experiences of surviving intimate violence and working in the sex trade are not synonymous, both groups are frequently labeled as victims or survivors. However, because these women also deviate from hegemonic femininity and experience oppression that intersects their experiences in the sex trades and in surviving domestic violence, the legal system may discriminate and assign them criminal status, despite their experience. Such contradictions have been seen through the enactment of policies of under the Trafficking Victims Protection Act and the Violence Against Women Act.

As a result of successful second wave feminist and social work policy campaigns for legislation to address gender-based violence, the Violence Against Women Act (VAWA) passed as part of the Violent Crime Control and Law Enforcement Act in 1994. In 2013, the VAWA was reauthorized and expanded to address the high rates of sexual assault on college campuses, the impact of sexual assault and domestic violence on housing, immigration, to be the culturally specific needs of indigenous, youth, and LGBT communities, and to increase legal responses to severe forms of trafficking (Legal Momentum, 2015). Notably, the initial enactment of the Violence Against Women Act in 1994 was instituted due to the severity of crime related to domestic violence, sexual assault, and stalking and ultimately, to end violence against women (Legal Momentum, 
2015). The act required the institution of legal consequences for offenders of intimate partner violence so that they would be held accountable for their behavior (VAWA, 1994). The Department of Justice allocated $\$ 800$ million in $\mathrm{STOP}^{6}$ grants to strengthen arrest policies, prosecution strategies, and services for survivors. VAWA improved criminal justice responses by "increasing rates of prosecution, conviction, and sentencing of offenders by helping communities develop dedicated law enforcement and prosecution units and domestic violence dockets" (www.whitehouse.gov). The increased emphasis on the justice system ultimately meant that a stronger police presence would control the neighborhoods of poor people and people of color (McArdle, 2001). Although these policies focus on protecting victims and survivors of domestic violence, trafficking, and gender discrimination, the women named above were harmed through incarceration, rather than provided with accessible services (Whittier, 2016).

Many scholars, activists, and feminist from marginalized communities have emphasized the connections between policies mean to protect victims of domestic violence, sex trafficking, and the criminalization of queer, trans, and non-binary people of color (Bierria, 2007; Davis, 2003; INCITE!, 2014; Mogul, Ritchie \& Whitlock, 2011; Richie, 2012; The Revolution Starts at Home, 2003; UBUNTU, 2007). Through the policing of gendered crime, women of color, trans people, and gender non-binary people have been subjected to violence through the state, while the crime of male violence against women is being pursued (Davis, 2003; INCITE!, 2014; Richie, 2012; Ritchie, 2016). For example, Kelley Williams-Bolar, a Black woman escaping violence in her neighborhood, relocated herself and children to her father's house in an affluent

${ }^{6}$ STOP: Services, Training, Officers, Prosecution Grants (VAWA, 1994). 
neighborhood and had her children transferred into the neighborhood school. After investigation into her W-2 forms, residency, and questioning whether she occupied the address on her official documents, she was found to be "guilty of what could be understood to be stealing an education for her children" and sentenced to 10 days in jail, 2 years of probation and community service (Richie, 2012, p.101). Despite studying to become a teacher, she was no longer eligible for hire once charged with a felony. Williams-Bolar found herself in a double bind; on the one hand disenfranchised by the justice system when they removed her ability to make a decent and living wage, on the other hand she was expected to find enough work to support her family.

Feminist activism focused on legislation reform that draws on increased law enforcement and threats of incarceration to help people named as victims, creates criminals out of women of color who have experienced state and gender-based violence. This is an important connection that threads responses to intimate partner violence and the labeling of people in the sex trades as victims. The criminalization of Black women who have experienced intimate partner violence as well as the criminalization of Black women who have traded sex for money highlight the many contradictions in feminist activism rooted in a punitive legal system. Even laws intended to criminalize aggressors make navigating the legal system for victims unsafe. For example, when domestic violence survivors file for a protection order, intended to protect the petitioner should the order be violated, the fear of retaliation is ever present. Although physically violating a protection order is cause for immediate arrest, there is time in between a call to law enforcement and arriving on the scene. In addition, the history of law enforcement 
violence against Black people may make reaching out to them more a threat to a victims' safety than the abuse being experienced from an intimate partner.

The widespread criminalization of Black cis and trans women, both adults and youth, disrupts a logic of compulsory victimization and exposes the Anglocentric foundations of rescue as a strategy for help. For many cis and trans women and youth of color the sex trades may be the most viable option for making money when escaping institutional violence, abuse, or exclusion. The experiences of youth and trans women in the sex trades is one in which blurs the lines between choice, circumstance, and coercion. While one may choose to do sex work to make money, one does not choose to experience employment discrimination based on their race and gender identity. While a person does not choose to experience abuse, they may realize that working in the sex trades is a lucrative means to making money and escaping the abusive situation.

The criminalization of marginalized people who have experienced domestic violence and of those who work in the sex trades leads me to question how social workers learn to participate in these processes of criminalization. Specifically, in the context of social workers engaging with the sex trades, Agustin (2007) has termed the "rescue industry" as a critique of helping professionals' emphasis on sex workers as victimized or helpless. A large part of the rescue industry is the continuous expansion of NonGovernmental Organizations (NGOs) that work in the spirit of humanitarianism to "rescue" trafficked women from their circumstances, house them, provide them with a structured environment, and teach them a trade such as jewelry making (Agustín, 2007).

The oppressive strategies used to disproportionately target people in the sex trades mark the importance to look beyond feminist "Sex Wars" discourse that has shaped sex 
workers as either victims or agents of sexual exchange (Chapkis, 1997; Hollibaugh, 2000; Barton, 2006; Duggan \& Hunter, 2006). In other words, when researching the sex trades we must go beyond binary discourses of victims and agents, and dig into the complexity of intersectionalities of race, class, gender, sexuality, disability, ethnicity, and nation of origin. An intersectional exploration of the rescue industry facilitates insight on how social membership categories mark the experiences of, accessing social and legal services, safety during work, violence, clients, and the likelihood of being targeted by the police.

Elena Shih's (2016) participatory research study with "vigilante" sex trafficking programs in L.A, highlight some of the problematic aspects of compulsory victimization. The specific programs she researched and volunteered with were centered on "vigilante rescue." She defines this term as a kind of volunteerism inspired by "rescue discourse," in which she states, "outreach volunteers go into communities where they have no stake in and measure victimhood and vulnerability through bias-driven perceptions of ethnicity, race, gender, and class difference" (2016, p. 59). Shih explains that due to the failed efforts of law enforcement to build community partnerships and their inability to identify victims of trafficking, there has been an increase nationwide in vigilante surveillance. Evidently, this type of surveillance accompanies new bills that penalize anyone who receives money that has come from a sexual transaction (such as OR HB4082 ${ }^{7}$ ). Moreover, Shih found that each of the vigilante rescue organizations she volunteered with worked in collaboration with the police, however were not all transparent about how

\footnotetext{
${ }^{7}$ Oregon House Bill 4082: Expands the crime of promoting prostitution to anyone receiving goods, services or other things of value derived from prostitution activity in certain circumstances. (§1 ORS167.012 (2016))
} 
the local police used their data. In her participatory research, as a volunteer with rescue missions, she was trained to use nativist, racist, classist, and gendered notions of who trafficked persons are (2016). The "civilian" groups she worked with handed out governmental anti-trafficking brochures in the case trafficked people need legal assistance, and thereby demonstrate how such vigilante groups become agents of the State. This is problematic particularly because these volunteers rely on race, class, gender, ethnicity, and age based bias to identify victims of trafficking (Shih, 2016). Such identification practices link communities already vulnerable to institutional xenophobia, racism, adultism, and transphobia to the very structures who legally sanction their work.

Sex work activists and scholars have recognized that anti-sex trafficking organizations dependence on getting sex workers out of the industry ultimately deny sex workers agency as well as human, political, and economic rights (Agustin, 2007; Ditmore, 2009; Jackson, 2016; Lerum, 1999; Lerum \& Brents, 2016; Shih, 2012; Shih, 2016). Anti-trafficking efforts work with law enforcement and threaten deportation or incarceration to ensure that the rescued will testify against $3{ }^{\text {rd }}$ parties. If "victims" testify against a $3^{\text {rd }}$ party, they may be in further danger. However, if they don't testify or provide information, they are placed under arrest or funneled into a rehabilitation program, both options that take away agency and the ability to earn money. Additionally, their daily activities are restricted, they are exploited through labor that will not reap a living wage, they may be removed from family and community, and forced to detox off of drugs. The consequences of receiving help from "rescue missions," resemble abusive dynamics, and may further the impact of trauma and systemic oppression in the lives of 
people working in the sex trade (Agustín, 2007; Brennan, 2014; Koyama, 2013; Lerum, McCurtis, Saunders, \& Wahab, 2012; Parrenas, 2011; Sex Workers Project 2011). In fact, Elizabeth Nolan Brown (2016), recently spoke in a TED talk about the Courage House (a house for trafficked women in Sacramento), which has isolated, traumatized, and exploited victims of trafficking in order to amass money for the organization. At Courage House, the director used the residents for photo opportunities and publicity and forced them to attend Christian education classes without providing the social services that they claimed to provide for residents of the house. Due to many citations for breaching confidentiality, breaking state-rights policies (such as withholding cell-phones from the women at the house for their own safety), the Courage House closed its doors (Lundstrom, 2016). Staff at the house included social workers and trauma specialists committed to working with this population.

Monica's story and Project ROSE. It is not uncommon for well-intentioned social workers to turn towards rescuing people from the sex trades. In fact, social work has historically committed itself to rescuing women who had "fallen from virtue" (Wahab, 2002). Through charity organizations and settlement houses, early American social workers sought to inspire moral conformity and gender rigidity among women who had lost their way, were sexually promiscuous, or had been lured into the life of prostitution. One contemporary and prominent example of social workers' "good intentions" gone bad through compulsory victimization is the case of Monica Jones, a Black trans woman, out-spoken sex worker activist, and graduate of Arizona State University's School of Social Work program (Strangio, 2014). Prior to beginning her social work classes at ASU, she was arrested through an undercover prostitution sting 
known as Project ROSE (a prostitution diversion program) in Phoenix, AZ. Project ROSE (now defunct) was an intervention headed by ASU social work faculty member, Dr. Dominique Roe-Sepowitz, through the Sex Trafficking Institute on Research. RoeSepowitz has determined that since it is difficult to tell who is working autonomously and who has been trafficked, every person encountered through the Project ROSE operation is assumed to be a victim of sex trafficking (2014). When arrested in this undercover sting, Monica was brought in handcuffs to a church where she was offered (if eligible) a chance to engage in the Project ROSE program or take a mandatory jail sentence. Project ROSE offered diversion as an alternative to arrest; any sex worker, who had no prior prostitution offense, or drugs in their possession when picked up, was eligible for the program. If participants successfully completed the program, their prostitution charges would be dropped. If they chose not to go through the program or deemed ineligible, they were given a mandatory jail sentence. Monica discovered that she was not eligible for their program, and was given a mandated jail sentence (which she later appealed a guilty verdict). Ironically though, she was arrested under the intent to be saved from victimization. Instead, with the help of well-intentioned social workers, she was criminalized and positioned at increased risk of violence by being a transgender woman placed in a men's jail.

Although she was arrested during a social work intervention that views all adults working in the sex trades through the lens of compulsory victimization, Jones was charged with "manifesting prostitution." The statute of manifesting prostitution is specific to the city of Phoenix (although similar legislation is titled differently in other states and cities) and depends on discretion of who fits the profile of someone working in 
the sex trades and therefore intending to engage in prostitution. Jones was guilty of, what the ACLU has claimed, "Walking While Trans" (Strangio, 2014). In other words, because of her "transness" and "blackness" as well as the pervasive knowledge that black trans women often experience barriers to employment in formal economies, Jones was targeted as she walked down the street.

Project ROSE, like other rescue focused organization, perpetuates oppression against marginalized peoples. In our editorial (Wahab \& Panichelli, 2013) we identified important ethical and human rights issues for social workers to consider when participating in "coercive interventions" with sex workers. Our specific critique of Project ROSE claims that such programs perpetuate oppression against marginalized people such as sex workers who are poor, drug users, immigrants, youth, and trans people. In fact, Project ROSE breaches ethical principles found in the NASW Code of Ethics, CSWE ethical standards, and the International Federation of Social Work Standards.

Project ROSE worked with law enforcement to conduct undercover police raids and arrests of people working in the sex trade with the goal of "rescuing" adult human trafficking victims, getting sex workers off the streets, and connecting them with health and social services (ASU, 2012). The project rested on the assumption that all identified sex workers need assistance. This assumption emerges out of a belief that sex work is violence against women, which has historically been a common belief system amongst some feminists, social workers, and other anti-violence advocates. However, in the hands of the police and legal system, sex workers lose their right to self-determination (a key 
value of social workers who commit to working by the NASW Code of Conduct). RoeSepowitz, describes the intervention used to engage sex workers:

Clients were brought to the Project ROSE event site by the Phoenix Police Department using vice enforcement tactics typical to law enforcement activities targeting prostitution. The Vice Enforcement Unit with the support of patrol officers mounted these operations. These operations included routine street enforcement where undercover detectives would engage suspected prostituted women in conversations that would ultimately lead to an offer of a sexual service for an agreed upon price or exchange of an object of value such as food, drugs, or alcohol. (RoeSepowitz et. al, 2013, p. 64)

While Project ROSE aimed to "save" victims of trafficking from assumed nonconsensual sex and coercion they violated all types of social work ethical codes by coercing people into diversion programs--assuming they were even eligible.

Given the coercion, breach of ethics, criminalization, and disenfranchisement wrapped up in Project ROSE's use of raids and a rescue paradigm (Wahab \& Panichelli, 2013), it is important to note that there is little to no evidence that suggests that this or other similar interventions are helpful to people in the sex trades (Brennan, 2008; RoeSepowitz et al., 2013; Wahab, 2006). This program depended on profiling many marginalized people and resulted in a removal of an immediate income source for all who were targeted. Shih's (2016) research highlights the need for critical feminist and anticarceral approaches towards issues regarding the sex trades. Without such an analysis the 
good intentions of "rescuers" (civilian or formally trained social workers) can do more harm by placing sex trade workers in further danger.

\section{Language, Terms, and Definitions}

In this section I provide definitions and rationale of the sex trade related terms I have intentionally chosen to use throughout the proposal. Since language is value laden, theoretically driven, and according to post-structuralists'-- creates reality, I define below, for the sake of transparency a range of terms including sex work, sex trades, sex industry, sex trafficking, prostitution, and compulsory victimization.

Sex work. Carol Leigh coined the term sex work in response to hearing "sex use industry" at a feminist conference she attended in 1980 because changing "use" to "work" centers the provider, rather than the client. She also felt the term "sex use industry" was embarrassing and objectifying (NWSP, 2014). "Sex Worker" refers to someone who exchanges sex or sexual services for money, drugs, housing, transportation, or other material needs. I will interchange sex worker with sex trade worker throughout this proposal.

Sex trafficking. The definition included in The Victims of Trafficking Protection Act, passed in 2000, defines sex trafficking as, "the recruitment, harboring, transportation, provision, or obtaining of a person for the purpose of a commercial sex act” (22 U.S.C. §7102). Stated more simply, the Act intends to demonstrate that a crime has occurred when an adult has experienced "force, fraud, or coercion to engage in a sex act for money or something of value." An addition to the Act says that a severe form of trafficking occurs when sex trafficking in which a commercial sex act is induced by force, fraud, or coercion, or in which a person performing sexual acts has not reached 18 
years of age" (22 U.S.C. $§ 7102)$.

Sex trade. I use the language sex trade, trading sex for money, sex trades, involvement in the sex trade when writing about participation in the sex industry whether it is by choice, circumstance, or coercion (www.sexworkersproject.org). In using this language, I follow in the language of activists and scholars whose work I admire and am influenced by including Emi Koyama, Alix Lutnick, Shira Hassan, the Young Women's Empowerment Project, and the Sex Workers Project in New York City. The term "sex trade" represents the range of sexual activities that are traded or exchanged for something of value including money, housing, food, transportation, drugs, or anything else that someone needs. Potential trades include: prostitution, stripping/dancing, performing in pornography, erotic massage, phone sex, sugar baby/sugar daddy relationships, and professional BDSM relationships. The experiences of people in the sex trades are multifaceted and can include a combination of choice, circumstance, coercion, or force. A project of the Urban Justice Institute in New York City, Sex Workers Project (SWP) uses a harm reduction approach to work with people in the sex trades and recognizes and names the varied and complex experiences of people working in the sex trades. The following quote is from the mission of SWP,

The Sex Workers Project provides client-centered legal and social services to individuals who engage in sex work, regardless of whether they do so by choice, circumstance, or coercion. One of the first programs in the nation to assist survivors of human trafficking, the Sex Workers Project has pioneered an approach to service grounded in human rights, harm reduction and in the real life experiences of our clients. Our professional 
service providers are multi-lingual, non-judgmental and bring more than ten years of experience. (www.sexworkersproject.org)

It is necessary to acknowledge that not all people in the sex trades define their participation by using the same language. Subsuming sex trafficking and sex work under sex trades can be advantageous in the sense that it disrupts "sex trafficking" and "sex work" as opposite points on a line and instead views them beneath an umbrella. Such a disruption is meant to show that sex work isn't free of violence, coercion, exploitation, and victimization. When positioned opposite of trafficking, sex work is recognized as the consensual experience. While there are important distinctions between all of the reasons people participate in the sex trades, whether it is based upon making a firm decision to do something because you feel empowered, excited, interested, intrigued or realizing that it may be the only option to provide for your family, pay a debt, or get high, it is very rare that some aspect of choice, violence, coercion, fraud, force, and circumstance do not overlap in one of the many forms, at some point. In addition, it is very difficult to determine from an outsider point of view who is a victim and who is an agent. Experience, choice, legislation, are all interpreted differently and as I will point out in this chapter, many times someone who identifies as a victim interpersonally or systemically is not seen as such. Therefore, by using the term sex trades in this proposal, it allow room for nuance and to understand the ways that intersectionality informs regulation and criminalization of people in the sex trades, and more specifically bleeds into the social work classroom.

Prostitution. Prostitution is a legal term used to describe the act of exchanging and soliciting sex for money. The sanctions, laws, and statutes for prostitution differ 
depending on the jursidiction. Prostitution's precarious status implies that it should not be used as an overarching term to describe all forms of commercial sex work.

Compulsory victimization. Adrienne Rich originally coined the term "compulsory heterosexuality," a concept meant to symbolize the assumption that all women are sexually oriented towards men and that any type of lesbian behavior should be viewed as deviant (Rich, 1980). In her article on sex work in Thailand, Burman (2015) states, "Pro-sex work feminist use the words 'sex work' instead of prostitution stressing on its monetary, commercial aspect and lack of compulsory victimization" (p.12). In this paper, I will use the term "compulsory victimization" as a substitute for the assumption made in radical feminist and anti-sex trafficking discourses that all people in the sex trades are victims, rather than workers or agents of their lives.

Sex industry. The term "sex industry" is used to be inclusive of the range of trades and types of sex work people engage in. Including, exotic dancing, massage therapists, telephone sex operators, receptionists (maids), and a whole host of people (including men) who sell sex (Delacoste and Alexander, 1987). In addition, within this project I also include sugar baby/sugar daddy relationships, BDSM and fetish based relationships, web-cam modeling, and porn.

Each of these terms outlined above may be used differently depending on the context in which they are deployed. For example, the term "sex trafficked" is a precarious one. If youth under 18 are working in the sex industry and arrested by the police or identified by social services doing so, under the JVTPA they are legally defined as victims of sex trafficking. However, if they are Black, Trans, foster youth, drug using, etc. and not the "ideal victim" as Alexandra Lutnick (2015) and Emi Koyama (2013) 
discuss, they are often criminalized and charged with additional crimes, in order to increase the chances of being incarcerated. Due to the pervasive intersections of racism, sexism, and cissexism and controlling images (Collins, 2000) that mark Black women and black queer or trans women as sexually or morally deviant, even people in the sex trades who have experienced violence, exploitation, coercion, and trafficking may not be seen as a victim or survivor. This racist contradiction illustrates the impact of carceral policies that deem certain sex workers victims and other criminals regardless of how they participate in the sex trades.

Finally, I tried to capture a range of terms used to discuss sexual exchange to try and be inclusive of the many ways people think about involvement in the sex trades. The use of language has long shaped the ways we work with people, understand their experiences, and advocate for practice, policy, and structural change.

\section{Significance of Issue to Social Work}

Code of Ethics. Agustín (2007) has described traditional social work with sex workers focused on helping sex workers get out of the industry. By leaning on raced, classed, gendered, and ethnocentric assumptions of who trades sex for money and who is the most vulnerable to trafficking (Lutnick, 2016; Shih, 2014), social workers stand to perpetuate many intersecting forms of oppression when they seek to rescue people in the sex trades. The NASW Code of Ethics (2008) set the standards for ethics and values of which social workers are expected to commit to as they do work in the profession. One ethical principle that social workers ascribe to self-determination (NASW, 2008), whereby social workers respect and support their client's goals and decisions. Many individuals work in 
the sex industry because they need to make money to live and survive. Yet often social workers encourage people who trade sex for money to find other options for income (Limoncelli, 2009; Wahab, 2004). Finding "other" (coded as formal sector) employment is extremely difficult, if not impossible, for sex workers who have criminal records, are picked up in police stings, sent to diversion programs and fail to complete them, and who are making more money in the sex industry than from another job. This is particularly significant for trans feminine sex workers who are often "forced" to do sex work, because of employment discrimination in formal sectors (Attia, 2016; Bradford, Reisner, Honnold \& Xavier, 2013; Nadal, Davidoff \& Fujii-Doe, 2014). And, sometimes, even if sex workers could find other jobs, there are many reasons they may not choose to work in the formal sector. These reasons could be due to documentation status, ability to make higher wages, flexible working hours, and more.

And an addendum to the code of ethics in 2008 is for the ethical standard of competency and social diversity. The code of ethics defines part $\mathrm{c}$ as such:

Social workers should obtain education about and seek to understand the nature of social diversity and oppression with respect to race, ethnicity, national origin, color, sex, sexual orientation, gender identity or expression, age, marital status, political belief, religion, immigration status, and mental or physical disability. (1.05)

By committing to the ethical standard of competency and social diversity (1.05 part c), social workers must discuss the endless intersections of social locations in the sex trades and how these various intersections and interstices impact sex 
workers experiences navigating the sex industry as well as the social services they may seek. Similarly, people in the sex trades work in diverse settings which lead people in the sex trades to be more vulnerable to policing, criminalization, and deportation than others. Sex workers include white women, women of color, transgender, non-binary, those who are single and married, those who are ablebodied and sometimes disabled, may be immigrants or citizens, indigenous, are gay, bisexual, lesbian, queer and pansexual. Education about the diversity of experiences in the sex trades is essential so that social work can engage with the range of practice and policy issues related to the sex trades.

In one instance of trying to teach social workers about the needs of sex workers, feminist social work scholar, Wahab (2004) offers messages to social workers from sex workers on how to better serve their needs. In her study, sex workers make suggestions for social workers including, "use a non-judgmental attitude," "do your education to understand what sex work is really like," and "do not assume that all sex workers want to exit the industry." When social workers encourage women to get out of the sex industry, social workers imply they know what is best for the client (Wahab, 2004). However, when social workers commit to the Code of Ethics, they are obliging to support clients' self-determination (1.02) and thus must put their own values, biases and prejudice aside to support their client's goals. As such, social workers must carefully reconsider their approach to sex work for hidden biases and prejudices laden within normative social work theories and methods that ascribe to compulsory victimization. 
Centering strengths. Recognizing the strengths of all people working in the sex trades is a salient perspective used in the world of social work as it offers a framework for how to engage with clients. The "strengths perspective" focuses more on the possibility of clients and their strengths rather than focusing exclusively on problems (Saleeby, 2003). An important application of the strengths perspective to sex worker lives is that it helps us to see the ways that people in the sex trades are powerful, resilient, and resourceful, regardless of their point of entry or circumstances impacting their participation in the sex trades. Social workers can recognize the strengths of people working in the sex trades including assertiveness, savvy negotiating skills, selfprotection, knowledge of sexual health, intelligence, navigating systems of care (Wahab \& Abel, 2016), and for some, the ability to use their learned sexuality and sexual skills to receive material gain.

In addition, it is imperative that we recognize the strength in people making informed decisions about the work that is the most accessible in a capitalist economy. While choice is often defined through the lens of individualism as making a decision to do something or not, choice is actually a precarious concept marked by cultural norms and context. Often grounded in individual, familial, or communal needs a sex worker may make a decision to work in the sex industry even if it is not the most desirable job opportunity. Although it may be the most viable option due to various forms of global, structural, and systemic oppression, the sex trade offers benefits such as flexible work schedules, quick money, and no criminal background check. Therefore, if social workers can adopt a strengths perspective to explore sex worker's agency and self-determined needs, they might find themselves deconstructing what they've been influenced to know 
through dominant discourses of pathology and stigma. It is important for social workers to see that sex workers survive daily within the context of their living and work conditions and that not all sex worker's need therapeutic care as a result of their involvement in the sex industry (Wahab, 2004; Williamson \& Folaron, 2003; Williamson \& Baker; 2009).

Trauma and oppression. Many of the clients that social workers encounter have experienced some form of trauma in their lives. To this end, many social service agencies have adopted the "best practice" of Trauma Informed Services. These services intend to train all staff that a client may come in contact with to understand the myriad impact of trauma on the lives of people being served (Elliot, Bjelajac, Markoff \& Reed, 2005). Agencies considered to be trauma-informed rely on procedures that are "most likely to be growth-promoting and least likely to be retraumatizing" (p.463). However, Elliot et al (2005) note that, "many common procedures and practices in service settings retrigger trauma reactions and are experienced as emotionally unsafe and disempowering for survivors of trauma (p. 463 as cited in Harris \& Fallot, 2001).

Given the consistent development of trauma-informed services and policies in the many fields that social workers occupy, it is imperative that we recognize how interventions social workers participate in may reproduce or perpetuate trauma. For example, arresting someone and putting them in handcuffs in order to "rescue" them from an exploitative situation is likely to invoke trauma-based responses. Interventions like the FBI's Operation Cross Country bring together law enforcement with social service agencies to conduct sweeps of people in the sex industry and find underage sexually exploited youth (FBI, 2014). In order to "rescue" victims they are arrested and often held 
in jail or juvenile detention centers until they can be placed with an agency or foster care placement. There is a wealth of literature documenting that youth in the sex trades often turn to sex work when they are running away from abusive foster care placements (Hall, 2014; Kessler, 2015; Koyama 2015; Stransky \& Finkelhorr, 2008). This operation risks the likely possibility of retraumatizing youth (and adults) when they are incarcerated (Segrave \& Carlton, 2010) and lacks a trauma-informed approach with a population that they are ironically trying to remove from traumatic conditions. As social workers encountering people who have experienced trauma, people who have worked in the sex trades, people who use drugs and do sex work, or perhaps have colleagues who have been in the sex industry, we must consider the impact of our practice on how the people we serve recover from trauma.

People in the sex trades should not have to fear interacting with social workers (YWEP, 2012). As stated in the previous section, sex workers encounter multiple barriers when trying to access the services they need, particularly as they fear arrest, stigma, and pathology related to their work. This fear may leave people houseless, without medical care, and without resources to care for themselves or families. Even more, social workers must examine systems of power and oppression that inform the experiences of people in the sex trades. An intersectional praxis that incorporates trauma informed principles must consider the challenges in how marginalized communities navigate systems. In addition, it is absolutely imperative to consider the impact of historical and intergenerational trauma within indigenous communities and communities of color. Legacies of trauma impact the ability to trust services and institutions like health care and the legal system as resources for support or safety (Mogul, Ritchie, Whitlock, 2011; Revolution starts at 
home, 2003). Trauma Informed Oregon, an organization based in and run by social workers maps the impact of such layers of oppression and trauma in considering how to create Trauma Informed Practices (Trauma Informed Oregon, 2017).

Social work and feminisms. Given how vital social change is to both social work and feminist praxis, it is crucial that social work grapples with the many debates related to the sex trades. These debates have been framed by competing strands of feminist theories that narrate the experiences of people working in the sex industry as either victimizing or empowering. In one interview-based study conducted with social workers, Wahab and Abel (2016) noted that the "thoughts, feelings, and perceptions [among social workers] about people engaged in the sex trades reflected a range of feminist discourses (marxist, liberal, radical, sex radical)" (p. 11). The range of feminist discourse used to describe the experiences of people trading sex represents how social workers are exposed to a diverse range of stories about people who work in the sex trades.

Wahab, Anderson-Nathe, and Gringeri (2012) acknowledge, "central to both feminism and social work has been the attention to power (personal and political) and the various ways power, in all its dimensions (interpersonal, intrapersonal, social, political, economic, spiritual, etc), inform individual and collective experiences (p. 456).” They recognize how vital social change is to both feminisms and social work, and "particularly social change focused on challenging systems and institutions that perpetuate power inequities, privilege and oppression (p. 456).” In working Sex, Janelle Galazia (2007) responds to the stigma and marginalization sex workers face through their economic and racialized social status. She suggests how feminism can be helpful to women in the sex industry: 
The real question here is, why are our options so lame? What are the economic realities that make the sex industry the most viable choice for many people?

That's where feminism comes in. That's where outrage becomes appropriate. The wage gap, welfare "reform," sexist and racist hiring practices, the decline in the real value of the minimum wage, lack of universal access to health care or rehab services, and the widening disparity between the rich and the poor...We have to ask ourselves, what is so compelling about blaming naked women for their own oppression? (Galazia as cited in Oakley, 2007, p. 89)

As Galazia makes clear, it is important to recognize that cis and trans women's experiences in the sex industry are diverse according to the intersections of race, class, gender, and beyond as their representations of femininity deviate from hegemonic ideologies of femininity (Collins, 2005).

Moreover, critical feminist praxis requires that social workers think about how practice, research, and theory contribute to social change. A critical feminist praxis employs reflexivity in order to attend to power differences in relationships regarding research and practice. Gringeri, Wahab, and Anderson-Nathe (2010) state "reflexivity is a cornerstone of good quality feminist research," and they insist on its centrality to rigorous and good quality social work in all of its forms (p. 402). In working towards social justice and ending oppression, we must attend to power on many levels when social workers are engaged with sex workers in research and in practice. Reflexivity is critical in this context, as when social workers participate in criminal justice and rescue-based 
interventions such as Project ROSE, their practice rests on an assumption that all people are victims, and that through "arrest" they will be given a better life.

In short, social workers must interrogate these assumptions for the betterment of their clients and service to the profession. Critical reflexivity pushes social workers to consider their own social location of power and privilege in order to critically investigate the origins of their service provision and goals. It is especially necessary for social workers to consider how internalized forms of oppression may impact their perceived needs of people working in the sex trade. Furthermore, social workers must consider how experiences of systemic oppression in the lives of sex workers change depending on their multiple intersecting identities.

Social work and child welfare. In considering our positionality and social locations as social workers, it is necessary to critically consider the root of our biases and perspectives related to the issues impacting people we work with. In my own social work education the prevalent discourse around drug abuse and prostitution centered on child abuse and neglect. While it is true that some people who use drugs also trade sex, such behavior does not necessarily lead to bad parenting. Involvement in prostitution often means experiencing stigma and disenfranchisement when trying to access health care, drug treatment, legal services, or welfare, thereby making it hard to access the things needed to be deemed "good enough parents" (Bryson, 2015, p. 18).

Wahab and Abel (2016) interviewed CYF social workers in New Zealand, where prostitution is decriminalized ${ }^{8}$, about their general perceptions of sex workers as well as

\footnotetext{
${ }^{8}$ Decriminalization is meant to remove laws that penalize or criminalize sex work, including laws and regulations that impact both provider and the client. The intention is to relieve sex workers of the fear of
} 
how the PRA (Prostitution Reform Act) influenced their practice with people in the sex trade. A prominent theme emerged related to mothers. Specifically, one social worker spoke to the stigma associated with prostitution that caused him to probe further into her life in a way that he would not do with someone in another profession (p. 9). Wahab and Abel noted how his statement points to the link between beliefs and practice (2016, p. 9). While working in the sex trade is highly stigmatized, social workers in their study made caveats that prostitution wouldn't be an issue as long as the kids weren't around or in the house where it was happening. These interviews are particularly powerful given that prostitution is decriminalized in NZ, yet some of the social workers interviewed hold deep seeded beliefs about the morality, stigma, issues, and pathology related to working in the sex industry. And, it is these beliefs that impact the ways social workers practice with people in the sex trade.

While decriminalization should make it so that people working in the sex trade do not face the consequences of breaking a law, Wahab and Abel's study (2016) suggest that it is possible that participation in the sex trade sends a signal to social workers to probe further into the lives of sex workers just to make sure that they are a fit parent. Considering that the state has control over family unification, it should be of great concern to social workers in the child welfare system to examine how harmful internalized bias may be. Furthermore, it should be of no surprise to social workers that sex working mothers or pregnant sex workers fear interaction with the Child Protection Services. Duff and colleagues found that that $35 \%$ of 399 pregnant or parenting sex workers encountered barriers accessing health or social services. These barriers included, support their basic human rights. (www.amnestyinternational.org) 
"restrictions on housing with children"; "age cut-off for infant services; lack of drug treatment support for moms/pregnant women; and fear of accessing Ministry involvement for fear of having their children removed by child protection services; fear of partner violence; lack of services for pregnant/parenting women experiencing partner violence, lack of trauma/violence counseling, fear of police, lack of access to programs for parenting women, lack of non-judgmental education on FSAD/infant narcotic withdrawal; fear of community stigma as a pregnant/parenting mama. (2015, p. 4)

Within the many roles that social workers take on before, during, and after formal social work education, we must examine our internalized bias, ethics, values, and political beliefs. Therefore, it is worth examining the tools we take with us into the field to support our practice of working with individuals, families, and communities. By which I mean, what did we learn about our roles as social workers? What were we inspired by in our coursework, and what made us a feel a connection to a specific way of doing social work, or a certain theoretical lens to approach practice with? In this project, I am guided by a curiosity around these questions (and more), particularly as they relate to the sex trades, classroom content, and carceral feminisms. 


\section{Overview of the Project}

There is much more to the sex trade than simple exchanges of sex for money.

There are stories of victimization, violence, empowerment, of racism, and policing. There are stories of youth escaping abusive foster homes and adults escaping abusive relationships. There are poor people, disabled people, people with fines to pay. There are people using drugs, who need more drugs. There are people with children and partners. Sex workers possess hopes, dreams, enjoyment and disgust. Some people in the sex trade experience criminalization and some have experienced the destruction that accompanies globalization. Simply put, social work programs have a lot to teach students about the sex trades!

There is no place of innocence in practice for social workers (Rossiter, 2001). This means that we will never be perfectly anti-oppressive all of the time; we will never work completely in the spirit of altruism, because the identities of helper and helped are maintained in the individualist capitalist society within which U.S. social work occurs. Through their position as helper they have access to privilege and power, while the helped often occupy oppressed social locations. Although those seeking help are more vulnerable to the exploitation of power, both social worker and client depend on one another to get their needs met. This interdependent relationship makes it so social workers will at some point be guilty of committing trespass, despite their good intentions to be helpful.

I dream of social workers putting themselves out of a job by working endlessly to eradicate racism, sexism, cissexism, homophobia, transphobia, ableism, xenophobia, ethnocentrism, whorephobia, the prison industrial complex and the myriad ways that 
these forms of oppression and subjection intersect to marginalize and disenfranchise the communities we work with. Part of the path to critical social work practice is understanding the privilege and subordination associated with social status categories and learning that we can seek the uncertainties, prioritize the 'not knowing', and recognize whose knowledge we deploy and depend on (Rossiter, 2001).

In this project, I situate the messages and stories that social workers have internalized and disseminated about the sex trades in conversation with the logic of Anticarceral feminisms. Instrumental to the development of the research question (and subsequently the design) for this project was personal communication with Dr. Noel Busch-Armendariz, a Professor and Director of the Institute on Domestic Violence and Sexual Assault at the University of Texas at Austin. Through our exchange I learned, "that 98 out of 108 (91\%) Research 1 universities in the U.S. held a seminar, workshop or other educational forum addressing human trafficking; 48 of 108 (44\%) have offered a course focused solely on trafficking in persons" (August $7^{\text {th }}, 2016$ ). Through conducting a content analysis of social work syllabi and thematic analysis of interviews with faculty, I provide insight into what instructors teach about the sex trades in social work education. In order to understand more about what social workers learn about the sex trades and the experiences of those working within the sex industry, this project was guided by the research question: What are social work instructors teaching students about about the sex trades in coursework?

\section{Social Work Education as the Site for Inquiry}

Social work is guided by a vision of ethics and values for how to practice in a way that will help people improve their lives. To help in this way often requires advocacy to 
eliminate the many barriers people may face when trying to get their needs met. Laura Agustín (2007) has classified social workers as social agents whose work is animated by the goal of "helping people improve their lives (p. 139)." As an anthropologist, she spends time with a progressive social work organization in Spain that hands out condoms and needles to Spanish and African women working in the sex trade. Agustín critiques the regulation of how many supplies are available for each participant and points to the issue that lies in "charity workers" determining what someone else needs.

Workers in helping professions are often in the powerful position of constructing moral standards and expecting their clients to follow suit. Agustín's example provokes questions for social workers to explore, such as how do we navigate need versus limited resources and who is "worthy" and of how much? How do we make decisions about other people's lives? While these are certainly complex questions with no objective answers, we can struggle through these questions and embrace the discomfort of not knowing all the answers.

I chose Social Work education as my site of inquiry for a number of reasons that have to do with how social work students are socialized to think about the sex trades. It is in the academic environment that social work students entertain a variety of perspectives, and consider their future practice with vulnerable communities. This happens through course curriculum, classroom dialogue, course content, class assignments, and other forms of pedagogy used to teach about how communities are impacted or made vulnerable to oppression, racism, poverty, classism, sexism, homophobia, transphobia, ableism, religious oppression, and ageism. 
In an education context, students are influenced to think critically and learn how to approach social work. There have been forms of social work critiqued as unethical, oppressive, and re-traumatizing, by other social workers and activists. Therefore, I sought to understand what it is within social work education that socializes social workers about how to participate in interventions with sex workers, some of which have been deemed problematic.

\section{Conclusion}

This introduction provided an overview of the many issues pertinent to social work and the sex trades that are ultimately rooted in carceral feminism, criminalization, good intentions, and the rescue industry. Sections on the code of ethics, the strengths perspective, the relationship between social work and feminisms, and social work and the state, highlight the many bodies of knowledge that weave the sex trades with social work education, practice, and policy.

Throughout the next chapters, I examine anti-trafficking activism and rescuebased social work interventions informed by carceral feminisms and good intentions that result in the criminalization of marginalized sex workers, including sex workers who are poor, using drugs, trans, hold precarious citizenship status, youth who have runaway and are people of color. In the third chapter, I discuss the essential use of critical feminist research strategies in this project, such as the contribution to social change, reflexivity, and attention to power and privilege. The design of the project draws on qualitative methods with the use content analysis of social work syllabi and thematic analysis of interviews with course instructors teaching sex-trade-related content. Lastly, the fourth 
chapter discusses study findings, and the fifth chapter analyzes the implications of these findings for social work education and research. 


\section{Chapter II: Literature Review and Theoretical Framework}

Almost 15 years ago I sat in a circle of thirteen other youth activists at a sevenday anti-oppression training held at a beautiful and serene retreat center in San Marcos, Texas. We were a diverse group in age, race, class, faith, gender, ability, and sexuality. We were united in our well-intended activist visions to combat social injustice. In an attempt to reflect on our good intentions we were asked to read a powerful speech by Ivan Illich (1968) titled, "To hell with good intentions." The speech raised important critiques of humanitarianism and volunteerism necessary for any person intent on volunteering, doing social work, or activism with a community in which they are not immersed. His critiques called out the danger of assuming you know what is best for a marginalized community, that you have something to offer, and that your values are the ones that should inform how others live.

It is imperative to question binaries of "innocent versus guilty," "perpetrator versus victim," "fallen versus virtuous," or "empowered versus disempowered," when engaging with the long histories of social work, sex trades, feminisms, and feminist social work. Without engaging in what lies between polarities, social workers risk complicity in the harm inflicted upon the communities our "good intentions" are meant to help. Therefore in the following literature review I've chosen to explore two major time periods related to the sex trades framed by intensive policy, regulatory discourse, and well-intentioned interventions focused on female sexuality. The first period explores the

context of early American social work practice, and the second is situated in late $20^{\text {th }}$ century feminist activism marked by radical feminist debate; both periods fueled, in part, by "good intentions" to do what was best for women. 
In 1889 Jane Addams co-founded one of the first settlement houses in the American Settlement House Movement, the Hull House (Morgaine \& Capous-Desyllas, 2015). As a social work leader motivated toward societal change, Addams was influential in framing discussions around prostitution. Addams was a strong proponent of abolishing the sex trade and deeply moved by notions of white slavery (Wahab, 2002). Settlement workers worried that innocent women would fall prey to men's sexual desire and be persuaded to prostitute themselves. They would then lose their virtue, be cast as "fallen" and thereby "dangerous," "diseased," and "contagious." Values laden with morality, purity, and innocence (hegemonic notions of white femininity) inspired the mission of evangelical Christian activists, social workers, and anti-white slavery advocates. In an attempt to respond to the lost virtue of women, prevent others from falling, and to protect white women from dangerous immigrant and newly freed African-American men, the Mann Act passed in 1910. The Mann Act criminalized the movement of women and girls for trade, as well as voluntary participation in prostitution (Doezema, 2002; Saunders, 2005; Wahab, 2002).

Not unlike this early social work period, the Sex Wars period that exploded in the 1970s was similarly guided by desires to see women resisting male dominance, the assumption that participation in prostitution was linked to victimization, and the maintenance of conservative family values such as sexual innocence and morality. Antiobscenity and anti-pornography laws actually regulated where, how, and when people could have sex and supported coalitions across feminism, religion, and politics to advocate for policies that would criminalize sexual deviance. Perhaps, most relevant to 
the sex trades, radical feminists were polarized at either end of the "victim" versus "agent" debate.

By politicizing sex and sexuality, throughout both of the time periods discussed in the following literature, efforts to rescue and reform people in the sex trade or those potentially vulnerable to prostitution were criminalized in an attempt to be redeemed. I am drawn to both of these periods as they are situated half century a part, yet share such poignant similarities, and continue to inform the current landscape of social work, feminism, and anti-sex trafficking interventions with people working in the sex trades today. That is, a carceral logic has informed the idea that criminalization will protect the victimized and punish the perpetrators. Despite the good intentions motivating carceral feminist policies and practices, this proposal discusses many examples of marginalized communities being harmed through the regulation of morality, femininity, and innocence.

To begin, I examine the history of social works efforts towards rescuing and reforming fallen women who were seen as immoral and contagious threats to society, followed by the influence of anti-white slavery campaigns on the profession of social work, which sought to protect and maintain the innocence of white women. Next, I briefly describe the context surrounding the feminist Sex Wars, which I follow with a discussion of literature that goes beyond the Sex Wars to engage with the cultural context surrounding the sex trades. I then discuss the critique of feminist practices defined by advocating for legal policies and action that make women of color vulnerable to incarceration and all people in the sex trades seen as victims to be rescued; carceral feminism. With specific examples of rescue-based social work that challenge the social justice values of social work, I highlight the need for a reflexive critique of carceral 
feminism and rescue-based social work. Finally, I conclude the literature review with a discussion of three categories that typically exemplify the problem of carceral logic and rescue-based social work: lack of intersectionality in praxis, criminalization as a solution to change, and the convergence of governmentality and feminism.

\section{Rescuing Fallen Women: A History of Carceral Feminism in Social Work}

In order to understand how rescue-based interventions work today, we must first understand the history of social workers participation in "rescue" based work and how the focus on saving sex workers evolved. In what follows, I will explain how a mission to "help," "save," and "do good" transformed into the rescue and criminalization of sex workers in social work today.

Some have argued that Jane Addams was one of the first "rescue-based" and carceral feminist social workers. Addams was greatly influenced by friends in the British movement working to regulate prostitution by sanctioning it (Joslin \& Addams, 2002). Therefore, she promoted practices employed by law enforcement and juvenile protection agencies to rescue young white women from the "traffic of white slaves" to deter them from continuing on a deviant life path (Joslin \& Addams, 2002, p. 66). Addams explained that juvenile protection workers and/or police would follow women after they left dance halls, amusement parks, and excursion boats (sites identified as luring white women into the sex trade). If young women were found going into a lodging house, the police conducted raids to rescue them from falling prey to a life of prostitution (Joslin \& Addams, 2002).

Because it was assumed that the weakening of family and community values could make young women vulnerable to work in prostitution (Abrams, 2000), social 
workers developed responses to the perceived problem of sex work, aimed at reestablishing order in society. Responses to the problem of sex work from social workers were organized around the twin goals of both protecting "weak" women and society more generally from the ostensibly negative effects of prostitution. Efforts towards protection of women vulnerable to the negative effects of prostitution centered on individual interventions, such as case work or counseling while little was done to change macro level issues related to the sex trade (Addams, 2002; Brock, 1998). Policy and practice with sex workers were designed to outlaw prostitution and "social evils" such as sexual promiscuity, deviating from heterosexuality, or immorality.

In her continuous efforts to shield women from social evils, Addams was influential in the establishment of settlement houses and benevolent societies like the Working Girls' Society, The Working Women's Protective Union, and Traveler's Aid. Organizations like these taught working and independent women domestic skills and distracted them from some of their activist sisters who were protesting traditional gender roles and positions (Abramovitz, 1996).

While middle and upper class women in social work stepped outside of gender norms in the $19^{\text {th }}$ and $20^{\text {th }}$ centuries by working, they were positioned as "guardians of virtue," and paradoxically their work was about regulating women's acceptance of gender roles (Abrams, 2000). These guardians of virtue sought to help women maintain or regain their sexual purity while prioritizing values that oriented women towards the family and performing a traditional gender role. A rejection of this role meant that they risked being socially scorned. Because sex workers did not adhere to hegemonic social standards they were classified by social workers as mentally sick lesbians, who tried to hide their 
sexuality by engaging in sexual activities with men for money. Links between sex work and lesbianism were drawn because both groups defied the heterosexual, chaste, pure, wait-until-marriage-for-sex gender roles that women were assigned. The only explanation could be that both groups struggled from mental illnesses including anxiety, poor selfimage, an inability to form lasting relationships, to be lonely, and suffer from depression (Duggan, 1993; Faderman, 1992; Hall, 2004; Miller, 2000; Wahab, 2002).

Charity organizations and friendly visiting. With a mission driven to rescue and reform, social work took shape through charity organization society's and friendly visiting (Joslin \& Addams, 2002). These organizations were formed to provide relief to the poor, yet it was widely believed that that the poor were directly responsible for their own circumstances (Abramovitz, 1996). Friendly visitors intervened in urban life in order to reform the sexually immoral character that described women in the city. The morally pure visitors (typically middle to upper-class women) hoped the poor would adopt their values and reject the "perversity" of urban life (Boyer, 1992, p. 1812).

Jane Addams and the settlement house movement were charged with restoring order to society and one of their missions was to work tirelessly on women's issues and causes from "suffrage to prostitution" (Lundblad, 1995). Leaders of settlement houses and Guardians of Virtue joined with other social reformer professionals to work towards state legislation that would regulate prostitution (Wahab, 2002). Social reformers expended a great deal of energy lobbying for anti-vice legislation organized around the goal of ridding society of prostitution and preventing women - who were expanding their ideas about the world beyond traditional gender and family roles-from becoming susceptible to prostitution. With a brief look at the early involvement of social workers 
with women in the sex trade, we can note the development of early social work interventions that depended on framing women as victims and thereby rationalizing the need for rescue from dangerous men. In addition we see the threat of incarceration and intimidation by law enforcement in alliance with social workers to deter women from engaging in prostitution and maintain their morality. Finally, the unity between anti-white slavery activists, feminist activists, and social workers, reveal just how embedded carceral politics have been in the lives of women in the sex trade over the last 200 years.

The Mann Act racializes rescue efforts. Jane Addams struggled with highlighting the strengths of women working in the sex trade and portraying them as victims in her writings for an audience that "were" obsessed with the vulnerability of girls from rural areas and Europe" (Addams\& Joslin, 2002, p. x). Not only was this a struggle for Addams, but also at the time (late 1800's/early 1900's) many scholars, social workers, and public writers had a hard time getting past the moral panic rhetoric of white slavery (Addams \& Joslin, 2002, p. x).

The Mann Act of 1910 otherwise known as the White Slave Traffic Act prohibited the transportation of women or girls for the purpose of interstate or foreign commerce or any other sexual immoral purpose (Blair, 2010; Doezema, 2002; Mackinnon, 1993; Saunders, 2005; Yale Law Review, 1947). Gretchen Soderlund (2005) argues that the Mann act offered a victim-based narrative that ultimately led to rescuebased, punitive interventions, and anti-trafficking policies that would prevent white women from getting involved in the sex trade - all while serving to criminalize and label sex workers of color as deviants. The Mann Act made the voluntary movement of prostitution illegal, which meant that any woman who voluntarily engaged in prostitution 
was committing a crime (Saunders, 2005). Saunders emphasized that the Mann Act invoked sympathy for innocent victims of prostitution, and stated that, "in 1914, 70\% of convictions were made from the voluntary movement of prostitution (2005, p. 346)," thereby highlighting the discrepancy in the portrayal of some sex workers as victims and some as criminals.

While there was a great deal of effort spent on promoting policy that saved white women from themselves, black sex workers were often left out of governmental anti-vice legislation (Blair, 2010). Black community leaders vocalized their concern that governmental policy regarding "white slavery" excluded black people and continued to disregard the toll prostitution had on black communities who were also fighting to maintain a politics of respectability (Blair, 2010). This differential in the regulation and monitoring of sex workers along racial lines illustrates a consistent pattern of penalizing the most marginal of sex workers.

The Mann Act drew on racism, xenophobia, and changing immigration relations to save white women from "foreign men" and immigrant outsiders. Therefore white women were seen as particularly vulnerable to the predatory lust of Black, Jewish, and other immigrant men (Saunders, 2005). Feminist abolitionists and anti-white slavery campaigners used notions of passivity to frame women as victims who needed to be protected from predatory men out to compel them into the sex trade, as it was believed that women would not choose to engage in prostitution without the animalistic desires of men drawing them in. While women were considered to be morally superior to men at this time, engaging in illicit sexual behaviors erased any social presumption of innocence and cast them as socially dangerous. Doezema (2002) says that at this point, "calls to 
protect women's purity alternated with the attempts to reform and discipline prostitutes through moral reform and criminalization (p. 28)."

In the next section I look at a period beginning in the 1970s that engages feminism, sexual politics, criminalization, and the intersectional role of social work through social, medical, and legal systems.

\section{Feminist Sex Wars}

With a leap forward to a major moment in $20^{\text {th }}$ century feminist history, which had a huge impact on the sex trades, I will engage with the period between the 1970s and mid-1990s categorized as the "Sex Wars." Within the feminist movement, the Sex Wars successfully polarized radical feminist philosophies of sex work that framed the sex industry as either empowering and liberatory or exploitative and victimizing (e.g., Barton, 2006; Chapkis, 1997; Dewey, 2011; Duggan, Hunter, \& Vance, 1985; Hollibaugh, 2000; Hunter, 2006; Kesler, 2002; Sloan \& Wahab, 2000; Wahab, 2003; Wahab; 2004). This was a time period of dangerous unrest of sexual ideologies and sex laws fueled by fears related to immorality, victimization, and social deviance (not unlike the concerns of anti-white slavery campaigners that led to rescue, reform, and criminalization).

In her influential text, thinking sex, Gayle Rubin charts the landscape of conservative, liberal, religious, and feminist based legal advocacy on sex laws, and advocates for a radical theory that contextualizes the social and historical meanings of sex, that also engages with the lived realities of communities and individuals labeled as deviants. Reflective of the institutions invested in the legislation of sodomy, were the issues of homosexuality, prostitution, age of consent, sex outside of marriage, kink, and 
non-monogamy. Intrinsic to such debates, were deeply embedded philosophies of morality, fear, and non-conformity. Binary concepts such as innocence and deviance were pitted against one another depending on the political ideology of activists proposing and defending sex laws. Rubin (1984) addresses the paradox of instituting morality in the following passage,

Moral panics rarely alleviate any real problem, because they are aimed at chimeras and signifiers. They draw on the pre-existing discursive structure which invents victims in order to justify treating "vices" as crimes. The criminalization of innocuous behaviours such as homosexuality, prostitution, obscenity, or recreational drug use, is rationalized by portraying them as menaces to health and safety, women and children, national security, the family, or civilization itself (p. 163).

As Rubin notes, the rationalization of behaviors as "deviant," "immoral," or "vice" by asserting that such behaviors harm the health and safety of the general public, women and children, state security, and the family is ultimately fueled by racism, sexism, classism, ableism, and homophobia. If homosexuality, prostitution, obscenity, or recreational drug use is perceived to be a threat to national citizens, then anyone engaged in sexual behavior falling outside of white, cis, heterosexual, male/female, procreative sex in which a penis was inserted in a vagina, risked the possibility of surveillance and criminalization (Rubin, 1984).

Particularly relevant to this project is the impact of anti-obscenity laws on prostitution and sex work (Duggan \& Hunter, 2005; Rubin, 1984). Many feminist scholars critique existing discourse focused on abolishing the sex industry that frames 
women working in the sex trade as victims in need of rescue - "those who have survived prostitution” (Bromfield \& Capous, 2012; Lerum, 1998; Sloan \& Wahab, 2000). Narratives framed by competing strands of radical feminism and sex radical feminism have had a strong influence on social work through anti-sex trafficking advocacy and activism (Jordan, Patel, \& Rapp, 2010; Kotrla, 2010; Lerum, 1999; Weitzer, 2007). The Sex Wars drew on laws meant to "protect the innocent" from "vice," enforced by police officers, healthcare workers, and social workers who have historically been called by the State to work with people vulnerable to homosexuality, prostitution, and mental health issues.

In 1980, Catherine Mackinnon and Andrea Dworkin introduced anti-pornography legislation in both Minneapolis and Indianapolis with the intention of addressing female degradation, violence against women, and lack of consent (Duggan \& Hunter, 2005). In the conservative era of Ronald Regan, the bill was able to gain support from the Right and Christian conservatives who found pornography to be a threat to family values and to be a cause of homosexuality. The support of the Right completely undermined the feminist intention behind the bill as it regulated the lives of women even more tightly (Duggan \& Hunter, 2005, p. 39).

\section{Radical Feminists vs. Sex Radical Feminists}

Radical feminists had framed sexuality as a social construct defined by patriarchy and as a site for men to assert domination over women, and in which women were always already submissive. The radical feminist position assumed that women were never able to consent to engaging in prostitution, because consent is seen as something that women have been socialized to give in their roles as submissive (Mackinnon as cited in 
Sutherland, 2004). All prostitution is viewed as human rights abuse, victimization, or a result of trafficking, and consequently radical feminism advocated for the abolition of prostitution (Sutherland, 2004, p. 2).

In contrast, sex radicalist theories drew on postmodernism and sexual nonconformity, to frame sexuality as a potential site for changing the "balance of power in society" (Sutherland, 2005, p. 5). Sex radical theories acknowledged that consent is central to a range of sexual activities and that consent can also be complicated by the historical privilege of those in dominant positions to legally draw on consent. Sex radicals recognize that exploitation and victimization can occur at the same time as subversion and agency. Sex radical feminists sought to shift the focus towards human rights for sex workers, advocating for legal interventions "geared towards self determination," decent working conditions, and freedom of movement (2005, p. 2).

There is evidence of social workers being influenced by radical feminist philosophies when people working in sex trades are framed as victims. Lerum (1999) notes that sometimes sex workers are framed as diseased or sick due to sexual abuse and drug addiction. She discusses the need for helping professionals to assign "sick" status so that sex workers can be helped and fixed. Lerum examines substance addiction, when framed as a disease as an explanation for why people do bad things, rather than examining the systemic factors that may lead to abuse and drug addiction. Given the reoccurring themes (historically) of labeling sex workers as either victims of social, physical, or mental disease or deviant, criminal, sexually promiscuous (and dangerous to society) it is worth going beyond a binary framework to engage with the cultural context shaping the lives of people in the sex trades. 
Beyond the binaries of feminist Sex Wars. The feminist sex wars were pivotal in shaping discussions of sexuality, sex trade, and policy in social work and beyond. Acknowledging the political nature of sexuality in all forms of oppression, it is essential to engage beyond dichotomies of "victimized" versus "empowered" when discussing sex trade. People working in the sex trades have complex experiences, which include both victimization and empowerment. Framing the conversation around binaries detracts attention from the important issues impacting sex workers lives. A binary view of the sex industry tells us little about systemic oppression, which often determine a person's circumstances, work setting, and client encounters in the sex industry. In fact, Lerum and Brents (2016) say that working conditions for all workers (sex workers included) exist along a continuum that is complicated, complex, and must be contextualized considering aspects of privilege, agency and structural constraint (p. 17 as cited in Brents et al. 2012, p. 36).

For example, an intersectional lens of the sex trades identifies how interlocking systems of racism, classism, sexism, heterosexism, cissexism, ethnocentrism, and ableism have made it so that women (cis and trans) working on the street have a greater risk of experiencing violence by law enforcement and clients, than women who work in indoor settings. In considering the intersections that make someone vulnerable to oppression, positioning someone as a victim or agent in the sex trades does not serve to eliminate the danger they face based on their positionality (Hooker, 2016; Ritchie, 2006).

The politicization of sex means that oppression, discrimination, and injustice related to gender, sexual activity, sexualization, sexuality, and sex work is embedded in legislation, welfare policies, social services, healthcare, and other state based institutions. 
Many marginalized communities are monitored, disenfranchised, and controlled via laws related to sex, welfare benefits, sodomy, pornography, prostitution, sex trafficking, sex education, age of consent, and HIV/AIDS based services. During the Sex Wars the religious and conservative right joined with radical feminists to advocate for antiobscenity laws that led to harming the most sexually marginalized communities. For some people in the sex trades, rescue in the name of help is a direct pathway towards institutional violence and as you will see in the next section, towards incarceration.

\section{What is Carceral Feminism?}

In 2010, drawing on the work of anti-violence activists and scholars of color critiquing the criminalization of women of color resisting and surviving violence around the globe, Elizabeth Bernstein coined the term "carceral feminism" (Davis, 2003; Falcón, 2006; Koyama, 2006; Law, 2014; Mohanty, 2003; Roberts, 2004; Smith, 2006; Sudbury, 2006; Sudbury, 2014; and others). The term is meant to capture the role of the U.S. women's movement in the development of policing and controlling the bodies and sexualities of women around the world. Further, the term has been used to describe the criminalization of violence against women, trans, and gender non-binary people as a strategy towards gender justice. While the term "carceral feminism" has gained popularity over the past ten years, anti-violence activists of color have been working on strategies for achieving gender justice outside of the criminal legal system since the early 1970s and prior (Bierria and CARA, 2007; Crenshaw, 1993; Critical Resistance and INCITE! Women of Color Against Violence, 2006; Davis, 2003; Mogul, Ritchie, Whitlock, 2011; Richie, 2012; Ritchie, 2003; Thuma, 2014; Thuma, 2015). Carceral feminisms represents a critique of the historical and contemporary legacies of mainstream 
liberal feminist initiatives that have prioritized the needs and visions of white women and depended on the threat of incarceration to fuel change. Within the scope of this project, I primarily discuss the impact of anti-violence and anti-sex trafficking interventions grounded in protecting or rescuing victims of violence.

The term and representation of "carceral feminism" has been cited and critiqued in various narratives and scholarly literature that use an intersectional lens to examine domestic and sexual violence policies as well as literature that addresses the federal government's funding of anti-sex trafficking initiatives framed as rescuing victims of commercial sexual exploitation of children. In addition, critical feminist scholars have looked at the diverse coalition of state agents, activists, Christians, and radical and liberal feminists who have unified to support anti-sex trafficking interventions rooted in a savior mentality. Not unlike the two time periods I focused on in the literature review, early American social work and the feminist Sex Wars, anti-trafficking agendas have been put forward by a diverse collection of activists made up of evangelical Christians, secular feminists, human rights activists, and celebrities. Bernstein remarks that, Despite longstanding disagreements around the politics of sex and gender, these groups have come together to advocate for harsher criminal and economic penalties against traffickers, prostitutes' customers, and nations deemed to be taking insufficient steps to stem the flow of trafficked women. (2014, p. 347)

Under the guise of working together on human rights causes, these groups reproduce the dangerous consequences of carceral feminism as they advocate for interventions that use police arrests to identify survivors of sex trafficking and 
programming that often reproduces the cycle of power and control; yet in these programs social service providers have the power to decide what is best for those who have been identified as exploited. Police have shifted towards arresting sex workers under the assumption that they are victims of sex trafficking and then hold them until a determination of their victim or agent status can be made (Farrell \& Cronin, 2015). Leaving the determination of victim or criminal to the discretion of the police may lead to profiling of marginalized communities and therefore who appears to be victim like and who does not.

Carceral feminist logic emphasizes that if innocent people or victims are rescued by law enforcement through raids or arrest, they can be saved from violence. However, when women of color, who hold multiple marginalized identities, turn to the police for help, they risk being assigned criminal status as opposed to victim status. Scholars across disciplines, feminists, activists, and social workers document the disproportional experiences of Black women being arrested because of how institutional racism, classism, transphobia, and xenophobia have labeled them as criminal, instead of innocent (Crenshaw, 2011; INCITE!, 2014; Ritchie; 2003; Richie; 2012).

In her book, Arrested Justice, Beth Richie (2012), provides three salient examples of black women arrested for their experiences of victimization, resulting from the wellintentioned feminist movement that advocated for policies meant to protect survivors of violence. First, she details the experiences of an elder black woman intimidated by law enforcement through the use of physical and sexual assault and false allegations of family members, to force her out of her long time home so that it could be demolished for the building of new housing. Second, she discusses the case of black teen girl, Tanya, who 
was demonized as brutal and uncaring after she gave birth in a dumpster behind her school and left her baby there. And, third, she describes the experiences of the NJ4, a group of black lesbian teenagers incarcerated after defending themselves against a physical assault that took place when they were harassed with homophobic, sexually violent, and sexist remarks. Although the harasser, who was eventually stabbed, told the police it was by a white man who had intervened to help the women, the NJ4 were charged with his assault.

The stories that Richie described about the intersectional experiences of oppression faced by black women, indicate the rise of a culture that turns to incarceration for punishment of any criminal act committed. However, the legal system disadvantages people of color and incarcerates them at exponential rates through disproportionate sentencing (Alexander, 2010; Davis, 2003) and biased discretion of the judicial system. Richie (2012) describes this prevalence of criminalization among black men, women, trans, and gender non-binary people as an effect of a "prison nation." Importantly, the harmful effects of criminalization do not rest in arrest or imprisonment, other harmful consequences include loss of parental rights, access to housing, welfare, employment, and education (Mogul, Ritchie, \& Whitlock, 2011). The impact of institutional oppression dictates a lack of access to affordable housing, social services, healthcare, employment opportunities, and other basic needs. Therefore, many disenfranchised communities including, women of color, trans and gender non-binary people, poor people, youth in the child welfare system, drug users, people with precarious citizenship, and queer people, disproportionately turn to survival economies to meet their needs (Hollibaugh, 2014) to get their needs met. 
Surviving outside of mainstream systems makes anyone participating in informal sectors or resisting violence through alternative measures, vulnerable to arrest, criminalization, and further disenfranchisement. For example, in 2006, Andrea Ritchie cited that $66 \%$ of domestic violence survivors arrested were Black women (p. 141.). And, in 2015 the National Coalition of Anti-Violence Programs Annual report states that, "31\% of LGBTQ survivors who interacted with the police said they experienced misarrest, meaning that the survivor was arrested rather than the abusive partner" (Media Release, 2015). Just these two statistics-based ten years apart- demonstrate the threat of survivors with intersectional identities being criminalized when they have been victimized.

Unfortunately, the specific experiences above are outcomes of the Violence Against Women Act that sought increased policing of violent crimes (among other "war on drugs" and "war on crime" policies). Singular solutions or interventions meant to combat intimate violence, such as harsher arrest laws do not eliminate the violence of institutional oppression faced by marginalized communities. These stories signify the dangerous and traumatic disparities in policies that depend on incarceration as a solution to social, political, and economic violence and injustice.

The stories above demonstrate the flaws of well-meaning feminist policy aimed at anti-violence and how it fails to protect marginalized people victimized by the intersections of structural racism, classism, sexism, homophobia, and cissexism. In the following section I explore the impact of trauma (Segrave \& Carlton, 2010) that accompanies criminalization and oppression. Additionally I present examples of how 
carceral feminism shows up in social work practice, specifically through rescue-based projects with people in the sex trades.

\section{Carceral Feminisms in Policy}

The goal of this section is to explore how the implementation of carceral feminism in policy and practice has harmed people defined through the law as "victims" in the sex trade and survivors of domestic violence. In this section, I particularly focus on legislation aimed at combatting domestic and sexual violence and sex trafficking that results in excluding individuals whose social status fall in the margins (Cheng \& Kim, 2014). Below, I revisit Oregon House Bill 4082 and VAWA legislation as examples of how feminist activism, specifically policy advocacy, without an intersectional focus has hurt marginalized communities of women.

Oregon HB 4082. Oregon HB4082 was an amendment passed in February 2016 to the state statute that regulates the promotion of prostitution. This amendment expands the crime of promoting prostitution to anyone who receives or benefits from the money that was made during an act of prostitution. In other words, if a landlord takes money from a person who exchanged sex for money, they could be indicated in the crime of promoting prostitution. The entire amendment to ORS 167.012 (Promoting Prostitution) reads,

Receives or agrees to receive money, goods, [or other] property, services or something else of value, other than as a prostitute being compensated for personally rendered prostitution services, pursuant to an agreement or understanding that the money, goods, [or other] property, services or 
something else of value is derived from a prostitution activity;

(ORS167.012, part c, 2016)

OR HB4082 was introduced by the Commercial Sexual Exploitation of Children workgroup made up of representatives from the Sexual Assault Resource Center, Lifeworks NW and the New Options for Women program, Shared Hope International, Door to Grace, U.S. Victim's Attorney's office, the Giving connection, Youth Villages, and Cares NW. Among these representatives were domestic and sexual violence advocates, anti-sex trafficking activists, prostitution abolition activists, evangelical Christian activists, and feminist activists (https://multco.us/file/38173/download).

Because there is an immediate threat of incarceration or legal sanction for anyone found to be receiving money derived from prostitution, the carceral practice of imprisoning anyone who receives money made through prostitution, creates barriers to immediate and long-term housing, transportation, social services, and safety for many people working in the sex industry. Above, I mentioned that landlords could be implicated in promoting prostitution if they receive money from someone who does sex work to pay for the cost of their rent. In order to avoid participating in illegal activity, landlords may decide not to rent to someone they know is a sex worker. If this is a result of the amendment, sex workers are then forced to either be clandestine about their work, which can lead to vulnerable and lack of safe working conditions or forgo housing all together; either choice further marginalizes sex workers. If we follow that same line of thinking in relation to social services, transportation, and healthcare, sex workers progressively lose access to their basic needs and human rights. 
Consequently, this law that has been in place now since January 2017, could result in the criminalization of social workers, health care providers, bus drivers, landlords, grocery clerks or anyone else who takes money that was acquired from sex work earnings. Therefore, it is necessary to consider the role that social workers play in the lives of people trading sex when social workers, feminists, and legal advocates champion policy intended to seek gender justice in moving toward a world without violence against women. Both the VAWA legislation and the HB4082 are in place due to good intentions of advocates who wish to punish those who abuse, traffic, or perpetuate violence based on gender.

VAWA legislation. The Violence Against Women Act, passed in 1994, was the first successful piece of legislation that brought together government entities, victim's advocates, and feminist activists to fight violence against women, including domestic and sexual violence. The legislation created new punishment for certain crimes, and expanded funding for prevention and intervention efforts. Currently some of the components of the law include:

Violence prevention programs in communities, protections for victims who are evicted from their homes because of events related to domestic violence or stalking, funding for victim assistance services like rape crisis centers and hotlines, programs to meet the needs of immigrant women and women of different races or ethnicities, programs and services for victims with disabilities, legal aid for survivors of violence, and services for children and teens. (Office on Women's Health, 2015) 
Social workers and feminists came together to advocate for policy to bring about funding for the services needed to help survivors. Speaking to the carceral impact of the VAWA, in 2013 with its reauthorization, " 1.6 billion dollars were given to law enforcement to investigate and prosecute domestic and sexual violence" (White, 2015). Whittier (2016) framed carceral feminist activism around the Violence Against Women Act as policy aimed at policing "gendered crime," crime that disproportionately targets women, meant to punish men who perpetuate violence against women, rather than an intersectional feminist frame (p.792). This is particularly notable, as any policy that increases the presence of law enforcement, will disproportionately impact communities already vulnerable to criminalization (Crenshaw, 2011; Richie, 2001; Roberts, 2004). There are countless statistics that show survivors of color being deemed the abuser, queer survivors mutually arrested as law enforcement can not determine who is the perpetuator or victim, and the use of racial and gendered stereotypes to determine abuser/victim (Crenshaw, 1991; Davis, 2000; NCAVP Report, 2015; Richie, 2000; Roberts, 1991; Smith, 2005; Sokoloff \& Dupont, 2005; Sokoloff \& Pratt, 2005;).

As a result of legislation like VAWA, the TVPA, and recent bills like HB4082, supported by advocates seeking to "end violence against women" (that framing is important) not aimed at eliminating systemic violence that create conditions that foster domestic and sexual violence and human trafficking, have negatively impacted survivors and sex trade workers of color through criminalization. The specific experiences of Bresha Meadows, Marissa Alexander, Latesha Clay, and Alisha Walker, named in the Introduction, illuminate the contradictions in how legislation like the VAWA and TVPA 
are applied to women of color. Legally speaking, their experiences were of surviving violence, yet they were incarcerated as criminals.

The Violence Against Women Act and the Trafficking Victims Protection Act are two policies achieved by what has been described as carceral feminist activism (Thuma, 2015; Whittier, 2016), implying that this form of feminist legal activism is rooted in someone being incarcerated as a success or path to end violence. Yet, the stories of Alexander, Clay, Meadows, and Walker are examples in which incarceration led to further violence, not the elimination of it. For instance, at 14 years old, Bresha Meadows was arrested for defending her mother's life when she shot and killed her father, who she witnessed abuse her mother for years. Although an important revision to the VAWRA of 2013 demonstrates a financial commitment to help families affected by domestic violence with improved grants programs to better train civil and legal responses to domestic violence (Section 102, Violence Against Women Reauthorization Act of 2013, (20132014), Meadows was penalized by such legislation while she awaited a determination of her sentence.

Additionally, the VAWRA of 2013 passed an amendment focused on "enhancing judicial and law enforcement tools to combat violence against women (Title 1)." The amendment included specific sections on: legal assistance for victims (§103), culturally specific communities $(§ 109)$, court appointed special advocates $(\S 106)$, outreach and services to underserved populations $(\S 108)$, and grants to encourage arrest policies and enforcement of protection orders (§102). Even so, Marissa Alexander, a black woman and domestic violence survivor was initially sentenced to serve 20 years in jail after firing a warning shot to defend herself and children from her abusive husband (Carmon, 2015) 
and did not benefit from any of these additional points of foci. Rather, Alexander's case is an example of how the intersections of racism and sexism treat Black women as criminal rather than as victims, in the legal system (Law, 2015).

Furthermore, in linking domestic and sexual assault legislation to the sex trades, included in the 2013 Reauthorization, was the reauthorization of the Trafficking Victim's Protection Act, which says that a severe form of trafficking occurs when a minor under the age of 18 is working in the sex trade (Title VII, B, Trafficking victims protection, $\S 1221$ (2013). And, not unlike the carceral injustice found in amendments related to domestic violence, there are consequences for youth and adults of color who work in the sex trades. Latesha Clay, a Black, cisgender girl, was sentenced to prison for 9-20 years after she was arrested for soliciting sex services and a third party with whom she worked robbed her client. Instead of relying on the federal law Clay was criminalized and convicted as an adult. She was not offered a diversion program, which are frequently offered to sex workers picked up by the police, often with goals of rescuing "victims" and helping to rehabilitate them so that they have other options besides working in the sex trades (O'hara, 2016). Although arrest alternatives such as diversion are also problematic, not offering the option to someone who is under 18 and participating in the sex trades (TVPA defines as a victim), highlights racial bias in the legal system. Inconsistent applications of the law such as this one, offer an explanation for why, "Black women are 6.9 times more likely than white women to be brought into the system" (p. 24). By not offering diversion to Latesha, a carceral feminist analysis would suggest that because she is a black woman she is unable to be seen as a victim and therefore criminalized rather than deemed worthy of "rescue" and "rehabilitation." 
Additionally, many scholars and activists have been critical of the disproportionate outcomes among those deemed victims and those who are viewed as criminals. Specifically, it is notable that victims are frequently forced to testify against their traffickers to aid the criminal investigation and to prove that they have been victimized. While making a determination whether or not they can testify, they are placed in detention centers until they agree or risk further incarceration and potentially deportation (Capous, 2007; Cheng \& Kim, 2014; Lerum et al, 2012; Lutnick, 2016; Schreter, Jewers, \& Sastrawidjaja, 2007). Under the TVPA if they are not a U.S. citizen they can be granted T-Visa status allowing them to stay in the county legally. However, a stipulation of receiving the T-Visa is often a willingness to testify against their traffickers (Capous, 2007; Ditmore, 2009; Schreter et al, 2007).

Lastly, I will share one more example that demonstrates the link between efforts to end violence against women and efforts to rescue victims of violence who work in the sex trades. Alisha Walker, a Black female sex worker was attacked by one of her clients and sentenced to fifteen years in prison. In her effort to defend the lives of herself and a co-worker she killed her attacker. As a Black female sex worker, she did not receive the assumption of innocence and instead the media has portrayed her as a monster not someone who was acting in self-defense. This case is meant to be a lesson, but it is a lifedestroying lesson. As ___ from “support ho's" states, " 15 years in prison can only impact Alisha from getting jobs in the future, having a felony on her record, she will have to deal with the trauma she faced" (Transformative Spaces, 2016). An advocacy agenda focused on rescuing "victims" encouraged by the Trafficking Victims Protection Act would not help Alisha in this case. 
INCITE! (2014), says that women and trans people of color are often racialized and gendered as sexually available and highly sexual, making them targets for arrest of prostitution related crimes (INCITE!, 2014). This extreme disparity is visible through carceral feminist policies that facilitate the criminalization of survivors of domestic and sexual violence faced by Black women who are cisgender, transgender, and queer. They are quickly arrested and assumed to be guilty of harm even though they have survived violence. Domestic and sexual violence are often linked with anti-trafficking initiatives under the umbrella of anti-violence and gender-based violence work. The influence of carceral feminist logic disproportionately impacts people working in the sex trade, and specifically trans sex workers, sex workers of color, sex workers who use drugs, who do not have citizenship. This is compounded by anti-trafficking initiatives that work with law enforcement that seek to "rescue" "victims" of sex trafficking.

At the Washington State Coalition Against Domestic and Sexual Violence annual conference in September 2016, co-founder of INCITE! Valli Kaleil Kanuha (School of Social Work UW, 2017) reminded participants in her workshop that through support of VAWA legislation, advocates are implicated in the incarceration of women, queers, trans people of color, sex workers, and victims of sex trafficking. When we advocate for carceral based laws intended to help survivors by criminalizing those who do harm we contribute to the prison industrial complex, which profiles and targets the most marginalized in our communities. An intersectional feminist approach to activism recognizes the ways that social, economic, and political forces intersect to shape different experiences and necessary solutions to violence. Whittier (2016) goes on to point out that some activists against violence against women reject any form of state intervention 
(including funding) as it puts women of color and other marginalized groups in harms way (Bierria \& CARA, 2007). Considering the violence experienced by marginalized people and the mission of social work to pursue social justice, I now turn to a discussion of how carceral feminism has informed social work practice with people in the sex trades.

Rescue-based social work. In this section, I discuss rescue-based interventions that social workers participate in with sex trade workers across the U.S. within both academe and social service organizations. Some participate via anti-trafficking advocacy and intervention, and others engage with sex workers through arrest alternative or prostitution diversion programs.

Contemporary anti-sex trafficking messages depict people working in the sex trade as victims needing to be saved. Shared Hope International is a Pacific NW anti-sex trafficking based organization led by social workers and lawyers that support rescuebased interventions with the sex trade in hopes of identifying victims of sex trafficking. They are recognized as an international leader in the Anti-Sex Trafficking Movement, and describe their mission as "striving to prevent the conditions that foster sex trafficking, restore victims of sex slavery, and bring justice to vulnerable women and children" (Shared Hope International, 2014).

In an essay found in the NASW newsletter, Social Work Today, Christina Reardon (2016) speaks with social work leaders in anti-sex trafficking work and quotes some of their advice to other social workers. Stacy Sloan, Human Trafficking program manager for the Illinois Department of Children and Family Services suggests that social workers recognize the reluctance of trafficking victims to disclose their experience and who may resist services as just needing to build trust with someone before they open up. 
Sloan says, "These kids go kicking and screaming [into services]." And, "They don't feel that they've been rescued" (Reardon, 2016).

The suggestion here is for social workers to recognize when exploitation or trauma has occurred, and to approach "trafficking victims" with care and support, so that rapport can be built. Messages like Sloan's infantilize young people in the sex trades and are intended to inspire social workers to participate in work that will help "save" those deemed victims, yet frequently serve to harm people working in the sex trades.

Additionally, local social services and legal advocacy groups staffed by social workers across the country collaborate with the FBI to identify and rescue victims of sex trafficking in the metropolitan areas where the sweeps are conducted. For example, in the Bay Area, Bay Area Women Against Rape has collaborated with the FBI to conduct sweeps and provide services (Lee, 2013). In Florida, "rescued victims" are brought to a safehouse after they are found, and one of these houses was forced to shut down after a woman left and was sexually assaulted. This event led some legislators and social workers to conclude that it may be necessary to keep the house locked so residents are not able to escape or leave freely. Crystal DeBoise of the Sex Worker's Project in New York City points out that, "we don't consider locking up any other victim the way we do with this population. It wouldn't occur to us that we should lock up a victim of, say, domestic violence, if she continued to go back to her abuser" (Silver, 2013). Such critiques of the FBI intervention remind us that is imperative to think through the strategies used to combat violence against people who experience it intimately, systemically, and institutionally, and develop an awareness of when social work is helping and when we are harming. 
Some schools of social work across the United States have instituted human trafficking centers for building research and interventions aimed at combatting human trafficking. Karen Country-Roswurm, a social work professor at Wichita State University is the executive director of Center for Combatting Human Trafficking at WSU, and considered to be a national authority on human trafficking (CCHT, n.d). In an article about Operation Cross Country she recently stated the following as to why she is in favor of Wichita adopting new legislation related to child exploitation, "This is bigger than human trafficking - this is about humanitarianism, dignity and social justice." CountryRoswurm's center for combatting human trafficking works with the FBI Operation Cross Country to search for exploited children. Between October $13^{\text {th }}$ and October $16^{\text {th }}, 2016$ the program identified three victims of child exploitation and arrested over twenty-seven adults accused of being pimps, johns, or otherwise involved (KY3 News, 2016). CountryRoswurm also states,

A proper response to youth sex trafficking requires the social work profession as a whole to do some soul searching about whether it has drifted too far from its social justice roots [...] For example, the increasing professionalization of social work has given social workers a level of privilege that can estrange them from youth victims of sex trafficking, many of whom are deeply distrustful of professionals trying to help them. (Reardon, 2016, p. 10)

In thinking about the racial disparities of incarcerated survivors of gendered crime, highlighted here among youth and adults of color, I continue to wonder, if rescue-based collaborations with law enforcement take social work further away from our "social 
justice roots" (used in the above quote) and cause irreparable harm to the people we aim to help?

In grappling with this question, and in forming a project focused on how social workers learn to help, I've continued to search for examples of social workers writing about their work with people of all ages in the sex trades. Carly Kalish, another social worker who works with youth involved in sex trafficking and interviewed in Reardon's (2016) essay for NASW remarks,

The most important thing for social workers to remember is to remain nonjudgmental and to not impose their own beliefs about sex trafficking on the child. (p. 10)

Kalish also says, "You have to be able to stomach that young people are having sex for money and even though we want them to leave, they may not want to leave" (Reardon, 2016, p. 10). The statement "stomaching having sex for money" presents an infantilized perspective of youth involved in the sex trade, rather than what the research shows as the average age of entry into the sex trade being between 15-17 (Lutnick, 2016, Stransky \& Finkelhor, 2008). It also brings a specific moral judgment related to young people and sexual activity contradicting the advice of Kalish (in Reardon, 2016) to stay nonjudgmental.

NGO and national experts have gone on record to say that data citing the number of youth involved in the sex trades is faulty. Stransky and Finkelhor (2008), researchers from the Crimes Against Children Research Center, suggest that the number of youth involved in the sex trades range from 1,400 to 2.4 million. However, in their fact sheet, they urge readers not to cite such statistics, "A close look at these diverse estimates 
reveals that none are based on a strong scientific foundation. They are mostly educated guesses or extrapolations based on questionable assumptions (p. 2)." Further emphasizing the lack of sound research, John D. Ryan, CEO of the National Center for Missing and Exploited Children (2013) says,

No empirical studies exist that estimate the number of children currently being sold in the sex trafficking industry nationwide. However 1 in 8 runaway youth exhibit characteristics that put them at risk for being trafficked. (Testimony, October 23, 2013)

It is important to note that the numbers of youth and minors under 18 in particular, rely on characteristics that put them "at-risk" for trafficking, not self-identification. Although, panic surges publicly when there is visible rhetoric and imagery of enslavement that asks anyone and everyone to be on the lookout for potential victims of "modern day slavery" (End Slavery Now, 2017), and emphasize extreme incidences of victimization among women, teens, and children in order to create a sense of urgency around the issue of sex trafficking. Many people work in the sex trades as a means to survive abuse or other forms of institutionalized oppression.

This is further exemplified in a report by the IDVSA based out of University Texas at Austin (2016) in which the number used to identify how many cases of trafficking occurred in the state were based on an estimate of factors that make someone "at-risk" for being trafficked, self report, and social service provider reports. In their qualitative interview study with youth working in the sex trades and who interact with social workers in New Zealand, Abel and Wahab (2017) trouble the idea that at-risk assessments accurately reflect the experiences of youth, as youth in their study discussed 
the street as a place of freedom and acceptance. Denise Brennan highlights the many contradictions and inaccurate statistics that accompany the passage of the Trafficking Victims Protection Act (2000),

One of the most remarkable aspects of the TVPA (2000) is that it was passed without reliable data on how many individuals are in situations of forced labor or servitude — in a variety of industries — in the United States. Even the U.S. Department of State's estimates of how many individuals are trafficked into the United States annually have fluctuated widely over the past few years. The U.S. Department of State's Office to Monitor and Combat Trafficking in Persons has revised its own estimate downward from 50,000 in 2000 , to $18,000-20,000$ in 2003 , to $14,500-17,500$ in 2006 (O’Neill Richard, 2000; U.S. Department of State, 2004, 2005, 2006). In addition, the report that Congress had requested from the U.S. Government Accountability Office (GAO; 2006) called the U.S. government's estimates of global trafficking questionable because of "methodological weaknesses, gaps in data, and numerical discrepancies." (2008, p. 2).

Additionally, Brennan notes that due to such weaknesses in methodology there is little scientifically rigorous scholarship on trafficking in the U.S, and even more importantly, there is no presence of narratives by those who experienced forced labor (2008).

The positing of data that isn't empirically based contributes to false public narratives about who participates in the sex trades and what their experience looks like. With such large numbers pervasive in the media about victims of trafficking, it is not 
surprising that interventions focused on rescuing people from sexually exploitative relationships are well supported federally and locally. Kari Lerum reflects that, "At first, well-meaning people may merely place their ideological spotlights on specific groups who are "in trouble," but eventually those spotlighted people may be seen as the source of trouble" (Lerum, 1999, p. 13). Historically, tracing the work of social workers with sex trade workers to the friendly visitor, we can observe precisely the transformation that Lerum identifies, as social workers have designated sex workers first as "people in trouble" or needing to be saved), and then as the source of disease and moral contagion (Abrams, 2000; Blair, 2010; Lerum, 1999; Wahab, 2002). However, if social workers are participants in the threat to either incarcerate people in the sex trades or motivate them to leave the sex trades, social workers may be a source of trouble rather than support in sex workers' lives.

\section{Critiques of Carceral Feminisms and Rescue Social Work}

Carceral feminism can be disguised as a complex web of good intentions; "helping" as a synonym for policing, advocacy for human rights in the spirit of social justice, and working towards safety and protection from violence through the hands of the law. Considering the damage that can be done in the name of helping, I present three common critiques of carceral feminism frequently marked by the appearance of combatting oppression yet, while they may help some, further oppress others. The first critique, a lack of intersectionality in praxis explores how carceral feminist policies and practices focus on a single solution for issues that require an intersectional analysis. The second, centers the flawed logic of criminalization as a solution for change, and focuses on how those who are supposed to be helped through carceral feminist campaigns are 
harmed instead. Finally, the third critique engages with the intersection of governmentality and feminism, and discusses the ways the government draws on systems of oppression (including racism, xenophobia, sexism, and cissexism) to regulate, criminalize, monitor people in the sex trades through rescue efforts supported by carceral feminists logic. In anti-sex trafficking interventions that use rescue as a tactic to identify victims in the sex trade, each of these critiques weave together under carceral logic and frequently result in perpetuating social injustice in the lives of already disenfranchised communities.

Lack of intersectionality in praxis. Kimberle Crenshaw coined the term intersectionality in her "Mapping the Margins" (1991) article that was influenced by woman of color feminisms and scholars like bell hooks, Gloria Anzaldua, Patricia Hill Collins, the Combahee River Collective and seminal texts like Black Feminist Thought, Coalitonal Politics and This Bridge Called My Back. Intersectionality as theory, praxis, and analysis has been most prevalent in feminist discourse to describe the intersections of sexism and racism and to describe the multiple interlocking forms of oppression that women of color experience. Intersectionality is a term used to describe the interconnected production of injustice among systems of oppression such as: racial, economic and gender oppression (Collins, 1990; Crenshaw, 1991;). Mehrotra (2010) discusses the inclusion of migration status, disability, and sexual identity to these intersections to produce an even broader scope by which to see the myriad ways that intersections of oppression target marginalized people.

One way that the impact of intersectional oppression is evident in the sex trades is through prostitution laws like, "condoms as evidence" (Human Rights Watch, 2012) and 
"manifestation of prostitution" that gives law enforcement the autonomy to identify sexually exploited youth and adults victims of trafficking. Individuals working on the street in the sex trades who are cis and transgender women of color, who may use drugs, are youth who have left foster care, living on little or no income, and may have prior arrests often find themselves in the double-bind (Collins, 2000). This double-bind consists of working in the sex trades because institutional oppression has made it so accessing formal employment, housing, and healthcare are nearly impossible, but they are criminalized and targeted for working in the sex trades as a means for survival, income, or to escape abuse.

Furthermore, social service workers that regulate resources related to housing, welfare, health care provision, therapeutic individual and group therapy, parenting, expect people in the sex trade to get off of drugs, work a full-time job, possibly recover from trauma (if identified as a victim), and perhaps go to school to prove they can provide a legal and decent living for themselves and families—all without much assistance from the state (Knight, 2016). Due to the stigma of the sex trades and incarceration, social workers may not realize that people with sex offenses, felonies, prior criminal arrests may struggle to find a job that will hire them. In addition, due to its flexibility, sex work can often provide other perks that will increase the ability to meet the needs of everyone involved. Of which may include more money in a shorter amount of time than a minimum wage job, allow for more time with children and families thereby increasing the ability to meet the needs of family members, increase family bonding, make education possible, and more. 
Sex trade workers need support and solutions that are multi-layered and address the various forms of oppression and barriers they experience. Carceral feminisms lack attention to intersectionality in theory and praxis and focus on a single issue and solution, such as incarcerating perpetrators of hate crime, mandatory arrests of domestic violence perpetrators, or rescuing sex workers in attempt to eliminate exploitation and violence (Spade, 2013). All of these are issues that require an in-depth intersectional analysis about who is impacted and how. Liberal feminist organizations like the National Organization for Women (NOW) recently recognized the harm that has been done by excluding the priorities of women of color and not centering an intersectional lens. At their $50^{\text {th }}$ anniversary conference, Kim Gandy, NOW president reflected on the unintentional harm, liberal feminist advocacy related to violence against women, has done to women across communities of color (Bader, 2016).

Important to note is that carceral interventions employed by anti-sex trafficking activists aimed at removing people from the sex trades or eradicating the sex industry all together have made many communities, such as youth and adults of color, transgender women of color, and undocumented workers further vulnerable to violence. Research has found that those who have been trafficked are often imprisoned and disconnected from their families and communities even further (Brennan, 2007; Ditmore, 2009). Imprisonment leads to disenfranchisement, lack of access to rights, which leads to the increased need to engage in sex work and potentially being incarcerated again, and disconnection from family and community impedes recovering from trauma and violence. The consequences of incarceration contradict the purpose of removing people from the sex industry and working towards complete abolition of the industry. 
If intersectionality is not considered in praxis then activists, social workers, and feminists may be putting people from marginalized and targeted communities at further risk of violence at the hands of the state. It is well documented that people of color, women of color, trans people of color, queer people of color, poor people of color, people of color with disabilities, migrant women of color, and other marginalized sexual, gender, racial, and ethnic intersectional identities are most likely to be targeted by the criminal justice system (Hollibaugh, 2001; Spade, 2013; Stern, 2011/2012).

Reliance on criminalization as a solution for change. Criminal legal based ${ }^{9}$ interventions often bring together law enforcement, social workers, social services and humanitarian efforts to help rescue and protect women and girls from trafficking (Brennan, 2008). These coalitions are formed under the umbrella of anti-sex trafficking initiatives and aided with funding under the Justice for Victims of Trafficking Act. As a function of neoliberalism, these interventions often serve to reinstate hegemonic sexual and gender norms rooted in Whiteness and Christianity.

In their participatory and evaluative research study, Cheng and Kim (2014) interviewed Jin and Kyungmi to understand the impact of an anti-trafficking organization on their lives. Initially the research was conducted with the hopes of seeing the positive influence of the program on their lives. When Cheng and Kim (2014) presented their findings to the research team they remarked that,

researchers were intrigued by their aversion to the law enforcement efforts and humanitarian interventions that claimed to offer them "rights"

\footnotetext{
${ }^{9}$ This term is used in the place of "criminal justice," to emphasize that interventions connected to the legal system rarely bring about justice or fairness for any of the communities involved. Particularly people of color, queer and trans people, drug users, people with disabilities, and other marginalized communities (Spade, 2013).
} 
as these two women "explicitly criticized the anti-trafficking initiatives

that were intended to "protect" them. (p. 357)

This quote highlights the distance between good intentions of anti-sex trafficking rescuers and the actual harm Jin and Kyungmi faced in the wake of rescue.

Many people who should (meaning they identify themselves as a victim or by law are under 18 and working in the sex trade) fit the Trafficking Victims Protection Act definition of "trafficked" in the U.S. and are not recognized as victims by law enforcement. If unwilling to cooperate, youth under 18 or adult sex trade workers are instead viewed as aiding in a crime or as criminals themselves, particularly if they are youth, trans, queer, people of color, visibly on drugs, or their citizenship status is undeterminable by authorities. They experience continued human rights violations, rather than being recognized as experiencing social and economic injustices. Lerum and colleagues state,

Furthermore, economic marginalisation due to the deep impact of racism in the United States means that people of colour make up the majority of sex workers in public spaces, and are relentlessly targeted by the police in their efforts to clear the streets. (Mcardle, L, 2001 as cited in Lerum et al, 2012, p. 89)

The implementation and enforcement of policies rooted in carceral feminism, like harsher penalties for perpetrators of domestic violence, trafficking, and sex trade often result in positioning the most marginalized workers of having to prove their innocence and thereby being re-traumatized through state violence (Bruxfoort, 2014; Ditmore, 2007). The attempt to try and prove innocence is futile, when poor 
people, sexual deviants, and people of color are already regularly profiled and targeted by law enforcement when they live and work on the streets (McCardle, 2001).

To that end, many marginalized sex workers are fearful of law enforcement, which should send a signal of caution to social workers about collaborating with law enforcement to enforce carceral policies. The Sex Worker's Project in New York City conducted a qualitative interview study, with fifteen immigrant women who had been picked up in a local police raid. Of the fifteen women picked up in the raid, nine were arrested and seven of them (who identified as trafficked), went un-identified by police as such (Sex Workers Project, 2009). This example shows why even individuals working in the sex trades who have experienced victimization and/or trafficking, may fear the police because of their criminalized work.

When working within the state to advance "rights" there are almost always consequences for the oppressed at the intersectional margins (Spade, 2015). A criminal based solution to the needs of people in the sex trades does not equate social change for people experiencing intersectional forms of oppression. For example, Emi Koyama, a sex trade activist, emphasizes the experiences of marginalized sex workers, even though some States have passed "safe harbor laws" that define minors who are "rescued" from prostitution as victims, not criminals, young people are still arrested and detained as juvenile delinquents, "material witnesses," mentally incapacitated, etc., or are "charged up" with drug and other crimes that result in longer sentences than simple misdemeanor prostitution offenses. Young people, especially young 
women of color and transgender women, are still profiled as suspected prostitutes, and are targeted for "stop and frisk" in search of drugs and condoms-which is construed as an evidence for prostitution. They are still forcibly placed under the child welfare system that many young people had to run away from in the first place for years, instead of serving 12 days in jail as they did before. (Koyama, 2012, blog entry 362)

Koyama's passage highlights the critical need to use an intersectional analysis when considering criminalization as solution for change among people working in the sex trades. Despite the circumstances of their entry into the sex trade must social workers, feminists, activists, and policy makers must acknowledge that criminal charges are not trauma-informed an do not lead to a path outside of the sex industry. Instead, involvement in the criminal system makes violence more likely and working conditions less safe.

\section{Relationship between governmentality and carceral feminism. Michel}

Foucault's concept of "governmentality" has been instrumental in expressing how a carceral state functions (Garland, 1997). The concept describes governing populations instead of individuals and thus how populations come to be seen as having predictable characteristics - people of color are understood as being more likely to commit crimes, poor people are understood as more likely to use drugs, etc. In fact, drawing on Foucault's concept of governmentality, Simon argues that, "crime has become a master narrative used to justify government intervention into people's lives" (Simon, 2007 in Shdaimah \& Leon, p. 251). This is evident through media stories of crime and violence in 
urban neighborhoods as well as brown faces being shown as perpetrators of Islamicbased terrorist actions.

With governmentality, the government—agents of the state, legislation, distribution of federal grants and funding - inserts itself into the lives of people through crime and assigning of criminal status. For example, within the Trafficking Victims Protection Act, federal funding is distributed through the Department of Justice to interventions that bring together law enforcement, child welfare, and social services to identify and rescue sexually exploited youth, and adults who have been trafficked through such programs like the FBI Operation Cross Country. In addition, a number of domestic and sexual violence agencies across the U.S. receive funding to support victims of sex trafficking. There is a notable relationship here, particularly because the more law enforcement becomes integrated into social services with marginalized individuals, the risk of criminalization for victim's who do not fit the idea image of a victim, become targets of criminality and governmentality.

A carceral state uses governmentality to assign punishment to those who do not conform to a contemporary Americanized hegemonic notion of femininity for exampleone that is based in whiteness, Christianity, heterosexuality, monogamy, and cisnormativity, and sexual submissiveness (Collins, 2005). Therefore, applying the concept of governmentality to the sex trades highlights the reality that when feminine workers do not conform to the standards of hegemonic femininity they are criminalized for their deviant behavior under the guise of "rescue." In the example of Monica Jones discussed above, a Black transgender woman was arrested through an intervention that was searching for adult victims of sex trafficking. In order to search for victims, law 
enforcement and social workers used their bias to determine who typically works in the sex trades (not unlike the vigilante outreach volunteers in Shih's research-mentioned earlier). They used this image to arrest sex workers and identify victims from there. Because Monica was a tall black woman walking down the street, she was stopped by a police officer and was identified as a sex trade worker. When taken to the location of Project ROSE she denied the program and was no longer seen as a "potential victim." She was then assigned criminal status based on her non-compliance of wanting to go through the program. The concept of governmentality shaped her interactions with the legal system and social service system beginning when the cop approached her on the street because she did not fit the markers of hegemonic femininity by being black, tall, perhaps recognizable as trans, and resisted engaging with the police or accepting services, and was criminalized in part due to her deviance.

Additionally, in their qualitative research study in which they served as evaluators for anti-sex trafficking program, that sought to learn how well they were doing Cheng and Kim (2014) discovered that the program they were working for brought more harm into the lives of program participants. They described how the intersection of feminism and governmentality hurt Jin and Kyungmi in the anti-trafficking program they were rescued into,

As women who carefully strategized around their immigration and labor conditions as sex workers - in what some of them call their own "construction projects"- they embody the sexual limits of neoliberalism. While they may personify the values of self-reliance, self-governance, and freemarkets [central values of neoliberalism] (Brodie 1996), they violate 
the neoliberal ideals of relational heterosexuality and middle-class femininity (Bernstein 2012). Even though the anti-trafficking movement hails women's human rights, gender justice, and protections afforded by the state, its operation relies mainly on framing sex work as a crime while reinforcing gender, class, racial, and global inequalities. We argue that global anti-trafficking initiatives as they have taken shape in the twentyfirst century are part of neoliberal governance, grounded in populist campaigns, racial codes, culture wars, and sex panics that justify the repression of those who are outside the norm (Duggan, 2003 in Cheng \& Kim, 2014, p. 357).

Jin and Kyumi (Cheng \& Kim, 2014), impacted by immigration policies and economic injustice, were strategic in planning their work in the sex trade. They embodied the neoliberal values of "self-reliance, self-governance, and free markets" (Cheng \& Kim, 2014, p. 357), yet, because of engaging in sexual labor and the racialization of their immigration status they were rescued into the anti-sex trafficking program so that they could conform to a different neoliberal example.

The critiques of carceral feminism named in this section, lack of intersectionality in praxis, criminalization as a solution for change, and governmentality and carceral feminism are extreme violations of human rights that social work education engages with on a daily basis. By interrogating the interwoven complexities of each marker, the oppressive consequences facing communities we work with become visible. 


\section{Theoretical Framework: Anti-carceral Feminism}

The feminist Sex Wars significantly impacted the values and visions of feminists grounded in various theoretical traditions. Along with the ever-expanding influence of neoliberalism on the U.S. society, family, and economy, the drive to incarcerate has permeated feminist agendas with justice being defined by penal codes. While the term "carceral feminism" has been framed as a critique of feminist agendas in relation to gender-based violence, a carceral feminist logic provides a useful lens for exploring antisex trafficking initiatives that depend on social services and the criminal legal system teaming up to rescue those who have been victimized. Even if sex workers have experienced victimization, they may face further trauma at the hands of the State. Women of Color activists, scholars, and feminists have been working against carceral feminist agendas for decades, particularly in the realm of the anti-violence movement. In the 1970's grassroots feminists came together to contest the "liberal feminist demands for more criminalization of rape and battering that were increasingly met by a carceral state (Thuma, 2015, p. 28) as they knew that increased criminalization would serve to put survivors of color at risk of arrest. This work has continued on through the work of INCITE!, Mimi Kim's Creative Interventions \& StoryTelling and Organizing Project, The Revolution Starts at Home zine (2003) and anthology (2011), UBUNTU, \#Sayhername, (to name a few), and numerous other collaborations, groups, and projects led by queer, trans, and non-binary people of color.

Anti-carceral feminism (AF), a term used by Bree Carlton (2016) and Emily Thuma (2015) is descriptive of feminist campaigns and ideologies that oppose carceral campaigns or carceral justification of policies that perpetuate the prison industrial 
complex and mass incarceration written about and critiqued by a multitude of critical scholars, many of who have been mentioned here. Likewise, the term "anti-carceral feminist logic" is used here to describe efforts that resist carceral feminist campaigns and goals. Informed by the work of scholars who write about prison abolition as it intersects with gender and anti-violence, an anti-carceral feminist logic (AF) offers an intersectional lens and approach for critically exploring the sex trades. AF is employed in this project to critique rescue-based and punitive interventions that make youth of color, queer and trans women of color, cisgender women of color, women using drugs, women without citizenship and poor women further vulnerable to violence and systemic trauma. Instead of focusing on rescue and criminalization, an anti-carceral feminist logic applied to social work interventions would value alternatives to the criminal legal system like community accountability processes, a focus on systemic change, harm reduction tools, and the selfidentified needs of people in the sex trades.

I've included research and experiences related to both youth and adults because carceral-based policies have similar consequences for both youth and adults who participate in the sex trades. Youth who enter the sex trades without the force, coercion, or persuasion of a $3^{\text {rd }}$ party, complicate the idea that social workers may be helping victims by working with law enforcement. A good or ideal victim is someone who wants to leave their situation, welcomes intervention by law enforcement and social service programs, and is willing to testify against a third party. Additionally, they would openly ask for and receive knowledge about how to plan for their future, recover from their traumatic experience, access mental health care, medical services, job training programs, and housing (Koyama, 2006). Rescue-based programs often favor "good victims," a 
position that depends on criminal history, race, class, age, and gender (Brennan, 2008; Lutnick, 2016; Randall, 2010; Uy, 2011).

Furthermore, people who do not fit the description of a good or ideal victim are more likely to be criminalized or penalized through rescue-based programs and not seen as victims, even though the law states that anyone under 18 is a victim. I make this specification, because if recognized as a victim, they may be able to forgo becoming entrenched in the legal system and provided social and rehabilitative services through community-based programs funded for helping youth and minor victims of sex trafficking. However, whether or not they identify with experiencing violence or trauma, they are not given a criminal record. And, youth working in the sex trade have frequently left abusive family or foster home environments, and are penalized for leaving the child welfare system (Burns, 2014; Koyama, 2012; Lutnick, 2016).

With the stories in the previous section girls of color are framed as criminals rather than victims. Similarly, in the early 1900s, social workers situated white women working in the sex trades as in need of rescue, while black women were viewed as beyond saving. When drug users are targeted and arrested for prostitution they often face stigma for their drug use when accessing health, social, and legal services. Trans people encounter cissexism in social services, the health, and legal system that are unequipped to address their housing, medical, legal, or employment needs. Abolition or rescue-based sex trade intervention programs rarely address such systemically rooted issues.

An anti-carceral feminist logic accounts for contemporary cultural dynamics surrounding the sex industry and the ways systemic oppression impacts individuals working in the sex trades differently depending on their social locations and intersecting 
identities. Anti-carceral feminist logic links critical feminist goals, like disrupting the gender binary, centering intersectionality in praxis, examining the impact of globalization on marginalized people [and in this case, people working in the sex trades], in addition to limiting dependence on state governance for protecting people in the sex industry.

Not unlike the contemporary carceral interventions upon the sex trades, the good intentions in early American social work were rooted in moral reform, spreading middle class values, and Christianity. During the Sex Wars, intense feminist debate rooted in good intentions and equality for women positioned women as victims of sexual oppression or sexually liberated and advocated for policy change with the hope of abolishing prostitution. Radical feminists supported rescue efforts and criminalization of women working in the sex trades in order to liberate them, facilitate the demise of the sex industry, and ultimately resist patriarchy and social injustice.

While there is no universal definition of what it means to work for social justice, the National Association of Social Workers reports their mission for social workers in the following statement,

Social workers promote social justice and social change with and on behalf of clients. "Clients" is used inclusively to refer to individuals, families, groups, organizations, and communities. Social workers are sensitive to cultural and ethnic diversity and strive to end discrimination, oppression, poverty, and other forms of social injustice. These activities may be in the form of direct practice, community organizing, supervision, consultation administration, advocacy, social and political action, policy development and implementation, education, and research and evaluation. 
Social workers seek to enhance the capacity of people to address their own needs. Social workers also seek to promote the responsiveness of organizations, communities, and other social institutions to individuals' needs and social problems. (NASW, 2008, Code of Ethics Preamble)

Clearly stated in the preamble is that social workers commit to help their clients maintain and access their basic human rights. They work to eliminate poverty, oppression, discrimination and other forms of injustice impacting their clients. Many clients of social workers have criminal records, experience oppression, injustice and lack of access to their basic human rights. Incarceration imposes huge barriers to getting such needs met. For example, many employers will not hire someone with a criminal background, making it hard to advance economically in a formal work sector. In turn, many people will access survival economies to make money. In addition, for transgender people prison is frequently a site of violence (Stern, 2012), threat of death, and somewhere they are unable to receive appropriate health care. I bring this up here, because a reliance on carceral interventions to rescue or help people who work in the sex trades is very likely to end in violence, trauma, and a return to poverty and oppression, rather than elimination. Applying an anti-carceral feminist logic to visions for social justice in social work lends itself to a call for practices that resist criminalization in the lives of those most vulnerable to incarceration. This study is situated in the value that participating in the criminalization of oppressed people is in direct contrast to the motivations of many students who choose to pursue a degree is social work; to be a positive force and ally in the lives of people vulnerable to oppression, exploitation, injustice, and violence on micro, mezzo, and macro levels. 
I chose anti-carceral feminist logic as the theoretical framework for this research study because it draws on the many faces of oppression (Young, 2013) that mark certain bodies as criminal and deviant. These "bodies" - are individuals viewed as such because they do not subscribe or conform to hegemonic expectations of gender, sex, and sexuality. Research that engages with processes of criminalization warrants a critical feminist methodology inclusive of exploratory and emancipatory aims. Anti-carceral feminist logic is deeply political in that it engages with the complex intersections of how oppression, trauma, and violence regulate and criminalize those who receive help and those who are punished through social institutions. In this study, I plan to engage academic social work, as we are historically and contemporarily guilty of participating in well-intentioned interventions that draw on criminalization as a solution for recovery, transformation, and healing.

In the next chapter, I dive into the ways the methodology of this project has been informed by three principles of anti-carceral feminist logic that,

- Employs intersectionality to critique rescue-based and punitive interventions that make marginalized communities vulnerable to systemic violence, oppression, and trauma.

- Values alternatives to the criminal legal system like transformative justice, community accountability, harm reduction tools, and self-identified needs.

- Engages with criminalization as a social, political, cultural process that marks certain bodies criminal and reinforces dominant beliefs about gender, sex, and sexuality 
These tenets of anti-carceral feminism are rooted in processes of undoing oppression and working towards transformative social justice. Because social work is grounded in a mission of eliminating social injustice in the lives of people we work with, the research question that guided this study asked, "What are social work faculty teaching students about the sex trades in social work coursework?" The principles of AF logic necessitate looking beyond the surface to understand how interpersonal, systemic, and institutional oppression and privilege appears in social work syllabi and education. Therefore, I asked this specific question because I wanted to understand the scope of content used to teach about the sex trades. In this project, the scope of content referred to the amount of, the type of, the diversity of, and the politics of course material used to teach about the sex trades.

Conducive to this study, content analysis is often used for exploratory and emancipatory purposes given its capacity to embrace reflective processes engaging with the data (Grbich, 2007). The benefits of content analysis include attention to attitudes, emotions, and intentions related to inequality, power, and propaganda (Grbich, 2007). The use of intersectional critiques within AF logic supports the engagement of a method that has the ability to see how a range of content data relates to inequity, power, and propaganda that lead some communities to be deemed criminal (as noted throughout the literature review). Consistent with feminist research tenets, Hulko (2015) remarks that,

The advantages of operationalizing intersectionality in research with equity-seeking groups [in this case social workers as they are called to seek social justice in their work] are that it makes visible the invisible, honors voice and subjectivity, links micro (subjective experiences) with 
macro (social structures), and embraces the complexity and messiness. (p.

73)

A content analysis has the ability to engage and wade through this exploratory process.

Given that researchers often engage in studies linked to their own situations and lives, rejecting myths of objectivity, socially locating oneself and standpoint are also critical to a feminist methodology (Hulko, 2015; Sprague, 2005). Anti-carceral feminist logic is grounded in critical feminist principles that require a reflexivity of the role of researcher within the study. As Becker (1996) argues (as cited in Hulko, 2015, p. 70), research is not neutral, and the researcher always has a position, making it imperative for researchers to be transparent about their intentions, honest about power dynamics, and to recognize their position within a social institution that engages many systems of oppression. Consistent with critical feminist goals of anti-oppressive emancipatory practices, praxis, content analyses and thematic analyses, in the next section I've provided a reflexivity statement focused on how my standpoint has directly informed the research question, site for exploration, data sources, and analysis of the data. 


\section{Chapter III: Methodology}

Methodology is the theorizing about research practice and focuses on the best means for gaining knowledge. Feminist sociologist Joey Sprague (2005) says, “a methodology works out the implications of a specific epistemology for how to implement a method" (p. 5) and thus draws on Sandra Harding (1987 as cited in Sprague, 2005) who situates three elements embedded in the research process: "epistemology, methodology, and method" (p. 5). Each segment in the methodology should be tied together given the expectations of each methodological paradigm and support the congruence among all activities in the methodology.

Given the vast range of feminist methodologies, throughout this study I drew on specific feminist scholars whose theories of epistemology and methodology have strongly informed this study. Some of these scholars include Chandra Mohanty, Marjorie Devault, Nancy Naples, Gloria Anzaldúa, Patricia Hill Collins, and Kimberlé Crenshaw. Marjorie Devault (1996) says, "feminist researchers have produced a distinctive body of writing about research practice and epistemology, and that is where I locate 'feminist methodology"' (p. 31). Devault views methodology as the fusion of ontology and epistemology (1996). Therefore, when deciding on a methodology we must take into consideration the strategies and tools we use to collect and analyze data. This particular study is feminist in its methodology, which is why I spend a significant portion of this proposal untangling the threads of methods and feminist tools that encompass feminist methodologies. 


\section{Ontology}

Ontology is considered the study of "being" or the study of the way things are. A study of being must consider why a particular thing occurs, how it relates to other things, and how those things came to be. Some feminist scholars acknowledge that the corporeal body is inseparable from the mind and emotions, and therefore it is imperative to draw on the physical, emotional, intellectual, and spiritual worlds of women when engaging a feminist ontology (Anzaldúa, 2002; Ortega, 2011; Stanley \& Wise, 1993). Historically, ontologies rooted in Cartesian thought deemed mind and body as separate, in order to support the assumption that men were rational and associated with the mind, while women were irrational based on their emotion and associated with the body (Stanley \& Wise, 1993). Stanley and Wise (1993) reject women's knowledge as irrational, and propose an ontology that disrupts the idea of particular behaviors, bodies, and minds as specific to genetic or biological sex. Thereby, they embrace the intersections of race, class, gender, sex, gender identity, ethnicity, and ability that differently inform the experiences of women.

Relatedly, Gloria Anzaldúa (2002) emphasizes that one's “facultades" or interactions with the world on emotional, physical, and spiritual levels inform "what" and "how" we know through diverse cultural processes of feminization; much of which is defined by Anzaldúa’s framing of "conocimiento" (p. 542). Gloria Anzaldúa rejects binaries of rational/irrational labels associated with gender and embraces the complexity and beauty of knowing when she describes conocimiento as,

Attention is multileveled and includes your surroundings, bodily sensations and responses, intuitive takes, emotional reactions to other 
people and theirs to you, and, most important, the images your imagination creates - images connecting all tiers of information and their data. (p. 542)

She suggests that binaries serve to "other" people and benefit those in positions of power, but cannot exist when the borders separating each side blur, which happens in the seven stages of conocimiento (2002).

Nancy Naples (2005) likewise discusses the need to disrupt the border of insideroutsider status in how we make meaning of researcher positionality. She emphasizes the importance of engaging with the either/or dualism by examining aspects of both insider and outsider identities in relationship to analysis of the research. Feminist ontology asserts that because knowledge is embodied in the mind, body, and emotions, processes of understanding what it means to know something will also change due to cultural, material, and social contexts. Stanley and Wise (1993), emphasize that the only "real" knowledge is beholden to the person being studied (typically those in oppressed positions). Meaning is made from the researcher as they interpret the words and experiences of their participants, through their own lens. With this understanding, researchers must recognize that all knowledge is socially situated, and the researcher will never accurately reflect the extent of someone else's experience.

A feminist ontology must engage many experiences that encompass the standpoints of women of color, queer women, poor women, women with disabilities, and other marginal spaces women occupy through sex, gender identity, and gender expression. The recognition of multiple perspectives is essential when engaging with how both ontology and epistemology help us to understand our relationships to knowledge. A 
feminist epistemology that centers intersectionality and Anzaldúan thought attempts to recognize the endless ways that we come to know what we know. In addition, given temporal changes, one's knowledge at one point in time will shift at another point as they accumulate additional experience and understanding of such experience. Knowing something about any subject requires attention to many processes that shape our social, emotional, physical, and spiritual worlds.

In this project, I express how my own experiences situated in between my multiple social group identities inform my interpretations and conclusions from the data. In my discussion of a critical feminist epistemology, I reject a universal feminist standpoint. Instead, like many critical feminist scholars, I embrace plurality, positionalities, and social locations shaped by intersectionality, globalization, and colonization (Mohanty, 1988; Haraway, 1988; Harding, 1993; Collins \& Bilge, 2016). Therefore, I deploy a feminist objectivity (Haraway, 1988) throughout the research process to explicitly address how social location and individual realities inform the meaning and analysis of themes identified in the data.

\section{Epistemology}

Epistemology posits questions related to what it means to know something. For example, how does knowledge come to be and what makes knowledge valid? Epistemologies relate to the scope and limitations of knowledge and strive to make meaning of the interactions between knower and inquirer. Feminist epistemology must be reframed as plural since our knowledge of women, gender, and femininity is never static or one-dimensional. As Mohanty (1988) points out, feminist theories explore the relationship between "woman" and "women" and the multitude of political processes that 
shape experiences individually, collectively, and globally. As such, it is also my belief that feminist epistemologies must account for the many and different experiences of feminized people shaped by privilege and oppression in the lives of men, women, trans, and non-binary individuals.

When describing the feminist research process, findings are particularly trustworthy when there is a clear claim that any highlighted knowledge is always incomplete and impacted by social location. Patricia Hill Collins recognizes epistemologies of standpoint as "partial truths" (1991). Specifically, one example that Collins emphasizes is that in African-American communities, dialogue, caring, and personal accountability lead to knowledge making and knowing. These processes of knowing have historically been deemed invalid and therefore, to name them as knowledge resists institutional intersectional oppression. With this example, intersectionality is used as an analytic tool and informative in practice, both critical to the building of knowledge (Collins \& Bilge, 2016). Through partial processes we as feminist researchers must be clear and assertive about the diverse means of acquiring knowledge and the privilege attached to having stories shared with us.

Since "legitimate" knowers are frequently defined through the scientific production of knowledge within the academy, which depends on the stories and knowledge of research participants, feminist researchers should be explicit about the knowledge-making process. Devault (1996) purports that a feminist researcher should "refuse to put aside her experience, and, indeed, must make her bodily existence, and activity a "starting point" for inquiry" (p. 39). Therefore, despite any commonalities of experience, the researcher must question insider-outsider dynamics, embrace borders, and 
articulate the process of analyzing material, data, and context. This is particularly important in feminist research, because it is frequently this in-between space or the "borderlands" where the meaning of knowledge is made (Anzaldúa, 2002; Keating, 2002; Naples; 2003; Devault, 1996). For example, as a white, queer, temporarily able-bodied, middle-class, cisgender woman, and former sex worker, I make meaning of my experience and how it informs my lens in the analytic process through the combination of my intersection of identities and the knowledge I have gained through navigating these identities and experiences in public and private spaces. Anzaldúan thought (2011) would suggest that there is not just one experience to be understood on either side of the binary of sex worker/non-sex worker, rather there is meaning in both being a sex worker in a specific context and not a sex worker in a different context. It is what lies in between such a binary that informs us of how meaning is made.

My interpretation of the data comes from a desire to be cognizant and explicit about how oppression impacts the experiences of all people in the sex trades, yet very differently and disproportionately considering the different intersections of oppression. Any one person's experience cannot be observed or interpreted solely as a woman or a man, cis or trans, queer or straight, poor or rich, able-bodied or disabled, because there are far too many unique intersections and overlaps that provide differently situated understandings of knowledge.

An intersectional engagement can then demonstrate how theory informs practice; thus when fused, knowledge is produced. Harding (1993) asserts that feminist objectivity is a method for making scientific analysis more rigorous and at the same time a strategy for rejecting one feminist standpoint. Similarly, tenets of critical theory and feminist 
inquiry acknowledge that the research process is always guided by our biases and values. Fusing tenets of critical theory and feminist epistemology (Collins, 1991; Collins \& Bilge, 2016; Crenshaw, 2012; Ruchti, 2012) offers a theory of knowing that engages with the vastly different ways that intersectional oppressions shape the feminization of knowledge.

\section{Feminist Epistemologies in this Project}

The inquiry for this project stemmed from an intersectional approach to epistemology informed by my social location, research experiences, and social service provision to sex workers. This study was guided by a desire to learn about the content social work education relies upon to teach about the sex trades, specifically in relation to an intersectional perspective. One feminist epistemological strategy I used is to research a question that has potential for social change. Namely, I analyzed how knowledge about the sex trades was shared and utilized by social work faculty. To understand how pedagogy was deployed required an examination of how such strategies embraced the vast array of experiences within the sex trades. Consequently, the goals that directed this study included social change, reflexivity, interrogating power in the face of state violence, and intersectional feminist praxis and knowledge production. Combined, these goals were intended to examine the connections between governmentality and good intentions within social work educational content on the sex trades.

As a social work and feminist academic, it is a part of my value system to help make visible knowledges that have traditionally been subjugated by those with epistemic privilege (Hartman, 2000). By drawing on the poignant insights of feminist epistemologies that value situated knowledges (Haraway, 1988), we can view sex 
workers as "knowers" - a community who has historically been dismissed in claiming knowledge. Therefore, when I encountered knowledge, content, and pedagogy related to the sex trades, I questioned where the research, course content, and faculty perspectives were rooted, and how such content represented the experiences of people in the sex trades.

Research within a critical paradigm that draws on feminist qualitative methods for data collection supports systemic change and resists oppressive measures that exist to regulate the lives of marginalized communities. Within this project I sought to engage with research that would help social work as a discipline move toward a critical definition of social justice that relies on intersectionality in practice, research, and education (Sensoy \& DiAngelo, 2017). In that vein, I explored the perspectives of faculty teaching social work courses and what Laura Nader (1972, p. 289) terms “studying up." Studying up refers to questioning structures of power, or how things came to be, as opposed to studying those who are usually described as "powerless." In this project, I studied up by interviewing social work faculty colleagues and analyzing social work course syllabi of those located in academic institutions, who thereby significantly influence how social workers think about and learn to practice with people in the sex trades.

\section{Qualitative Methods}

Qualitative methods draw on a number of tools and techniques to engage with data, analysis, and design. As a blend of approaches that continues to evolve, significant historical moments shape the many processes of qualitative research (Denzin \& Lincoln, 2003). The current time period, which Denzin and Lincoln have categorized as "the future moment" of qualitative research (2000-present), depends on the blurring of 
qualitative genres concerned with moral discourses that engage critical theories, interpretive theories, and feminisms in critical dialogues. In this time period of qualitative research focused on the interconnections between democracy, race, class, gender, nation, globalization, and community, Denzin and Lincoln discuss a "crisis of representation" (2003, p. 4). This crisis rests on the assumption that the analysis of data is never truly accurate, as positionality of the researcher and analyses are inseparable. A researcher will never fully be able to represent another's experience, and thus must attempt to translate the process of making meaning.

While all research is a process defined by the interconnectedness of theory, method, and analysis, feminist and qualitative research prioritizes transparency in discussing how each of these activities are linked, through explicit discussions of ontology, epistemology, and methodology (Denzin \& Lincoln, 2003). With transparency about how these activities are interrelated, we can arrive at a point where the "inquirer" and the "known" (Devault, 1999, p. 31) are represented in all aspects of the research process. Ultimately, qualitative researchers acknowledge the the role of researcher in the world of the observed as contributing to the research process. Therefore, it is imperative to attend to the many issues that arise in the progression of knowing about a specific phenomenon and central to demonstrating rigor is making the process visible. Qualitative methods allow for a range of in-depth stories and more specifically the opportunity for participants to frame their experiences in their own words.

In this research project, not only did I want to analyze the content social work faculty use to teach about the sex trades, I wanted to hear it contextualized in the stories of the faculty teaching these courses. Throughout my the discussion of findings and 
analysis of course syllabi, I draw on themes and quotes from interview participants to further frame the lens I used to interpret syllabus content. A qualitative approach in this project helped to explore the content and stories of what faculty teach students in social work programs about the sex trades.

\section{Feminist Methods in Qualitative Research}

No single method or methodology can make research feminist, rather it is a combination of methodology, ontology, epistemology as well as the project's contribution to social change (Devault, 1996). Many pieces of the research can make a project feminist, including collection of data, construction of the research question, analysis of data, dissemination, and implications for social change. To engage this study's research question, I begin this methods section with a discussion of how and why the methods used to collect, analyze, and demonstrate the trustworthiness of data rest in feminist research and methods.

Feminist research requires attention to interlocking social identity categories, which are inextricable when examining gender inequality. These intersections also change the impact of power and authority on marginalized communities and interactions within social environments, systems and institutions (Collins, 1990; Crenshaw, 1991). A significant component of feminist research is naming the impact of structural inequality on marginalized communities. Orme (1998) critiques how social work has traditionally deemed research "feminist" when it attends to women's issues, and instead she demands that feminist research requires more than attention to women's issues or the exclamation of research being feminist, "because I say so!" (2003). Feminist research does not simply imply research on women or gender inequality through binary gender categories, but 
extends to include expressions of femininity, masculinity, multiple gender identities, sexualities, and how such constructions intersect race, class, disability and other social group memberships (Wahab, Anderson-Nathe, \& Gringeri, 2012).

Critical feminist praxis requires that social workers use an intersectional framework to explore how practice, research, and theory contribute to social change (Collins, 2000; Collins \& Bilge, 2016; Crenshaw, 1991; Mehrotra, 2010). This focus on praxis is essential to conducting research with the sex trades, particularly because a certain perspective, theory, or ideology in relation to the sex trades may lead to a specific approach to social work practice within the sex trades. Feminist methodologies and socially just praxis place important value on power, privilege, and the many manifestations of how power permeates the experiences of marginalized communities, both in individual and communal ways (Wahab, Anderson-Nathe, \& Gringeri, 2012). For instance, Wahab and colleagues (2012) recognize how vital social change, focused on interrogating micro, meso, and macro levels of oppression, is to critical feminist research. In the following section, I discuss the qualitative methods that I used in data collection and content analysis and their relationships to feminist and qualitative methodologies.

\section{Methods}

Katherine Frank and Laura Agustín (2007) push researchers investigating the sex industry to look at the larger cultural meanings and dynamics shaping the sex trade. By looking at the current cultural landscape of social work education, I gained a deeper understanding of the relationship between how governmentality and well-intentioned carceral feminist social work informs education about the sex trades. In a feminist research project using qualitative content analysis, I primarily explored what social work 
faculty teach social work students about the sex trades. To garner this information, I accessed two types of data. The first data source comprised social work syllabi, both those that specifically focused on the sex trades and those that incorporated material, discussion, or topics related to the sex trades. The secondary data source I drew on for analysis was interviews with social work faculty, some of whom provided their own course syllabus for analysis and some who could not provide a syllabus, but met the study's qualification criteria of including sex-trades-related content in their course.

By collecting these two sources of data I was able to gain an understanding of the specific content used to teach about the sex trades in a data set of 20 social work courses located in CSWE-accredited programs in the United States. Concomitantly, from 20 indepth qualitative interviews with course faculty, I learned about the messages instructors hoped students would take away and, more specifically, examples of content that instructors relied on to inform those messages. I utilized a data collection template to organize the ideologies, values, and theories found within course syllabi and was able to examine where programs both embraced and resisted dominant U.S. narratives about the sex trades. Further, in my analysis I was able to identify a set of linked themes that directly respond to what social work instructors teach students about their role in social work as it relates to the sex trades. Finally, I was able to use my interview conversations with social work faculty to further support my own as analysis of the meaning and implication of each content-based theme.

Drawing on Hsieh and Shannon's (2005) framework of directed qualitative content analysis, I constructed a data analysis template (see Appendix A) to condense information in each course syllabus to a single template utilizing deductive codes rooted 
in the study's conceptual framework. Additionally, I used an interview guide including questions that would provoke responses to guide my analyses. After I analyzed three syllabi and three interviews, I altered the questions slightly to further draw out what course instructors identified as the most pressing needs of people in the sex trades and, thus, what they thought students should know. Before revising the questions I received vague responses that indicated that I (as the researcher) knew what participants were talking about, without them having to explicitly say the words they assumed were implied through their statements.

At this time, I am aware of no other study that has used content analysis and interviews with social work faculty to focus on what social work faculty teach their students about the sex trades. Therefore, this project has significant implications for social work educators and social work programs about the necessity of an anti-carceral, feminist, intersectional, and, consequently, anti-oppressive approach to teaching about the sex trades.

\section{Research Question}

This research project was guided by an anti-carceral feminist conceptual framework and used to contextualize the course content and the social work faculty experiences teaching about the sex trades. The question that grounded the project asked, "what are social work faculty teaching students about the sex trades in social work coursework?" Furthermore, to help interpret data, I asked myself three analytic questions: 1) How does course content represent the experiences of people who work in the sex trades? 2) Where do good intentions and carceral feminisms show up in course content focused on the sex trades in social work courses? and 3) What does the content selected 
from social work courses suggest about how social work students are socialized to understand the needs and experiences of people working in the sex trades?

\section{Sampling and Recruitment}

In the United States, there are 538 accredited Bachelor of Social Work programs and 261 accredited Master of Social Work programs (CSWE, 2017). These programs meet the CSWE standards for "competent preparation," demonstrating that their curriculum equips social work students with the tools and knowledge necessary to practice in the field (CSWE, 2017). At least twenty programs among the 799 offer courses that include sex trade content in some capacity, although none of these programs requires a sex trade related course.

Sampling. To collect social work course syllabi and other content related to sex trades, I drew on purposive sampling strategies (Patton, 2015) to recruit research participants to provide syllabi and participate in interviews. In total, I gathered a diverse sample of 20 syllabi and recruited twenty social work course instructors to participate in interviews. Of the twenty interview participants, eleven provided a syllabus, and I found the other nine syllabi through an internet search, using the terms, "social work and sex work syllabus, social work and sex trafficking syllabus, sex trade and social work syllabus."

Michael Patton (2015) suggests a range of strategies for purposive sampling. To recruit interview participants and collect social work course syllabi I drew on four primary strategies. First, I contacted some of my own former professors, acquaintances, and colleagues in social work programs across the country. Through this method I connected with eight interview participants; five provided a syllabus from a course they 
teach. Second, I used snowball sampling and was connected with four interview participants, one of whom provided a syllabus. Third, I identified social work scholars, researchers, and faculty who have published journal articles on the sex trades. To identify these contacts, I used the search terms: sex trade(s), sex trafficking, sex work, sex industry, adult entertainment, pornography, and prostitution to search social work journals, including Social Work, Journal of Social Work, Qualitative Social Work, Journal of Social Work Education, Journal of Interpersonal Violence, Violence Against Women, and Affilia. I then emailed each contact individually with a description of my research and invited them to participate in the project. I received three confirmations to participate in interviews and numerous rejections explaining that while they wrote an article but did not teach the content in their courses. Of the three interview participants, two provided a syllabus.

After two months of interviews I received access to the BSW Program Directors (BPD) listserv and sent an email describing the project and qualification criteria. From the email to the listserv, I completed my recruitment goal of 20 by connecting with five interview participants; four whom provided syllabi. Of the 20 interview participants, nine declined to share their syllabi due to issues related to academic freedom, no content specifically written into the syllabus, and feeling cautious about anonymity. To collect the last nine, I explored university websites to download social work course syllabi that were publicly accessible. With these purposive strategies and snowball sampling among study participants, I met both my goal and thematic saturation with 20 interview participants and 20 course syllabi. 
There are many political factors that shape the landscape of academic social work and that influence what sex-trades-related content shows up in social work courses. In some courses, regional influence, cultural politics, and geographic location had an impact on content related to sex trade, while in other examples the academic rank of the course instructor made a difference. To ensure sampling from all geographic regions, I included either an interview or a syllabus from 14 states and each of the following geographic regions: Northeast, Southeast, Southwest, Northwest, and Midwest. Additionally, I spoke with three interview participants who teach at private Christianaffiliated universities, twelve interview participants from large research-intensive universities, and five from teaching-focused universities (one private, four public, and one online). All interviewees held a PhD except one person, who was a PhD student. Table 1 organizes the research participants with the type of institution and the type of course taught. 


\section{Table 1}

\section{Description of the Data Sample}

\begin{tabular}{|c|c|c|c|}
\hline & $\begin{array}{c}\text { Type of Course } \\
\text { Taught } \\
\text { (Not specific name) } \\
\end{array}$ & $\begin{array}{c}\text { School/Department/Program } \\
\text { Demographics }\end{array}$ & $\begin{array}{c}\text { Geographic Region in the } \\
\text { United States }\end{array}$ \\
\hline \multicolumn{4}{|l|}{$\begin{array}{l}\text { Participant } \\
\text { ID }\end{array}$} \\
\hline SW1* & Sex Trafficking & Private Research University & Midwest \\
\hline SW2* & Human Trafficking & Public Research University & West \\
\hline SW3* & Human Trafficking & Public Research University & South \\
\hline SW4 & Human Trafficking & $\begin{array}{l}\text { Private Christian-Affiliated } \\
\text { University }\end{array}$ & South \\
\hline SW5* & $\begin{array}{l}\text { Sexuality \& Social } \\
\text { Work }\end{array}$ & Public Research University & West \\
\hline SW6* & $\begin{array}{l}\text { Sexuality \& Social } \\
\text { Work }\end{array}$ & Private Metropolitan & Mid-Atlantic \\
\hline SW7* & Human Trafficking & Public Research University & Southwest \\
\hline SW8 & Research Methods & Public Research University & South \\
\hline SW9* & $\begin{array}{l}\text { Sexuality and Social } \\
\text { Work }\end{array}$ & $\begin{array}{l}\text { Private Christian-Affiliated } \\
\text { University }\end{array}$ & West \\
\hline SW10 & Social Policy & Public Research University & Southwest \\
\hline SW11* & Travel Abroad Course & Public Research University & Midwest \\
\hline SW12* & $\begin{array}{l}\text { Human Trafficking- } \\
\text { online }\end{array}$ & Public University & Southwest \\
\hline SW13* & $\begin{array}{l}\text { Sexuality \& Social } \\
\text { Work }\end{array}$ & Public University & Mid-Atlantic \\
\hline SW14 & Human Trafficking & Public Research University & Southwest \\
\hline SW15 & Addictions \& Deviance & Public Institution & Mid-Atlantic \\
\hline SW16 & Policy & $\begin{array}{l}\text { Public Land-Grant Research } \\
\text { University }\end{array}$ & Midwest \\
\hline SW17* & Children at risk & $\begin{array}{l}\text { Private Christian-Affiliated } \\
\text { University }\end{array}$ & West \\
\hline SW18 & Advanced Practice & Public University & Mid-Atlantic \\
\hline SW19 & Research Methods & Public Urban Research University & Midwest \\
\hline SW20* & Direct Practice & Public Research University & Midwest \\
\hline
\end{tabular}

* participant participated in an interview and provided a syllabus.

Recruitment. In my participant recruitment emails, I briefly discussed my

background, vision, and lens for this project. I listed the purpose, risks, and benefits of participating in the study. I discussed confidentiality in my introductory email and with all interviewees either via email or in the beginning of our interview conversation. My introductory email explained the research project and asked recipients if in their schools 
of social work there were courses at any level focused specifically on the sex trades $o r$ that incorporate discussion, lectures, and other material related to the sex trades. Additionally, I explained that any program or individual instructor who met the criteria were invited to share their syllabi or other content related material and participate in an interview for the project.

Many interviews expanded beyond the scope of the interview guide. When that happened, I turned off the recorder and told participants that I had done so. I felt that the extra conversation built a sense of camaraderie and rapport. I ended almost every interview beaming, and excited about the passionate conversation on both ends, even if it seemed our research and theoretical orientation to teaching, practice, and research diverged. Everyone I spoke to centered good intentions and empathy in their teaching values, which I found inspiring. I waited several weeks before reviewing most transcripts to provide emotional distance and ensure a more critical analysis of the conversations. I frequently returned to my reflexive journal to remember what I was thinking and feeling after an interview.

Most study participants were immediately interested in the project and had no questions prior to our interview. However, at least three interview participants wanted to hear more about my vision for the study. One interview participant (SW17) told me that she had no questions about the project and that I was free to "use her however I need to" for my research. Before I even asked the first question SW17 told me that she included a number of feminist abolitionist writers and activists, like "Donna Hughes, Melissa Farley, Kevin Bale, and Gale Dines" (August 2017) in her courses. Although I was curious about her mention of these specific scholars and writers, I assumed she was keenly aware of 
their contentious work among diverging feminist viewpoints and I did not probe further. Marshall and Rossman (2012) remind researchers to use sensitivity when engaging with potential participants' questions about the study and their willingness or interest to participate and to remind individuals about their absolute right not to participate. I took this to heart and strived to remain both authentic and open in the interviews.

Interviews were semi-structured, lasted between 30 and 90 minutes, and were conducted on FaceTime, Skype, Google Hangout, or telephone.

\section{Data Analysis: Content Analysis of Data}

Qualitative content analysis is a systematic approach used to search for and describe meaning in many types of textual sources (Drisko \& Maschi, 2016). A benefit of using content analysis in a project rooted in an intersectional feminist epistemology is that when analyzing the data the research can attend to attitudes, emotions, and intentions related to inequality, power, and propaganda (Grbich, 2007). For this study, content analysis fit with my desire to explore how specific types of course content represented the needs and experiences of people in the sex trades. The use of intersectionality within AF logic requires research methods enable the exploration of inequity, power, and multivocality in discourse. A qualitative content analysis facilitates engagement in research that is both exploratory and descriptive. Content analysis is used to closely examine texts and language in order to categorize content that has similar meanings (Weber, 1990 as cited in Hsieh \& Shannon, 2005). Hsieh and Shannon (2005) have categorized the use of qualitative content analysis into three distinct approaches: conventional content analysis, directed content analysis, and summative analysis. 
I used a directed approach because my analytic lens is deeply informed by theory, and consequently I used existing codes drawn from the literature to analyze data (Hsieh \& Shannon, 2005). The codes were included in a data analysis template that I constructed and used to organize sex trade content found in course syllabi. Teresa Morris (2006) reminds researchers coming from a critical epistemology that they should assess data through three stages: emergent, ideological, and social action and offers suggestions for how to engage with the data through each phase. Ultimately, each phase symbolizes the active nature of analyzing data simultaneous to data collection, immersion in content, and questioning the meaning of findings.

Throughout each phase of analysis, I immersed myself in the data, took notes, consulted with colleagues, and engaged in reflexive journaling to enhance the robustness of my research. Below, I discuss the meaning-making process in relation to each data source and how analyses of syllabi and other content-related material informed the subsequent stages of the project.

Content analysis of syllabi. Congruent with feminist goals of reflexivity and rejecting value-neutral research, a directed approach to content analysis makes clear the researchers' bias and intention to expand upon already existing theory. Hsieh \& Shannon (2005) remark,

The main strength of a directed approach to content analysis is that existing theory can be supported and extended. In addition, as research in an area grows, a directed approach makes explicit the reality that researchers are unlikely to be working from the naive perspective that is often viewed as the hallmark of naturalistic designs. (p. 1283) 
This approach to content analysis has helped identify the content that social work classes use to teach about the sex trades in comparison to carceral and anti-carceral feminist logics.

Following the suggestions of Hsieh and Shannon (2005), to anticipate and identify any possible occurrence that could influence the coding process, I first reviewed each syllabus to get familiar with its content. I took notes of my general reactions and questions directly on the syllabus. Second, I read through each syllabus and marked where content fit into the deductive codes, that were based upon anti-carceral feminist logic. Third, I read the syllabus and filled out as much of the template as possible. In many cases I needed to research the content listed and determine whether it applied to any of the codes on the template.

Overall, the template served to condense information in the syllabus and initially categorize the content. The following is a description of the template and rationale for each section that was included (see Appendix A for illustration of template):

Title of class; description of class; course objectives. In each template I included condensed descriptions of title/description of class, key messages, learning objectives, examples of how content represented the role of social work, and content that included ideologies, values, and theoretical perspectives. This was included to understand the range of course names, content used to describe the class, and the stated course objectives in relation to the sex trades.

\section{How does the syllabus discuss social work interventions related to the sex}

trades? This section was included to identify the exemplars of social work practice highlighted in syllabi. I began this project with a concern about social workers reliance 
on rescue-based interventions to help people in the sex trades. Such interventions assume that all people working in the sex trade are victims.

\section{What content is used to address criminalization, law enforcement, carcerality,}

criminal justice system, if any? This section explored course content related to the intersections of the criminal justice system and sex trades to examine content that explicitly engaged with criminality. If content in the syllabus mentioned law enforcement, the judicial system, the criminal justice system, incarceration of third parties, arrest alternatives, criminalization of prostitution, or other signifiers of criminality or criminal processes, I included such content in this section.

U.S. based narratives or approaches related to the sex trades. The last section in my template included narratives/approaches rooted in governmentality, intersectional praxis, various feminist positions, carceral feminisms, rescue, sex worker rights based approaches, harm reduction, and a section for other narratives I had not considered. This section was primarily based on my own interpretation of their dependence on such narratives (sometimes it was explicit within content). By the time I got to this portion of the template, much of the information I'd gathered was repetitive and redundant.To determine what kind of content rooted in feminist principles was used to address the sex trades, I examined course syllabi for examples of feminist principles such as reflexivity, attention to social change, power, praxis, intersectionality, disrupting the gender binary, and other foci that may be identified as feminist by faculty.

After I completed the template, I separated each section of the template and recorded all responses from each of the twenty templates section by section. For each 
section/question on the template I made a document in which I recorded the info I drew from the syllabus under each code. These were labeled as follows.

- Title \& description of class

- Key messages and/or learning objectives of the course

- Role of social work in relation to sex trades

- Ideologies, values, theoretical perspectives that shape content

- Content for criminalization \& criminal justice system

- Needs and experiences of people in the sex trades

- Types of feminisms addressed in the syllabus

- U.S. based narratives related to the sex trades

After compiling the data in each section, I went through — line by line - - to identify common content, repetitive phrases, repetitive words, and repetitive policies. For an in-depth audit trail of how the data were sorted, please see Appendix E. After I coded each syllabus with the template, I wrote all titles of content (articles, books, chapters, films, guest speakers, and class topics) on a notecard. I then organized the cards into clusters of similar content and created descriptive terms for each cluster, which became a code. Then, I started drawing illustrations of the codes and brainstorming possible connections between codes.

After numerous attempts to arrive at meaning from illustrations of "word maps" I started journaling about how I perceived the themes fit together, and developed a "story of the data." To do this I specifically asked myself how the data related to the principles of AF logic, specifically to explore how intersectionality was used as a framework to explore rescue and punitive interventions; how content demonstrated values that were 
alternatives to the criminal legal system, like transformative justice, harm reduction tools, and self-identified needs; and how engagement with criminalization as social, political, and cultural processes marks certain bodies as criminal and reinforces dominant norms about gender, sex, and sexuality.

Descriptions and analyses of content were driven by responses to the following questions: 1) How are the experiences of people in the sex trades represented through social work course content? 2) Where do good intentions and carceral feminisms show up in course content focused on the sex trades? and, 3) What does the content selected from social work courses suggest about how students are socialized to understand the needs and experiences of people working in the sex trades?

Analysis of interviews. I conducted a thematic analysis of interviews after the completion of syllabi analysis, by partially following Braun and Clarke's (2006) six phases of thematic analysis. Braun and Clarke's process was particularly useful in this project because it attends to the need for flexibility around inductive and deductive approaches to analysis in qualitative methodologies. Such flexibility was required as I drew on specific data items to add context around the edges of the in-depth syllabi analysis. Braun and Clarke (2006) acknowledge that the researcher is searching for potential responses to the interview question within the data set, and that sometimes those responses are based on a specific theoretical framework guiding the research approach and sometimes the interview participants responses are useful for developing a theory. Braun and Clarke's process of thematic analysis is an adaptable "recipe" for conducting thematic analyses of different types of data, a process that they indicate frequently goes unspecified (2006). 
Following the first phase of their recipe, "Familiarizing yourself with your data," I transcribed 17 of the 20 interviews myself. After transcription I read through each transcript at least two times and took notes of my questions, reactions, and ideas for further consideration. The second phase, "Generating initial codes" suggests that researchers begin coding "interesting features of the data in a systematic fashion across the entire data set" (p. 87). Since the interview analysis included components of both deductive and inductive analytic approaches, the initial codes applied were terms derived from interview questions. For example, I attached codes to specific sections of transcripts that demonstrated, "decision-making process," "student take-away lessons," "favorite teaching methods," "discussions of social justice," "impact of soc-poli-relig-geo climate," "most pressing needs of people in the sex trades," "what students need to know," and "roles social workers serve."

After the deductive coding process noted above, I developed a table with a column for each code and a row for each interview. I went through the transcripts and collated data under each code. Upon completing the table, I began the third phase of Braun and Clarke's analysis process, "Searching for themes." I went through the data under each code to identify potential groups of codes that would contribute to the construction of a theme. It was during this third phase of identifying themes that I started to recognize how the interview themes aligned with the findings of syllabi content that had been earlier identified. For example the themes I'd initially identified as "Role of Structural Oppression," "In your Own Backyard," and "It's Complicated" each captured coded transcript data that fit into the syllabi finding of, "Instructors Socialize Students to Grasp the Experiences of People in the Sex Trades." At this point that I was able to 
recognize where themes from interviews resonated with content findings in course syllabi, and then revisited transcripts to find quotes that would add emphasis and context to findings from the syllabi analyses. In total, I used fifteen quotes from the interviews to support the content analyses of the syllabi, but was able to make additional references to statements made by interview participants throughout the findings chapter.

Ultimately, the interviews with social work faculty provided further insight about how the content used in courses highlighed the needs of people in the sex trades, as well as the role of social workers with people in the sex trades. Additionally, faculty shared how they facilitated critical thinking activities based on course content found in the syllabus. Since individual interviews were semi-structured there was room for unstructured questions to surface during course of the interview (see appendices C and D for interview guide). Finally, interviews illuminated how specific content was employed by some of the instructors of these syllabi, how some social work faculty made sense of the experiences of those working in the sex trades, and what they wanted students to understand about the sex trades.

\section{Demonstrating Rigor/Quality in Content Analysis}

The significance in establishing trustworthiness is to detail the researcher's process of data collection and arrival at conclusions, so that the process is transparent and understandable. Qualitative researchers have responded to quantitative notions of proving validity by offering alternative strategies that demonstrate research processes as trustworthy, dependable, confirmable, and transferable (Lincoln \& Guba, 1981). Strategies suggested for qualitative researchers to demonstrate trustworthiness and enhance credibility and dependability, include immersion in data, member checking, peer 
debriefing, and reflexive memo-ing (Grbich, 2007; Lincoln \& Guba, 1981; Marshall \& Rossman).

Credibility. Credibility is developed throughout the beginning, middle, and end of the research process. First, it is useful to focus the intent of the research question by conveying the target audience and the characteristics to determine the sample population (Drisko \& Maschi, 2016; Graneheim, 2005). Credibility can be demonstrated by the confident portrayal of how data collection and analysis match the focus of the research question. To enhance credibility in a content analysis, it is necessary to specify how the question arose, decision-making regarding the context of data, approach to gathering data, and how eligibility of study participants were determined. Credibility is assessed upon how well the themes and categories derived from data cover the range of data. Therefore, researchers may provide multiple examples of raw data and the process of making coding decisions (Graneheim \& Lundman, 2003; Polit \& Hungler, 1999). Importantly, given that every data analyst has a different perspective and standpoint when approaching the data, there will never be just one answer or one explanation that describes what was found in the data analysis process (Denzin \& Lincoln, 2003; Drisko \& Maschi, 2016). Relatedly, credibility is enhanced by acknowledging that data change over time given changes in one's perspective or experiences; therefore discussions of findings should be contextualized in time, location, and culture and provide examples that demonstrate changes over time. When discussing the results of content analysis it is necessary to make sure that the conclusions and data are closely connected (Denzin \& Lincoln, 1994 as cited in Denzin \& Lincoln, 2003). 
Ultimately, the data analysis template guided the organization of content from syllabi. Following the suggestions of qualitative researchers to demonstrate credibility in content analysis (Denzin \& Lincoln, 2003; Drisko \& Maschi, 2017), I have included examples of raw data that show content divided by codes in Appendix E. Additionally, within the findings chapter I've included tables that organize all content into themes and sub-themes.

Dependability. Lincoln and Guba recognize dependability in qualitative research as, "the degree to which data changes over time and the alterations made in the researchers decisions during the analysis process $(1985$, p. 299).” To demonstrate dependability in this study, I used the qualitative tools of peer debriefing and reflexive memo-ing at multiple points post interview and through my final analyses.

Peer debriefing. Marshall and Rossman (2011) discuss peer debriefing as sharing findings and data with friends or colleagues who are familiar with similar qualitative research tools. The colleague reviews some of the data and arrives at their own analysis. Then researcher and peer are able to see if their interpretations of data align with one another. After close readings of transcripts, I spoke with two colleagues about what I interpreted to be appearing in the data. Both of them asked me first, "What do you make of that?" and "Are you sure that is all that is there?" These questions pushed me to continue re-thinking the meaning I assigned to the presence of specific content and to look at the meaning of certain content not being included in the syllabi sample.

Additionally, mid-way through interviews and syllabi collection, I contacted a colleague who is deeply engrained in domestic violence, sexual assault, and trafficking research for feedback around some commonalities that were beginning to arise in the data. She was 
able to provide political insight on local, state, and federal levels related to research funding for sex trafficking related projects around the country. The insight she provided was helpful in terms of understanding what content was being used repeatedly and as related to funding priorities on state and federal levels.

After I completed all of the interviews and transcribed each one, I debriefed with two colleagues, about the range of topics and themes that came up with each research participant. I was able to share how my own experience as a sex worker triggered certain responses during conversations, as well as how my own approach to social work practice made me critique some participant's perspectives. It was helpful to trade ideas back and forth based on how conversations related to various feminist theoretical perspectives showed up in conversations and to consider the implications towards how social work students were to be socialized around the sex trades. Finally, after drafting the findings section and mid-way through developing my analysis of findings, I spoke with a colleague about the implications prioritizing specific interventions over others when practicing social work with people in the sex trades. This conversation was helpful in terms of flushing out ideas about how this finding relates to anti-carceral feminism.

Reflexive memos. Congruent with feminist epistemologies and the partiality of a standpoint, reflexive memo-ing has been shown to be an important link between analysis and interpretation (Bailey, 2007). The process of analyzing findings involves taking reflective notes about the process of making conclusions, asking questions of the data, keeping track of thoughts, feelings, ideas, and phenomena. Bogdan and Biklan (1992), describe reflexive memo-ing as, 
Embedded in the process of establishing a convincing case for the trustworthiness of qualitative research is the expectation that researchers be reflective about the analytical process and capture the evolution of thinking as it unfolds through memoing and field notes. Memos require reflexivity about the evolution of the design and analysis, as well as about relationships to participants and the setting (as cited in Creamer, 2005, p. $88)$.

Reflexive memo-ing is a critical strategy for establishing trustworthiness and for transparency in the formation of analyses. The reflexive memo journal I kept through the research process has been essential to making meaning of syllabi content, interview conversations, and my interpretations.

In qualitative analysis, a researcher must immerse oneself in the data. One way that I did this was by reading and re-reading syllabi, data analysis templates, and interview transcripts. As I initially reviewed the content in each syllabus and sorted data into the template, I began taking notes of my immediate reactions, thoughts, and questions, although I was cautious not to jump to premature conclusions. I added on to my notes after each pass through the data. Immediately following each interview, prior to transcription, I recorded notes about my thoughts, ideas, and reactions to the interview. These initial notes have been instrumental in analyzing the content included in course syllabi, as well as what was not included. I transcribed all but five of the interviews myself, and as I did this, I found myself having a set of different reactions than I had directly following the interview. I did not begin transcription under after I finished conducting all of the interviews. The space between interview and transcription allowed 
me to have a new reaction from immediately following the interview, which I found meaningful. Upon reviewing my journal entries post interview, I found myself writing similar comments and over and over again, as I was relieved to have finished one interview, learn about different ways of teaching content, and witness the passion each participant brought to teaching.

Notably, every researcher arrives at knowledge through different methodological decisions. By revealing the strategies that help us to identify implications for the field or lessons learned from analyses, we strengthen our conclusions.

Positionality as researcher. A feminist objectivity (Haraway, 1988) provides transparency of the perspective, social location, theoretical approach, and experience a researcher brings to the process, rather than leaving this out and symbolically removing oneself from the research process. In a sense, this implies that "researcher bias" is actually crucial to the generation of new knowledge and establishing trustworthiness of the project. Reflexivity openly positions internalized bias or oppression based on the status of social categories. A critical feminist praxis employs reflexivity in order to attend to power differences in relationships regarding research and practice. Gringeri, Wahab, and Anderson-Nathe (2010) state that, "reflexivity is a cornerstone of good quality feminist research" and reflect on its centrality to rigorous and good quality social work in all of its forms (p. 402). Critical reflexivity pushes social workers to consider their own social locations of power and privilege in order to critically investigate the origins of their service provision and goals (Daley, 2010).

As I dive deeper into my own reflexive process, I have to acknowledge that this research is deeply personal. One reason is that I am a former sex worker and worked in 
the sex trade for about ten years. While I often feared encountering law enforcement, I was never targeted for arrest or incarcerated. As a White, middle-class, college educated, student, queer, able-bodied, U.S citizen, and feminine-identified person, I've had quite a bit of autonomy, independence and privilege while working in the industry. As an academic, I've been privileged to access critical, feminist, and anti-oppressive driven theoretical scholarship guiding me in making meaning of my personal experience and how that informs my engagement in the research process

As a social service provider at a needle-exchange program serving sex workers, I learned about the praxis of intersectionality. In this environment, I engaged with cisgender and transgender women who injected heroin, crack, and hormones, and traded sex for money. My clients were white, Black, and Latina, and mostly lived on the street and in other temporary spaces. From 10pm-2am, three nights a week, I conducted outreach on a strip of the avenue well known for visible sex and drug trade. On outreach shifts we asked everyone that we encountered if they needed condoms, needles, or a bad date sheet. While not everyone we saw worked in the sex industry, through conversation we built connections with sex workers, the surrounding community, and revealed to everyone who we were and what we were doing there. We became recognized as the "condom ladies," a designation that marked our outsider status in the neighborhood.

Although our outreach crew was a majority of people who had experience in the sex trade, we were "different" as told to us by one of our program participants. Our difference was marked by our whiteness, modes of transportation (bike or car), our physical stability and alertness. Such markers are important for social workers to consider when working with sex workers. The community we targeted for outreach could be 
described as working out of "circumstance" (Sex Workers Project, n.d) or survival. I learned about the range of experiences in the sex trades and that people working in the sex industry often have precarious circumstances. The privilege of gaining such knowledge as a social worker immersed in this specific community made me keenly aware of the many barriers that people in the sex trades experience when they are trying to access health care, employment opportunities, welfare, education, housing, and legal services.

The participants I worked with were often stigmatized as deviants, drugs users, "junkies," "whores," "hookers," and shamed, violated, or criminalized. Therefore it was important to covertly distribute supplies. If our participants were found with an excess of condoms on them, needles without their syringe exchange card, or drugs, this could be cause for a fine, warrant, or incarceration. Similarly, if our visibility as "condom ladies" stuck out to our participants, we were likely recognizable to law enforcement as well.

The outreach team I worked with tried very hard to stay out of view of law enforcement, particularly because we wanted to help our program participants to have access to supplies mentioned above. However, as I analyzed data from syllabi and sometimes interview transcripts, I found many social workers embracing collaboration with law enforcement, which invoked one of two reactions at different times. I felt mad, sometimes at the individual instructor using the syllabus and other times at the state of social work education. The other reaction was a feeling of being disoriented, as I'd be inundated with content drawing on advice from social service providers to advocate for police training to identify victims in the sex trade and to protect victims from scary men. In this disorientation, I found myself wondering if maybe they were more helpful to 
marginalized people in the sex trades and did have some clandestine methods for identifying the "true" victims. Peer debriefing with colleagues quickly helped bring me back to reality, so that instead of staying in my reactions I could start to explain why I had fallen into those emotions and how other social workers might be easily socialized into potentially harmful interventions under the auspices of help. Further, as I reflected on my outreach experience with sex workers I recalled that the experiences of people I met nightly were real.

For the vast majority of time I worked with the needle-exchange program, I was enrolled in a Master of Social Work program. I imagined that my education would enhance my work with drug users and people in the sex trades. While I did learn many important lessons related to the sex trades, they were often learned through discriminatory comments and my own analysis of how to respond. Mostly though, indepth conversations about the sex trades were left out of course content all together. For example, the influence of race, class, gender identity, sexual orientation, ethnicity, and ability on the working experiences of people in the sex industry went completely unaddressed and instead people in the sex trades were portrayed as either victims or criminals and neglectful parents. Unfortunately, our conversations in class frequently ended in generalizations about sex workers, leaving out vital information related police violence, vulnerability to incarceration, and social work specific approaches to the sex trades.

The experiences in my own social work education led me to this research project, and a desire to understand the depth to how issues related to the sex trade are engaged across the country in social work education. In my MSW program, we weren't privy to 
critiques of social work interventions such as prostitution diversion programs or anti-sex trafficking initiatives. Not because issues related to the sex trade didn't exist around us, instead I believe it was because it was assumed all people in the sex trades were victims. Without a critical engagement of the cultural contexts surrounding the sex trades and drug use, many of the social work students in my program were left unequipped to advocate and pursue social justice in the personal and political institutions related to the sex trades.

\section{Ethical Issues in Feminist Research}

Feminist research approaches should value every participant's experience and relation to oppression. All of the individual identities of research participants have been kept confidential and assigned a unique identifier. I've used quotes from interview participants, but have not linked them by name or institution. Further, when referencing content from a specific syllabus, there is not enough information to identify the research participant affiliated with the syllabus. Additionally, one of my methods for analysis was to compile all the content from syllabi on to notecards so that the content was detached from the syllabus it was associated with and then I divided the content into codes and eventually themes. Each interview participant consented to participate in an interview and to be recorded while doing so.

In considering ethical issues beyond informed consent, storage of data, and confidentiality, a feminist research approach means that that researchers must be aware of the politics of location. A feminist research ethic situates the need to be transparent about power dynamics, voice, representation and social justice implications (Roof, 2012; Sprague, 2005). 
Representation and voice. While I did not specifically sample for people who worked in the sex trade, it is possible that some of the study participants do have experience working in the sex trades. In addition, I believe that findings and analyses I've come away with represent perspectives shared by some of the faculty who teach about the sex trades, while other analyses of the data, specifically of content that has been implicated to harm people in the sex trades through criminalization, may not accurately represent how some of the research participants view their engagement with sex trades content. It is possible that even if research participants acknowledge that oppressed communities are being harmed through social work interventions that collaborate with law enforcement to rescue people in the sex trades, they also think in the long run they will be helped.

The analysis of findings are linked to the theoretical framework of anti-carceral feminist logic. It feels as though the findings in this project, although based on a small sample, have important implications for how social work can engage with sex trades in ways that don't depend on incarceration of disenfranchised communities. As noted throughout this proposal, AF logic centers principles that explore and interrogate systems of power. Therefore, while I have used quotes from interview participants to help contextualize content I recognize that it is my interpretation of all data that structures the findings and analysis. Furthermore, because the quotes are meant to contextualize larger discourses around sex trades, I chose not to use pseudonyms for individual participants.

A critical lens helps to make meaning of how power shapes the perspectives present in the data. My own perspective related to the sex trades, given my experience both working in the industry and doing social work with people in the sex trades, has 
ultimately influenced how I represent the experiences of my research participants. Additionally, during interviews I learned that some people did not develop the syllabus they used in their class, but due to departmental or university politics used the syllabus anyway. In other words, sometimes course instructors had little control over what was on the syllabus they taught from and their voices and perspectives were not actually reflected in syllabi. Given the critical nature of this research study, it is impossible to accurately and truly reflect participant's voices and experiences, and thus, the "crisis of representation."

Negotiating power. I suspect that the individual benefits of participating in this research project were far greater for me than for the research participants. As my doctoral dissertation this project brought me closer to a doctoral degree in Social Work and Social Research. Upon its conclusion I aim to publish journal articles based on the project's methodology, findings, and implications for social work, to build my academic credentials and increase my academic credentials. Additionally, it is important to note that scholars feel passionate and compelled by the work they do, which means that these conversations have been emotionally charged, particularly through a commitment to eradicate violence against people in the sex trades.

Another issue of concern is that I approached this project from a very specific theoretical grounding and investment in how social work educates about the sex trades. I come from this place due to a strong commitment to anti-oppressive values and dreaming of equity for all marginalized communities. In an effort to be transparent about my specific sex trade politics I wrote about the harm reduction and anti-carceral feminist lens I use in teaching and researching about the sex trades in my research recruitment letter. 
This felt important because I did not want to be misleading about my intentions with the research and I am aware that approaches and beliefs about the sex trades are frequently contentious.

With the observation that researchers often engage in studies linked to their own situations and lives, it is critical to reject myths of objectivity and socially situate oneself (Hulko, 2015; Sprague, 2005). Before beginning the project, I imagined it might be possible someone would ask me if I have experience in the sex trades. In my recruitment letter I disclosed that I have experience, however it did not seem to prevent participants from expressing values that strongly opposed mine. It turned out that no one inquired about my experience, although I do wonder if there were some moments that participants treaded more lightly in their responses had I not disclosed my former sex worker status.

Although my disclosing risked impacting social desirability in participant responses, I felt that in my assertion of this project as feminist, I must be transparent about my experiences and the lens I use to make meaning of the data.

Attention to social justice. Central to anti-carceral feminist logic is an understanding and exploration of the many processes of criminalization that shape the lives of marginalized sex workers, rescue interventions in collaboration with law enforcement that result in further violence upon sex workers, and intersectional perspectives on oppressions that impact people working in the sex trades regardless of their circumstances. While a content analysis is descriptive of what is there, the meaning made from the representation of sex trade content has direct implications for how social workers strive to pursue social justice in the lives of the people they work with and policies that they attempt to influence. 
There is not a singular strategy for navigating the territory of a feminist research project. In recognition of the many manifestations of power and privilege that shape the experiences of people in the sex trades, I have situated and outlined my research questions, methodology, and tools for learning about the role of social work education in these manifestations. This content analysis of social work course syllabi focused on the sex trades along with interviewing social work faculty. I have depended on feminist and qualitative methodological strategies to establish the trustworthiness of a research project absolutely situated in my own biases and values related to supporting the use of content that engages the logic of anti-carceral feminisms when educating current and future social workers about the sex trades. 


\section{Chapter IV: Findings \& Discussion}

In pursuit of understanding how carceral feminisms influence social work education related to the sex trades, I asked the broad research question, "What are social work instructors teaching about the sex trades in social work coursework?" To answer this question, I collected twenty "sex-trade-related" social work course syllabi as defined by guidelines written into my recruitment letter. Additionally, I interviewed twenty social work faculty teaching sex-trades-related content to learn more about what they intend to teach students.

In the participant recruitment letter that I distributed, I stated that interested social work faculty qualified for the study if they taught a course "specifically on" or "inclusive of" content related to the terms: "commercial sex work, prostitution, sex trafficking, sex trades, sex industry, adult entertainment, sex/sexual or underground economies, sexual exploitation, and pornography or porn industry.” From this request, eleven faculty members sent me their syllabi, and I found the other nine - to reach my sample goal of twenty - syllabi through a Google search using the search terms: "social work and sex work syllabus, social work and sex trafficking syllabus, sex trade and social work syllabus."

Out of the sample of twenty syllabi, ten of them used "trafficking" in the course title to represent a course focused on sex trafficking, labor trafficking, international or domestic trafficking, or some combination of each.Another six of the twenty syllabi that included sex trades content came from social work courses focused on social welfare policy, generalist social work practice, human migration, international perspectives on women and children, human development, and criminology of addictions. Finally, the 
last four syllabi of the sample came from social work courses focused on human sexuality and social work practice.

This chapter is divided into three sections, each based on a question I've asked of the data to guide my analysis. These questions are 1) How do course content and faculty perspective represent the experiences of people in the sex trades? 2) Where do good intentions and carceral feminisms show up in course content focused on the sex trades in social work courses? And, 3) What does the content selected from social work courses suggest about how social work students are socialized to understand the needs and experiences of people working in the sex trades? I begin each section with a discussion of the guiding question for analysis, and then follow with a discussion of themes and the findings that constitute each theme.

\section{Background of Data}

This project asked the research question, what are social work instructors teaching students about the sex trades? In posing this question, I aimed to better understand what was being taught to social work students about the constellation of sex trades experiences. There was a very minor representation of content that specifically used the language of "sex trade" or "sex work" to acknowledge some people choose to engage in

sex trade. When sex trades content extended beyond the "all sex workers are victims" narrative, it was represented among topics of sex and sexuality, neoliberalism, intersectionality as a theory and practice for understanding sex trade, culturally specific approaches to working with sex workers, and the ethical implications of social work interventions rooted in rescuing people from the sex trade. 
Through interviews with social work faculty teaching content or courses on the sex trades, I learned that there are some common strategies and techniques employed by instructors to teach sex-trades-related content. For instance, participants used media to invoke empathy, critique the application of various theoretical frameworks, or apply critical thinking skills, and case vignettes were used to help students think through the needs of a hypothetical client. Additionally, guest speakers - such as law enforcement, NGO workers, non-profit staff, and both anti-trafficking and sex work activists - spoke in classrooms to engage students in discussion. In some courses, instructors had students examine policies and protocols related to human trafficking, to discuss current events, and debate one another on sex trade and regulation. Some faculty included syllabus content on program evaluation for students to analyze the effectiveness of specific programs aimed at helping survivors of sex trafficking. Furthermore, one course drew on a learning abroad opportunity to learn first-hand from survivors of trafficking about their needs, experiences, and culture. Finally, instructors also used "values clarification" exercises to help students identify their own values related to the sex trades and how those opinions were formed. Not only did the values clarification illuminate student's values related to sex trades, the exercises were also intended to help students "bring it home"--a theme further explored throughout this chapter.

Although I hoped to review a syllabus from a course specifically on "sex work," none surfaced in the sample. Instead, multiple courses included one or two articles on "sex work," which were primarily used for discussion on legalization; deconflating sex work, commercial sexual exploitation of children, and sex trafficking from one another; and in social work and sexuality courses. My choice in framing the research through the 
broad term "sex trade" was intentional; sex trade represents a range of experiences related to exchanging sex for something that is needed. By looking at the scope of "sex trades" content, I've identified the types of content abundant in educating social work students about the sex trades and, perhaps more importantly, the gaps in critical information.

The course descriptions for the data sample have set parameters for how students are expected to approach information about the sex trades. For instance, 8 of the 10 human trafficking course descriptions clearly state that human trafficking is modern day slavery and one of the greatest human rights challenges of all time. Additionally, course descriptions for human trafficking syllabi state that women and children are particularly vulnerable to trafficking. One course description connected the micro, mezzo, and macro dimensions of sex trade and described the purpose of the class as to explore "Trafficking in Persons (TIP), in the context of social justice, human rights, and feminist perspectives." Another syllabus for a class specifically on "Sex Trafficking" provides a course description of the complex circumstances produced by structural oppression that facilitate sex trafficking,

Sex trafficking is a complex social problem with factors rooted in intersecting inequalities related to sex, sexual orientation, gender, identity, gender embodiment, power, class, opportunity, education, culture, politics, and race, ethnicity, and sexual objectification related to sexual exploitation and sex trafficking. (SW1, 2017)

Reflecting the ideas circulated throughout the twenty syllabi, both course descriptions and course objectives are represented throughout the content discussed in this chapter. 
Course objectives in Human Trafficking syllabi specify the need to teach social workers how to collaborate among social, medical, and legal systems, as well as the need for students to learn about treatment modalities for working with survivors of sexual and psychological trauma. Further, course objectives frame the experiences of people in the sex industry as victimized, as they name people in the sex trades as "survivors of sex trafficking" when discussing who students will be working with. Other course objectives indicate the importance of students gaining knowledge of federal policies on human trafficking to enhance their work collaborating across systems.

The themes represented in the data (syllabi and interviews) describe what twenty social work classes teach about the sex trades, including some background context on why and how faculty teach the content found in their syllabus. The findings are not meant to represent social work curricula as a whole but rather a snapshot based on twenty social work course syllabi that include sex trade content at this moment in time.

\section{Experiences of People in the Sex Trades Represented in Courses}

The themes discussed in this section reveal an emphasis on victimization as representative of the experiences of people in the sex trades. The victimization of people working in the sex trades is evident in three primary ways. First, cisgender women and girls in the sex trades are portrayed as victims. Second, women and girls of the Global South are represented as especially vulnerable to sexual exploitation. Third, the demand factors for the sex trade are characterized as violations of human rights via third parties.

Content outside the "sex trade equates victimization and necessitates rescue" model was confined to just a few syllabi. Non-victim-based content on sex trades focused on decriminalization of prostitution and represented sex work as a stigmatized but 
potentially empowering profession that some people choose. Non-victim based content emphasized that sex work is often a blend of choice, circumstance, and coercion.

Cisgender women and girls as victims of "bad" cisgender men. The idea that cisgender women and girls in the sex trades are vulnerable to being victimized or persuaded into the sex industry by abusive cisgender men was a prevalent theme found in social work courses and as such answers my project's foundational research question, "what are social work instructors teaching about the sex trades in social work coursework?" This theme teaches social work students that women and children are primarily vulnerable to sexual exploitation due to the intersections of sex, gender, race, nation, geography, and poverty. At the same time, this theme accentuates the innocence of women and girls by emphasizing the need to rescue them from sexual exploitation. However, rescue-based narratives often fail to address the insidious role of systemic oppression as it relates to sexual exploitation. Furthermore, there was an abundant focus on women and children from the Global South (Kempadoo, 2001; Mohanty, 2001; Vance, 2012).

Moreover, within content that situated women and girls as vulnerable to sex trafficking, there was very little indication that women and girls who participate in the sex trades consider their circumstances anything other than coercive or victimization. For instance, content that centers the work of Rachel Lloyd, a self-identified sex trafficking survivor and activist, appeared in 6 out of 10 syllabi focused on human trafficking and indicates a popular medium for educating students about the sex trades. Lloyd founded GEMS, an organization in New York City that supports young women in getting out of the sex trade. A documentary included in course content, Very Young Girls (2014) 
documents the work of GEMS, which primarily focuses on the lives of African American teens with troubled home lives who fell in love with men who eventually became their "pimps." These teens were lured into a relationship, forced to have sex for money, and struggled to "leave the life." The documentary narrates the teens' experiences as they find their way to GEMS and go back and forth from GEMS housing to be with their pimps. In the film, Lloyd says that she started the organization to help other women "get out of the life." As an example of her determination to help others get out of the life, the documentary shows her traveling to Florida from New York to answer the call of a former GEMS client to come get her. While Lloyd debates the benefits and consequences of flying to Florida to rescue the teen, viewers eventually see her sitting with the teen by a motel pool and expressing hope that the teen will return to GEMS housing in New York City. The young woman declined to return to New York City with Lloyd, and Lloyd articulates her lament, wishing the best for the woman. The film demonstrates the ways in which "entering" and "exiting" sex work are not as simple as rescue-based narratives often imagine and instead shows how economic survival, belonging and feeling desired, and power and control, render "entering" and "exiting" as revolving rather than linear processes.

Study participant SW3 emphasized the importance of Lloyd's work, given that Lloyd is a "survivor" herself. SW3 stated that her own personal bias values survivor leadership and therefore assigned her students Lloyd's (2011) memoir, Girls Like Us: Fighting for a World Where Girls Are Not for Sale, an Activist Finds Her Calling and Heals Herself. About her decision to use the content, SW3 said, 
I had her read-I don't know if you have heard of Rachel Lloyd - her memoir, Girls Like Us, because I think she does a good job telling her story and she has worked towards serving others and opened an agency to help others. She's really pioneered that term "survivor leadership"... and been a huge advocate in listening to survivors. (Interview, SW3, June 2017)

SW3's comments, and the omnipresence of Lloyd in social work syllibi, highlight a distinct emphasis upon innocent women and girls in need of rescue from the always negative and abusive experience of the sex trade (which is why the term "survivor" is frequently used in relation to the sex trade). For SW3, Lloyd's positionality as a former sex worker lends credibility to this particular perspective.

The values of social work as a profession endorse content that centers the vulnerability of women and girls in the sex trades and therefore it is not surprising that Lloyd's work and others like it are popular within social work curricula. Although the core of social work's mission is to advocate for and address the needs of the vulnerable (NASW, 2017) the authority of social workers to define "vulnerable populations" is troubling. If people in the sex trades are continually portrayed as "vulnerable," then sex workers are primarily, if not exclusively, viewed through a deficit lens --which leads to problematic consequences for those involved in the sex trades. How "vulnerability" is defined informs the theory and practice of who and how we choose to help. In their article found in a syllabus on sex trafficking, Hoyle, Bosworth, and Dempsey (2011) critique a compulsive focus on vulnerability and suggest that if someone in the sex trades does not match up with an ascribed image of a "victim" (very young, innocent-looking, 
weak, light-skinned white woman or woman of color), they may be viewed as a criminal instead and labeled as purposefully engaged in illicit work. For example, my discussions with SW4 reflect some of the conflicted ways in which social work instructors define vulnerability and agency in relationship to sex work. In the following, SW4 drew on ideas of vulnerability, choice, and force to complicate how women get into the sex industry. SW4 wrestled with her own ideas as she stated,

I think there are a lot of misconceptions, like women are getting into it [sex industry] because they like sex or because it's a choice and I think that I try to dispel some of those myths, and there are some, but the majority of people I've talked to did not get into it out of choice. Well, I shouldn't say that...some have gotten into it and perhaps made a conscious choice, but their choices were very limited to begin with. You know some would say it's a choice, but if I have to figure out how to feed my family and have the background for certain jobs...that presents itself as a forced situation and as their only option. I think that's different than being led into a life of sex trafficking. (Interview, SW4, July 2017)

SW4 continued to state that she specifically shares content with students to make them think through the multiple micro, macro, and mezzo factors that make women who have experienced trauma in their lives vulnerable to trading sex for money.

Another book included in three of the human trafficking syllabi that contributes to the pattern of vulnerability and victim narratives routinely offered to social work students was Holly Austin Smith's Walking Prey: How America's Youth are Vulnerable to Sex Slavery (2014). The book was written with law enforcement and health professionals in 
mind who may be working with minors in the sex trades who do not identify as victims or those Smith refers to as "willing victims" (Smith, 2014). Smith shares some of her own experience as a survivor of child sex trafficking and aims to provide realistic and practical advice for parents, friends, and community members to come together and stop the Commercial Sexual Exploitation of Children (CSEC) (Smith, 2014).

Additionally, two organizational website-based resources, both found in three course syllabi, were from Polaris Project (www.polarisproject.org) and Shared Hope International (www.sharedhope.org). One document is a report from Polaris Project titled, "Sex Trafficking in the United States: A closer look at U.S. citizen victims." The report discusses factors that lure women and girls into the sex trade and the barriers that prevent them from leaving. The findings and statistics in this report are based on 292 reports that were made to the agency-specific hotline. From those Polaris clients who shared what made them vulnerable to trafficking, the top ten risk factors for being sex trafficked were:

Child Abuse, Neglect, Homelessness, Runaway, Sexual Abuse/Assault, Domestic Violence, Poverty, Youth involved with the Child Welfare and/or Juvenile Justice System, Mental Health Concerns, or Other Types of Trauma. (Polaris, 2015, p. 5)

Self-identified survivors named violence on both an individual and systemic level as factors that made them "at risk" for entering the sex trade. The report continues to discuss methods of recruitment by pimps and traffickers that include marriage proposals and promises of a bright future. 
Additionally, one syllabus included the documentary DEMAND (Shared Hope International, 2013). The documentary is based on investigations into the commercial sex trade in four countries conducted in 2005-2006. The intention of the film was to document the connections between sex trafficking, pornography, legalized prostitution, other demand factors that make women and girls vulnerable to sex trafficking (SHI, 2013). As billboards that say, "Girls, Girls, Girls" and "Full Nude" appear on the screen, the narrator of the film states that women and girls have become commodities and "are branded as prostitutes and whores." She describes the sex market as dependent on supply and demand; as demand continues to increase, the supply must also continue to increase. Since women and girls are the "supply" they become vulnerable to trafficking to help keep up the supply (2013). This documentary joins ample content in course syllabi to highlight the specific vulnerability of cisgender women and girls to become victims of the sex trade.

Content that represents the experiences of cis women and girls as solely rooted in victimization socially constructs the image of "victim" and ultimately the people believed to be worthy of help. Although book chapters and journal articles by self-identified survivors are included in the syllabi, survivor narrators that conform to themes of vulnerability and victimization are oversampled. Their experiences do not speak for all people in the sex trades, and if taught without other types of experiential narratives, students may assume that victimization is universal or compulsory within sex work. Hoyle, Bosworth, and Dempsey (2011) state the importance of understanding that labels like "victim" are most frequently determined by "the perceptions of those who come in contact with them and have the power to affix or reject such a label” (p. 315) as opposed 
to those who have received the victim label. Moreover, when encountering those that do not see themselves as victims, social workers might face additional confusion that impacts their ability to perform their helping role.

Table 2 shows a complete list of content used to construct the theme of this section.

\section{Table 2}

\section{"Cisgender women and girls as victims of "bad cisgender men"}

\begin{tabular}{|l|l|l|}
\hline \multicolumn{1}{|c|}{ Title of Content } & \multicolumn{1}{|c|}{ Author } & \multicolumn{1}{c|}{ Type } \\
\hline $\begin{array}{l}\text { Hidden in plain sight: Clinical } \\
\text { Observations on prostitution }\end{array}$ & $\begin{array}{l}\text { Judith Herman in Melissa Farley } \\
\text { (Prostitution, Trafficking, \& } \\
\text { Traumatic Stress) }\end{array}$ & Book \\
\hline $\begin{array}{l}\text { Girls Like Us: Fighting for a World } \\
\text { Where Girls Are Not for Sale, an } \\
\text { Activist Finds Her Calling and } \\
\text { Heals Herself }\end{array}$ & Rachel Lloyd (2011) & Book \\
\hline $\begin{array}{l}\text { The Making of a Girl } \\
\text { Sex trafficking in the U.S.: A closer } \\
\text { at U.S. citizen victims }\end{array}$ & www.polaris.com & Website \\
\hline $\begin{array}{l}\text { DEMAND } \\
\text { wemsems-girls.org }\end{array}$ & Website \\
\hline $\begin{array}{l}\text { Walking Prey: How America's } \\
\text { Slavery are Vulnerable to Sex }\end{array}$ & Holly Austin Smith (2014) & Film \\
\hline $\begin{array}{l}\text { Domestic Minor Sex Trafficking } \\
\text { Domestic Minor Trafficking in Las } \\
\text { Vegas }\end{array}$ & Kennedy \& Pucci & Article \\
\hline $\begin{array}{l}\text { Juvenile Officer } \\
\text { Child Protection Dept. }\end{array}$ \\
\hline
\end{tabular}




\section{Women in Global South are particularly vulnerable to sex exploitation. In}

addition to vulnerability narratives, social work instructors are particularly attentive to the sexualization of young women and girls from the Global South, specifically from countries such as Thailand, Cambodia, Vietnam, India, and Nepal. The sexualization and simultaneous vulnerability of women from the Global South are overemphasized in content. A plethora of trafficking literature focused on the Global South is evident in these courses. While some of these materials were included in classes that specifically addressed international social work, most content was in classes that otherwise primarily focused on the United States. It is possible that these courses aim to include material that is culturally relevant to the communities in which students are located, but the sole inclusion of women from the Global South is problematic in that it supports colonial and neocolonial stereotypes.

Such stereotypes show countries in the Global South as guilty of extreme human rights abuses, particularly toward women and girls in the sex trades. For example, law enforcement in India is described as violent, corrupt, and content with sexual exploitation, making them part of the demand and unable to provide help to victims. One research participant brought her students on a study abroad trip to learn about sex trafficking in India from "survivors themselves." SW15 spoke about the corrupt police in India and how an NGO, International Justice Mission, had to work with international law enforcement to rescue the vulnerable women and girls sold held captive in brothels.

A set of short films on the experiences of women and girls in India were included throughout course syllabi on human trafficking. For example, Stolen Innocence (2015), a documentary about human trafficking in India produced by education-based NGO Effect 
International, highlights the "worst of India's brothels" (Rao, 2017). This documentary showed up several times in syllabi. The narrator states that investigative filmmakers have gone undercover and "risked their lives to tell the stories of modern day slavery" as they travel to many cities throughout India. In Stolen Innocence the narrator remarks that 1 in 4 girls in India is trafficked everyday, 150,000 girls are sold into the sex trade annually, and that "even the locals deny it is happening." Further, the film contrasts images of children on a playground with images of people living in impoverished conditions, Indian men physically assaulting one another, and clips of conversations with survivors of trafficking. One survivor talks about being forcibly raped and wanting to die.

Also appearing in several syllabi, the short film Caged Until Broken (Thompson, 2014) further endorses the rampant problem of sex slavery of women and girls in the Global South. In this film, Hazel Thompson, a photojournalist, sought to document the egregious conditions of young girls being held in cages in the red-light district of Mumbai, India. Thompson narrates the film and tells viewers that up to 15 million people live in slavery in the neighborhood of Kamathipura, most of who are women and girls trafficked into the sex industry. Guided by a former "street-boy" who currently works for an aid organization that rescues victims of trafficking, Thompson enters the brothel to photo-document the "slave-like" cages that hold women and girls. Thompson then further explores the life of Guddi, a 26-year old prostitute who was brought to a brothel in the city when she was eleven years old by a neighbor, and was told to have sex with men. Guddi grew up in poverty in rural India and wanted to help her family by looking to make easy money. When she found out what was expected of her, she asked to return to her family, but was told she must repay her debt first. Guddi's story is meant to represent 
the experiences of many of women and girls working in the sex industry of Mumbai, India (Thompson, 2014). By highlighting the large number of women and girls trafficked into the sex industry, Thompson indicates that women and girls of the Global South who grow up in poverty are particularly vulnerable to being lured into the sex industry and exploited.

Other syllabus content that represents women and girls in the Global South as vulnerable to sex trafficking was the article titled, "Welcome to Rape Camp: Sexual Exploitation and the Internet in Cambodia" by Donna Hughes (2000). Hughes argues that child prostitution in Cambodia is an enormous problem, citing one study from July 1999 that said 2,291 girls under the age of 18 were engaged in prostitution. Another study from November 1999 (three months later) cited in the same Hughes article suggested that 16,000 girls in prostitution were under the age of $18(2000$, p. 9). Hughes explores the links between prostitution, sex tourism, and trafficking of women and girls in Cambodia, particularly its facilitation through online pornography. Hughes declares that "usually" women and girls are forced into the sex industry and do not choose to enter on their own accord, without citing research that supports this claim. Throughout this article Hughes repeats the phrase, "women and girls" to imply younger and older than 18 years (the U.S. legal-based marker to symbolize adulthood), yet only mentions specific statistics for girls under the age of 18 in one paragraph.

In Hughes' (2000) depiction of women and children as being "used" for men's pleasure, she makes numerous generalizations that represent women and girls under the age of 18 as always submissive, non-consenting, and tricked or sold into the sex trade. The statistics and generalizations in this article construct an image of women and girls as 
lifeless and passive victims of sex slavery, family cruelty, and global poverty. When used as the sole resource on the sex trade, students may see women and girls whose lives are stolen from them and who are destined to experience sexual violence. Through this lens, social work students learn that women and children in the Global South are likely to end up trading sex for money, and therefore "help" in the context of sex trafficking may mean relying on anti-trafficking organizations led by white westerners to save brown women and children from dangerous conditions and enslavement by heartless brown men (Spivak, 1988).

Content, such as the examples above, that specifically portrays women from the Global South as "trafficked victims" who experience excessive violence, indentured servitude, and captivity, appears completely removed from the ways global capitalism and power has encouraged the sex trade to boost local economies (Baker, 2014; Capous, 2007; Kempadoo, 2001; Kempadoo, 2015). Indeed, although the World Bank describes their purpose as "to end extreme poverty" by "providing low-interest loans to developing countries" (The World Bank, 2018) in reality such loans accrue interest, are nearly impossible to repay, and lead to continued poverty. This means that as local communities work to build the economy and repay loans through structural adjustment programs, they continue to go further in debt and turn to underground and informal sectors to contribute to debt repayment - including the sex trade (Chang, 2016). Working in the sex industry to help with debt-repayment then becomes a function of structural oppression (Capous, 2007; Kempadoo, 2001; Kempadoo, 2015) and cannot be relegated to predatory male traffickers intent on exploiting women of the Global South . This over-emphasis on women of color from the Global South shown as "forced" to work in the sex trades, as 
separate from structural conditions justifies the ever-present rise in NGOs throughout the Global South, particularly because they are then viewed as victims in need of rescue (Kempadoo, 2001; Limoncelli, 2016).

In interviews with faculty members teaching courses inclusive of sex trade content, instructors were critical of imagery and terms that they felt sensationalized the experiences of people in the sex trades by portraying them through their innocence and their sex/sexuality as objects being taken from them. Multiple instructors acknowledged that these realities publicized in the media lack empirical evidence and yet, it is these stories that faculty members discussed as being "sexy" and appealing to students interested in working with people in the sex trades. There were at least two instructors who both critiqued the use of exaggerated stories used to provoke empathy in students as problematic and unrealistic, and who included such content in their syllabi. One instructor discussed the concerning allure of the "sexy" imagery juxtaposed to her struggle with trying to represent "both sides," (i.e. those who experience victimization versus those who experience empowerment) of the sex industry,

How do I present this dichotomy of views that doesn't influence what my students think, but allows them to understand that there is a wide variety of thought and that they need to critically evaluate what it is and decide for themselves? How do I open up this world for them that there is more than just this one way of thinking about it and encourage them without influencing them to figure out what it is that they truly believe? (Interview, SW16, June 2017) 
The effort to represent "all sides" is perhaps an explanation for including content that may inaccurately represent the experiences of people in the sex trades, but the consequence of presenting such sensational imagery in the name of "diverse" viewpoints is surely problematic in terms of teaching students "how to promote social change and social justice with and on behalf of clients" (NASW, 2017, Preamble to The Code).

Another interview participant, SW1, revealed that her justification for using sensationalized imagery is for students to apply critical thinking skills to a range of theoretically based content and decide what they themselves think about the sex trades. SW1 does this by teaching students about various feminist theories such as Marxist feminism, liberal feminism, radical feminism, Black feminism, sex radical feminism, transnational feminism, and intersectional feminism. After teaching theory, she has students view documentaries like DEMAND or Selling of Innocents and has them "put on their theoretical hats" to deconstruct and process the films. In other words, she provides the opportunity for students to unpack dramatic imagery and potentially problematic representations of the sex trade.

Although interview participants have used sensationalist content for critical thinking exercises, content that situates hungry traffickers as the sole culprit of sexually exploiting innocent cisgender women and girls misses critical opportunities to engage with sex trades content that is central to undoing systems of oppression. In particular, scholars and activists have produced content that critique the positioning of women and girls of color as innocent and in need of protection and rescue in both the Global North and South as having a troubling connection to colonization and the white savior complex (Capous, 2007; Coates, 2014; Flaherty, 2017; Hackett \& Whalley, 2017; Spivak, 1988). 
And, yet there is an absence of content in social work courses that names the role of colonization, white people saving people of color, and structural oppression that creates demand for the sex trade.

Within a variety of disciplines and theoretical models it has been established that the dichotomous representation of women into two distinct groups - those from the liberated Global North and those from the subjugated Global South - has been used for a variety of purposes that ultimately disenfranchise women and girls worldwide. Rather than consider the global/local -"glocal” (Kumsa, 2002) connections, causes, and consequences, the content illustrated above aims to instill an urge to rescue. While the social work focus on women and girls from the Global South may inspire action, it does not posit realistic and anti-oppressive remedies to the issues of structural inequality that may have forced people into the sex trade.

For a complete list of syllabi content included in this section theme, see Table 3.

\section{Table 3}

\section{"Women and girls in the Global South are especially vulnerable to sexual exploitation"}

\begin{tabular}{|l|l|l|}
\hline \multicolumn{1}{|c|}{ Title of Content } & \multicolumn{1}{c|}{ Author } & \multicolumn{1}{c|}{ Type } \\
\hline Child Sex Tourism & Fiona David (2011) & Text \\
\hline $\begin{array}{l}\text { Welcome to Rape Camp: Sexual Exploitation } \\
\text { and the Internet in Cambodia }\end{array}$ & Donna Hughes & Article \\
\hline Stolen Innocence & Effect International & Documentary \\
\hline Lilya-4-ever & Lukas Moodysson & Film \\
\hline
\end{tabular}




\begin{tabular}{|l|l|l|}
\hline Caged Until Broken & Hazel Thomson & Documentary \\
\hline Sacrifice & Ellen Bruno & Film \\
\hline $\begin{array}{l}\text { Making the Harm Visible: Global Sexual } \\
\text { Exploitation of Women and Girls Speaking Out } \\
\text { and Providing Services }\end{array}$ & Donna Hughes & Text \\
\hline
\end{tabular}

Modern slavery. An additional message in social work syllabi is that slavery has returned in the modern form of sexual slavery, coercion, and exploitation. This message is often attached to the materials discussed above where women and children in the Global South are situated as particularly vulnerable to sex trafficking. Social work students are explicitly directed to combat, rescue, and redeem those experiencing modern-day slavery by supporting the criminalization of the third parties responsible for enslaving the innocent.

Multiple web activities, book chapters, and historical documents on legislation utilized in course syllabi proclaim that engagement in the sex trade is modern-day slavery. In particular, two of the websites used in course syllabi that espouse melodramatic (Vance, 2012) narratives of enslavement are: http://slaveryfootprint.org and http://www.freetheslaves.net. The Slavery Footprint website asks viewers to question how many slaves have worked for you by way of looking at the productive chain of labor. The "trafficking and slavery" fact sheet on "Free the Slaves" explains, "researchers estimate 40 million people are in slavery across the world." This figure presents an enslaved population that is more substantial than any other point in history and has led claims such as modern-day slavery being the greatest human rights violation of all time. In his book Disposable People, Kevin Bales (1999) encourages those anti- 
slavery activists to join Free The Slaves to learn about the conditions in which people are enslaved today (through the global sex trade, labor exploitation, and domestic servitude) and to engage in action with others to end slavery.

Research participants articulated understanding the severity and scope of modern day slavery as a learning objective. For instance, SW9 emphasized that social workers need to understand the severity of trafficking in the United States and abroad. She said the following about her approach to discussing trafficking as slavery:

I very much approach it from a human rights perspective and try to present all sides of an argument. You know some of it is not up for debate when you are talking about human trafficking. Slavery still exists. It's one of the big messages. It didn't end with the emancipation proclamation. It's global. Happening here more than you think. (Interview, SW9, August 2017)

SW9 acknowledges that students are often familiar with and drawn to stories of sex trafficking but that labor trafficking is, in fact, more prevalent.

Content found in syllabi consistently equates sex trade and prostitution with modern-day slavery, and even titles of book chapters, documentaries, and journal articles unequivocally send the message that sex trade is modern slavery and that women and children are enslaved. Some of these specific titles include the "Prostitution—A modern form of slavery," a chapter from the book, Prostitution, Trafficking, and Traumatic Stress (Farley, 2003); Sex Trafficking: Inside the Business of Modern Slavery (Siddarth, 2009); "Thailand: Because she Looks Like a Child" (Bales \& Soodalter, 2002); a documentary titled, Sex Slaves (Bienstock, 2005); and "The first modern anti-slavery law: 
The TVPA of 2000" (Ryf, 2000). Sex work as slavery is a particularly ubiquitous learning objective for social work students.

One participant I interviewed recognized the connection between race and moral panic discourse and commented on how she discusses it with students, I don't have to bring up the issue of race. The first day is focused on policy, which is rooted in slavery, so even the discussion of slavery in the United States is bothersome. We do talk about that and I don't have to bring up a lot of the intersections of oppression. There are some things I will point out. There are two images that are consistently shown in the media that are stock images and I do show them how often those images are shown and how the "saviors" are typically shown as white, usually church people. And those of us that are minorities understand that history and what it means. (Interview, June 2017, SW7)

SW7 asks students to look beyond the individual and seek to remedy the systemic forces such as poverty, racism, classism, sexism, citizenship status and other systems of oppression that make sex trade an accessible choice for the people we work with. In the same interview, SW7 brought up the contradicting narratives within anti-trafficking activism. SW7 told me about speaking on a panel related to labor trafficking with other trafficking activists and experienced racial bias within the trafficking movement first hand,

[a] white woman who called herself an abolitionist actually hinted that I should go back to my country, but I was born here. Just in general, no one really questions white people and their perspectives and their expertise, 
but there is a lot that needs to be questioned about their perspectives on human trafficking. (Interview, SW7, June 2017)

SW7 attends to the dominance of whiteness within the movement and the importance of questioning the perspectives of those who claim that carceral interventions are the most effective way to stop sex trafficking.

Drawing on the insidiousness of whiteness in anti-trafficking activism, Beutin (2017) scrutinizes the juncture of anti-trafficking activism and anti-black racism found on a website called, "Antislavery usable past.” In doing so, Beutin (2017) explores how contemporary abolitionist movements appropriate the experiences of African-American chattel slavery by consistently draw on imagery of "cages", "innocence", and "slavery" to remind the public of the dehumanizing conditions cisgender women and girls experience in the sex trade. At the same time these very same "abolitionists" advocate for the incarceration of the third parties that demand sex trade, thereby advocating for their legal enslavement.

It is troubling that most course content on human trafficking ignores the reality that over 2.3 million people are held within the United States justice system alone (Wagner \& Rabuy, 2017), that mass incarceration disproportionately impacts people and communities of color, and that prisons are profitable for the elite. Even though slavery was outlawed in the $13^{\text {th }}$ amendment, during the Reconstruction Era, if convicted of a crime, African-Americans were stripped of legal rights such as the right to vote, due process, and equal protection under the law, thus became "Slaves of the State" (Alexander, 2010, p. 31). 
Among the course materials that equate the sex trade, trafficking, and prostitution, not one of these items discusses the number of Black, indigenous, and Latino/a/x men, women, trans, and non-binary people held in the American prison system, thereby ignoring the vast amount of literature that identifies the "prison industrial complex" itself as a modern form of slavery (Davis, 2003). Instead, and perhaps ironically, much of the named content advocates the jailing of traffickers and pimps as the solution to modernday slavery. Anti-trafficking content that utilizes slavery metaphors and supports mass incarceration is at odds with other approaches that recognize the sophisticated ways in which sex work, transnational labor, and the prison industrial complex form a web of privilege and oppression based upon race, gender, sexuality, and class within a neoliberalist economy. Simply put, abolishing slavery cannot be reduced to saving innocent women from sexual servitude and the bad men who should be jailed for profiting from their enslavement.

In Table 4 you can find a complete list of content that represents experiences in the sex trades as "Modern Slavery."

\section{Table 4}

\section{"Modern Slavery"}

\begin{tabular}{|l|l|l|}
\hline Title of Content & Author & Type \\
\hline Slavery Footprint & http://slaveryfootprint.org & Website \\
\hline $\begin{array}{l}\text { Supplementary Convention on the } \\
\text { Abolition of Slavery, the Slave Trade, and } \\
\text { Institutions and Practices of 1954 }\end{array}$ & UN Treaty & Text \\
\hline Slavery Convention 1926 & League of Nations & Treaty Text \\
\hline
\end{tabular}




\begin{tabular}{|c|c|c|}
\hline $\begin{array}{l}\text { The First Modern Anti-Slavery Law: The } \\
\text { TVPA of } 2000 \text { HR } 972 \text { TVP } \\
\text { Reauthorization Act of } 2005\end{array}$ & Melissa Farley & Journal Article \\
\hline $\begin{array}{l}\text { Three Things You Can Do to Stop Slavery } \\
\text { (chapter in book), } 3 \text { steps he references are: } \\
\text { o Learn } \\
\text { o Join with others who want to end } \\
\text { slavery } \\
\text { o Act, Join free the slaves \& Anti-slavery } \\
\text { international }\end{array}$ & Kevin Bales & Chapter in book \\
\hline $\begin{array}{l}\text { Global Sex Trade } \\
\text { Sex Slaves }\end{array}$ & Rick Bienstock (2005) & $\begin{array}{l}\text { Class topic \& } \\
\text { Video }\end{array}$ \\
\hline $\begin{array}{l}\text { Sex Trafficking: Inside the Business of } \\
\text { Modern Slavery }\end{array}$ & Kara Siddarth (2010) & Book \\
\hline $\begin{array}{l}\text { The Slave Next Door: Human Trafficking } \\
\text { and Slavery in America today }\end{array}$ & Bales \& Soodalter (2009) & Book \\
\hline Slavery in the $21^{\text {st }}$ Century & Amparo Trujillo & Book \\
\hline $\begin{array}{l}\text { Ch. 1: The New Slavery } \\
\text { Ch. 2: Thailand: Because She Looks Like a } \\
\text { Child } \\
\text { In, Disposable People }\end{array}$ & Bales, K (2004) & Book \\
\hline Prostitution-A Modern Form of Slavery & Ali Tabatabaeinia & Essay \\
\hline Free the Slaves Model for Fighting Slavery & http://www.freetheslaves.net & Website \\
\hline
\end{tabular}

\section{Representations of the $3^{\text {rd }}$ parties who facilitate sex trade}

Although many scholars do explore structural or economic factors that shape demand for the sex trade, I've found a significant emphasis within social work course syllabi on individuals as the demand factors (i.e. johns, pimps, traffickers). Most prominently, cisgender men are named as those trying to exploit cisgender women through sexual transactions. Some of these men are referred to as "pimps" or 
"traffickers." I prefer the term "third party ${ }^{10}$," which sex trade researcher Alexandra Lutnick (2016) and others have used to describe the various types of intimate relationships in the lives of young people trading sex. For me as well as these other scholars, terms such as "pimp" and "trafficker" are highly raced and classed terms (O'Connell-Davidson, 1998), namely due to their historical and contemporary cultural association with black and brown men who are economically disadvantaged. Indeed, in addition to using racially problematic terms, some social work faculty utilize materials that draw on racism to propagate rescue interventions.

The film DEMAND (SHI, 2013), mentioned earlier to demonstrate the portrayal of women and girls as particularly vulnerable to sex trafficking, expands on the racialization of the term "pimp" as one embodied by black and brown men. Just as the narrator of the film says the words, "pimping now describes a lifestyle," an image of the Black hip-hop artist Snoop Dogg, in a white suit, gold chains, and top hat, flashes across the screen. Interestingly, Snoop Dogg has been quoted in Rolling Stone Magazine (2013) as being fascinated by the "pimp lifestyle" and identified himself as serving in a "pimp" role at one point in time. Further, as the narrator describes the various forms that trafficking can take, the screen shows a black man standing outside of a car window; the audience is meant to presume he is negotiating a sex transaction.

Furthermore, additional content in the data sample that portrays third parties as threatening and dangerous includes one news article that interviewed three black "pimps" who are currently incarcerated. The interviews highlight how they built relationships with

\footnotetext{
${ }^{10}$ The term "third party" serves as a non-judgemental placeholder for boyfriend, family member, husband, drug dealer, sister, friends, or people often assumed to serve the role of making someone else have sex for their gain.
} 
the women and girls they worked with, the vulnerabilities they exploited, and the various ways they used profits to protect and care for the girls they had working for them (Walters, Satija, \& Smith, 2017). In one sense, it appears the article serves to humanize the pimps by discussing how poverty and violence affect the connection between third parties and sex workers. On the other hand, Walters, Satija, and Smith framed former "pimps" as hyper-violent and uncaring by asking leading questions about practices of recruitment, sexual exploitation, and economic control. Likewise, another syllabus draws on chapters from the book Without Conscience: The Disturbing World of the Psychopaths Among Us to describe the psychopathic characteristics of third parties as violent, manipulative, and abusive (Hare, 1993).

In addition to characterizations of third parties as monstrous and hyper-violent, some materials focus specifically on how third parties recruit "adolescents" and women into street-level prostitution. For instance, the article "Routes of Recruitment: Pimps' Techniques and Other Circumstances that Lead to Street Prostitution” by Kennedy, Klein, Bristowe, Cooper, and Yuille (2007) states that the legal definition of the colloquial term pimp "is someone that connects customers to sex workers" (p. 5). However, they note that in reality, the definition of a pimp extends far beyond a simple connection, and that pimps are people who live entirely off of sex worker earnings by using tactics of manipulation and control to keep them engaged in sex trade (Kennedy, Klein, Bristowe, Cooper, \& Yuille, 2007). Their research found that such tactics include, "love, debt, addiction, physical might, and authority" (p. 4). Kennedy and colleagues' findings were based on interviews with former prostitutes between the ages of 19-45, 
parents of former prostitutes, VICE police officers, and social service workers, but not current sex workers or the third parties in relationship to them.

Third parties are also the focus of another article used in syllabi titled "Understanding Human Trafficking: Development of Typologies of Traffickers" that is intended to help prevent trafficking (Busch-Armendariz, Nsonwu, \& Cook, 2009). By defining the character traits, demographics, social circumstances, and recruitment methods of twelve pimps and traffickers prosecuted in Texas for trafficking women and adult women and children, Busch-Armendariz and colleagues constructed typologies of sex traffickers. The sample in this instance suggests that traffickers are usually male, lowincome, and focus their recruitment efforts on young women with troubled home lives. The racial or ethnic identities of two prosecuted "pimp-traffickers" of U.S victims of sex trafficking were not mentioned in the article. They further posit that their typology of recruitment and control tactics along with character traits of pimps and traffickers can help prosecutors, prevent human trafficking, and develop services for victims and survivors (Busch-Armendariz et al., 2009). For example, the typologies of sex traffickers describe them as hanging out at Greyhound bus stations looking for chronic runaway youth who would be easy targets to coerce into exchanging sex for money. Finally, Busch-Armendariz and colleagues (2009) report that pimps and traffickers specifically target minors to facilitate their sex trade because johns will pay more for sex with a child (p. 9).

Some content represented relationships between sex workers and third parties as more complicated than simply using deceptive tactics (promises of love, introduction to drugs, money, and authority) to entice women into the sex trades. In particular, two 
syllabi drew on ethnographic research, both participant observation and in-depth interviews with "former pimps" and sex workers who discussed their relationships with one another (Marcus, Horning, Curtis, Sanson, \& Thompson, 2014; Raphael \& MyersPowell, 2010). Marcus and colleagues (2014) contradicted the typologies of pimps and traffickers (Busch-Armendariz et al, 2009) in their study of former pimps and sex workers which found that $87.2 \%$ of their respondents under the age of 18 engaged in sex trade wanted to stop doing sex work but that their barrier from doing so was not a controlling "pimp." Instead, they identified needing changes in "employment options, educational opportunities, and housing" (2014, p. 231).

Further challenging the prevalent idea that third parties are out to exploit minors by profiting off of their sexual labor, interviews with "full and part-time pimps" indicate that minors are viewed as less profitable than adults, given their lack of sexual skill and experience (Marcus, Horning, Curtis, Sanson, \& Thompson, 2016). While Marcus and colleagues' (2016) sample included both adults and minors working in the sex trade, they suggest male clients are not hyper-focused on sex with youth sex workers.

In fact, Marcus and colleagues (2014) argue many of the traditional stereotypes and narratives that frame understandings of the relationship between sex workers and third parties rely on sex worker and third party testimonies after "punishment and rescue" interventions (p. 225). This finding in their interviews disrupts a pervasive narrative that third party relationships are simply about exploiting adult and youth sex workers for money. Their interviews uncovered that very few third party-sex worker relationships were maintained via dynamics of power and control even in Atlantic City, NJ, a city that is nationally pinned as a hub for child sex trafficking. Rather, their relationships 
depended on mutual exchange of needs. For example, a third party might provide protection for a sex worker in exchange for a commission, sex, or intimacy (p. 57). Their findings suggest that both sex worker and third parties have power in different contexts and sex worker/third party relationships cannot be reduced to the roles of victim and villain.

A nuanced look at representations of third parties within the sex trades provides students with opportunities for re-examining the many layers of systemic oppression that regulate and criminalize people engaged in the sex trade, and may help them better understand the technologies of racism.

For a complete list of syllabi content included in this theme, see Table 5. 
Table 5

"Representations of the Third Parties who facilitate sex trade"

\begin{tabular}{|c|c|c|}
\hline Title of Content & Author & Type \\
\hline $\begin{array}{l}\text { How Texas Pimps Recruit and Sell Underage } \\
\text { Girls for Sex }\end{array}$ & $\begin{array}{l}\text { Walters, Satija, and } \\
\text { Smith, 2017. In Texas } \\
\text { Tribune }\end{array}$ & Newspaper Article \\
\hline $\begin{array}{l}\text { Routes of Recruitment: Pimps Techniques } \\
\text { and Other Circumstances that Lead to Street } \\
\text { Prostitution. }\end{array}$ & $\begin{array}{l}\text { Kennedy, Klein, } \\
\text { Bristowe, Cooper, \& } \\
\text { Yuike, } 2007\end{array}$ & Journal Article \\
\hline $\begin{array}{l}\text { What Do We Know About the People Who } \\
\text { Make Up the "Demand" Side of Trafficking? }\end{array}$ & Torrey \& Dubin (2004). & Conference Report \\
\hline $\begin{array}{l}\text { Modern Day Comfort Women: The U.S. } \\
\text { Military, Transnational Crime, and the } \\
\text { Trafficking of Women }\end{array}$ & $\begin{array}{l}\text { Hughes, Chon, \& } \\
\text { Ellerman (2007) }\end{array}$ & Journal Article \\
\hline $\begin{array}{l}\text { Ch. 1: Experiencing the Psychopath } \\
\text { Ch. 3: The Profile: Feelings \& Relationships } \\
\text { Ch. 5: International Controls: The Missing } \\
\text { Piece. }\end{array}$ & Hare, 1993 & Book \\
\hline $\begin{array}{l}\text { Understanding Human Trafficking: } \\
\text { Development of Typologies of Traffickers }\end{array}$ & $\begin{array}{l}\text { Noel Busch- } \\
\text { Armendariz, } 2009\end{array}$ & Conference Paper \\
\hline $\begin{array}{l}\text { From Victims to Victimizers: Interviews } \\
\text { With } 25 \text { Ex-Pimps in Chicago. }\end{array}$ & $\begin{array}{l}\text { Raphael, J. \& Myers- } \\
\text { Powell (2010) }\end{array}$ & Journal Article \\
\hline $\begin{array}{l}\text { Conflict and Agency Among Sex Workers } \\
\text { and Pimps }\end{array}$ & Marcus, Curtis, et al. & Journal Article \\
\hline Demand and Debate & $\begin{array}{l}\text { Leidholdt. D.A. (2005) } \\
\text { CATW }\end{array}$ & Speech Text \\
\hline $\begin{array}{l}\text { The Swedish Law that Prohibits the Purchase } \\
\text { of Sexual Services: Best Practices for } \\
\text { Prevention of Prostitution and Trafficking in } \\
\text { Human Beings. }\end{array}$ & Gunilla, Ekberg (2004) & Journal Article \\
\hline
\end{tabular}


The subjectivity of human rights. Social work course content spoke to the myriad ways that the demand for sex trade violates the human rights of women and children. Human rights are outlined in the Universal Declaration of Human Rights and easily align with the core values of Social Work (Reichert, 2007). Article 4 of the Universal Declaration of Human Rights (2015) says that, "no person shall be held in servitude; slavery and the slave trade should be prohibited in all its forms." Other human rights often violated in slave-like conditions include access to healthcare, adequate housing, education, body and reproductive sovereignty, food, clothing, fairness, and social, civic, and economic equality (United Nations Human Rights Commission, 2018). Therefore if sex trafficking is modern-day slavery, then those who are victims of sex trafficking are having their rights violated. More specifically, the Palermo Protocol defines the conditions that must be met to determine if human trafficking has taken place. Under the protocol the definition of trafficking depends on, ...the recruitment, transportation, transfer, harbouring or receipt of persons, by means of the threat or use of force or other forms of coercion, of abduction, of fraud, of deception, of the abuse of power or of a position of vulnerability or of the giving or receiving of payments or benefits to achieve the consent of a person having control over another person, for the purpose of exploitation. Exploitation shall include, at a minimum, the exploitation of the prostitution of others or other forms of sexual exploitation ...

Although the definition highlights three different elements that must be in place to define trafficking, sometimes trafficking is defined more narrowly by social service providers, 
law enforcement, or advocates in the court system (Dank, 2011; Hoyle, Bosworth, and Dempsey, 2011). Therefore, the human rights framework used to assert "human rights violations" in each context is necessary to understand the experiences of people in the sex trades and to interrogate the socially constructed victim narrative often assigned to adults and youth in the sex trades.

Course content included debatable solutions for mitigating human rights violations, as well as definitions of human rights. One syllabus included three types of content on human rights, the article "The Movement to Decriminalize Sex Work in the U.S. (Weitzer, 2010)," the Universal Declaration of Human Rights, and a documentary, Behind Closed Doors: Voices from the Inside. Each resource discusses human rights through a different lens. For example, the Universal Declaration of Human Rights outlines the human rights that all people deserve and should have access too. Even as these rights are set forth, there are endless ways of interpreting how to ensure they are accessed. Weitzer (2010) suggests that the human rights of people in the sex trades are infringed up through political debates that affirm neoliberal policies that are both enforced through criminalizing prostitution and the legalization of prostitution. The film Behind Closed Doors was made by social work students and received a CSWE Virtual Ovation Award for capturing the experiences of adult survivors of domestic minor sex trafficking. The student creators of the film focused on the stories and interviews of survivors, some whose parents trafficked them, and some who reflect on how they got caught up in drug addiction, incarceration, homelessness, prostitution, and relationship violence (Ambrosino, 2013). As such, the film suggests that these factors are used to keep people trading sex for the profit of a third party who violates their human rights. 
Also included in syllabi were three different articles that proposed three different definitions for a "rights based approach" with people working in the sex trades (Leuchtag, 2011; Preble, 2017; Rijken \& Koster, 2008). For example, in “A Human Rights Based Approach to Trafficking in Human Beings" Rijken and Koster (2008) drew on a "human rights legal framework" that obligates the state to criminalize the trafficking of human beings, investigate and prosecute traffickers, protect and provide assistance to victims, and address the root cause of human trafficking (p. 216). Additionally, a chapter by Preble (2017), "Client-Centered Harm Reduction, Commercial Sex, and Trafficking: Implications for Rights Based Social Work" offers a human-rights-based approach based on harm reduction principles. A harm reduction approach recognizes that people are the experts on their own lives and that structural oppression impacts how people experience, navigate, and respond to the world around them. Therefore, in her chapter, Preble (2017) remarks on the importance of a non-judgmental approach when working with people in the sex trades, particularly those who use drugs or continue their involvement in the sex industry after attempting to exit. Preble's approach contends a harm reduction philosophy acknowledges that all people deserve access to safety, healthcare, employment, food, housing, and fair treatment in the legal system.

One documentary included in a syllabus, Where's the Justice? Sex Work in Hungary (SZEXE \& HCLU, 2013) represented Hungarian sex workers as workers who deserve human rights despite how they use their bodies in their labor. The Hungarian Civil Liberties Union and the Association of Hungarian Sex Workers collaborated to produce the documentary as a form of advocacy for sex workers rights. In the film, advocates draw on harm reduction principles to illuminate the experiences of Hungarian 
sex workers and their need to access quality health care, social services, and legal protections to help them resist discrimination and exploitation.

One interview participant named the importance of presenting many perspectives for students so that they can have the information to think critically. SW12 says, I want them to know that there are many facets to this conversation about prostitution, should it be it legal or not? How does that affect our efforts to fight true trafficking, which has to do with coercion? I present a lot of info from Amnesty International and their proposals. From a social work perspective the self-determination piece is very important to me. I sort of help people see beyond their initial reaction to someone doing legitimate sex work and how that is different than trafficking. (Interview, SW12, June 2017)

SW12's distinction between trafficking and "legitimate sex work" situates human rights violations in relationship to trafficking, particularly as SW12 has equated human trafficking with slavery and the inability to independently decide what to do with one's body.

See Table 6 for a complete list of content included in syllabi that constitute this sub-theme. 


\section{Table 6}

\section{"The subjectivity of human rights"}

\begin{tabular}{|l|l|l|}
\hline \multicolumn{1}{|c|}{ Title of Content } & \multicolumn{1}{c|}{ Author } & \multicolumn{1}{c|}{ Type } \\
\hline $\begin{array}{l}\text { The Movement to Decriminalize Sex Work in } \\
\text { the U.S. }\end{array}$ & Weitzer, R. (2010). & Journal Article \\
\hline $\begin{array}{l}\text { Human Rights of Sex Workers Proposal for } \\
\text { Decriminalization }\end{array}$ & Amnesty International & Proposal \\
\hline $\begin{array}{l}\text { A Human Rights Based Approach to Trafficking } \\
\text { in Human Beings }\end{array}$ & Rijken \& Koster & Journal Article \\
\hline $\begin{array}{l}\text { Universal Declaration of Human Rights } \\
\text { Behind Closed Doors }\end{array}$ & United Nations & Protocol \\
\hline $\begin{array}{l}\text { Health Effects of Prostitution } \\
\text { Client Centered Harm Reduction, Commercial } \\
\text { Sex, and Trafficking: Implications for Rights } \\
\text { Based Social Work }\end{array}$ & $\begin{array}{l}\text { Ch. 6 in Nichols, by } \\
\text { Kathleen Preble }\end{array}$ & Text \\
\hline
\end{tabular}

\section{People in the Sex Trades Have Complex Experiences}

There was minimal content representing the complex experiences of people in the sex trades. This is not very surprising, particularly because such a large portion of the analyzed syllabi came from classes on human trafficking and tended to be more victimfocused. However, there was one course on sex trafficking, one course on human trafficking, and two courses on sexuality for social workers that did include nuanced content to represent the experiences of people in the sex trades.

An article published in New York Magazine, "Is Prostitution Just Another Job?" interviewed sex workers about their perspectives on decriminalizing prostitution (Mcclelland, 2016). The journalist interviewed sex workers ranging in age from 19 to 65 
years old who started engaging in sex work through various avenues, including being trafficked, signing up a for a sugar daddy website, being introduced by friends, and developing curiosity in college courses. Each person interviewed had unique economic needs and expectations of the work itself. At the time of interviews everyone identified as a voluntary worker, and were almost unanimously in support of decriminalization. Some sex workers did acknowledge that even if prostitution were decriminalized, law enforcement would find another way to arrest them. However, sex workers interviewed did feel that decriminalization would help them feel safer in their work and they expected that the stigma of sex work might be reduced if it were not criminalized.

Expanding on the stigma of engaging in sex work, another article, "The Dangerous Catch 22 of Coming Out as a Sex Worker," focused on the experiences of a sex worker who identified as both an activist and social service advocate, but could not come out to their parents or friends for fear of being ridiculed and shunned. This article states that indoor sex work is becoming more normalized by the day and that indoor workers are said to make up about $80 \%$ of the sex industry, whereas visible street sex work has been on the decline (Pasulka, 2016).

Both online news articles embrace the many experiences of people working in the sex industry and acknowledge that people in the sex trades can experience empowerment, violence, fatigue, coercion, healthy relationships, and financial rewards. While there is a great amount of diversity related to privilege and oppression that often shapes experiences in the sex trades across the world, individuals within the sex trades are multifaceted, in need of healthcare, labor rights, non-judgmental support, recognition of their skills, and beyond. 
Table 7 represents the content that was used to construct the theme for this

section.

Table 7

"People in the sex trades have complex experiences"

\begin{tabular}{|c|c|c|}
\hline Title of Content & Author & Type \\
\hline $\begin{array}{l}\text { Prostitution: Still a Difficult Issue for } \\
\text { Feminists. }\end{array}$ & $\begin{array}{l}\text { Alexander, Priscilla (1987). In F. } \\
\text { Delacoste \& P. Alexander (Eds), } \\
\text { Sex work: Writing by women in the } \\
\text { sex industry }\end{array}$ & Chapter in Text \\
\hline $\begin{array}{l}\text { Labelling the Victims of Sex } \\
\text { Trafficking: Exploring the Borderland } \\
\text { Between Rhetoric and Reality. }\end{array}$ & $\begin{array}{l}\text { Hoyle, C., Bosworth, M., \& } \\
\text { Dempsey, M. (2011). Social \& } \\
\text { Legal Studies, 20(3), 313-329. }\end{array}$ & Article \\
\hline $\begin{array}{l}\text { Sex Trafficking, Human Rights, and } \\
\text { Social Justice }\end{array}$ & Zheng, T.T, (2010). & Book \\
\hline $\begin{array}{l}\text { Where's the Justice? Hungarian Sex } \\
\text { Workers }\end{array}$ & $\begin{array}{l}\text { The Association of Hungarian Sex } \\
\text { Workers and Hungarian Civil } \\
\text { Liberties Union } \\
\text { (https://www.youtube.com/watch?v } \\
=- \text { M4zJgWPMSU) }\end{array}$ & Documentary \\
\hline Is Prostitution Just Another Job? & $\begin{array}{l}\text { Mac Mclelland. (2016). } \\
\text { https://www.thecut.com/2016/03/se } \\
\text { x-workers-legalization-c-V-r.html } \\
\text { (Appeared in the May } 2016 \mathrm{New} \\
\text { York Magazine) }\end{array}$ & $\begin{array}{l}\text { Online } \\
\text { magazine }\end{array}$ \\
\hline $\begin{array}{l}\text { The Dangerous Catch } 22 \text { of Coming } \\
\text { Out as a Sex Worker }\end{array}$ & $\begin{array}{l}\text { Nicole Pasulka. (2016). } \\
\text { https://splinternews.com/the- } \\
\text { dangerous-catch-22-of-coming-out- } \\
\text { as-a-sex-worker-1793853893 }\end{array}$ & $\begin{array}{l}\text { Online } \\
\text { magazine }\end{array}$ \\
\hline
\end{tabular}

LGBTQ people in the sex trades. Albeit limited, there was some representation in content of young LGBTQ people trading sex to meet their survival needs. Their stories are primarily represented as a group (LGBTQ), rather than distinct by sexual or gender 
identity. Unlike cis women and girls who are presumably straight and portrayed primarily as victimized in the content, LGBTQ youth are represented moreso as "at-risk" for trafficking and exploitation due to systemic oppression. Interestingly, representation of LGBTQ youth as a vulnerable community is limited to two syllabi, and LGBTQ youth are ultimately recognized as engaging in sex trade to survive living on the street.

When I spoke with SW1, I asked if she focused on specific marginalized populations within the sex trades. She referenced a specific lecture she includes in her syllabus that centers on designing programs with an intersectional focus to work with LGBTQ young people who have experienced trafficking and "Child Sexual Exploitation" (CSE). SW1 deferred to research reports from the Urban Institute and said, I do a section related to practice with LGBTQ populations and use some really great work by the Urban Institute. I'm sure you're familiar with Meredith Dank and colleagues who have authored a couple of different pieces. One of them talks about interactions with the police and then another talks about experiences of youth in the commercial sex industry-mostly homeless or transient youth--but then we tie in the social work piece like what's your role with this on a micro, mezzo, and macro level. Then kind of bring in intersectionality and I ask them, how is this different for LGBTQ people who are POC or not? And so on. (Interview, SW1, June 2017)

SW1 included a report by Dank, Yahner, Madden, Bañuelos, Yu, Ritchie, Mora, and Connor (2015) out of the Urban Institute that studies the experiences of LGBTQ Youth, Young Men who Sleep with Men (YMSM) and Young Women who Sleep with Women 
(YWSW) engaged in survival sex trade. This research report highlights findings significant to the education of social workers. For example, youth engaged in the sex trade face violence and abuse from many sources including families, strangers, one another, social service workers and agencies, clients, law enforcement, and exploiters, thereby reducing their access to basic resources and the likelihood that they will access social services.

Notably, Dank and colleagues (2015) correlate LGBTQ youth involvement in the sex trades with systemic oppression based on reports by youth in the study that identified issues of "familial poverty, social and familial discrimination and rejection, physical abuse, sexual abuse and exploitation, and mental and emotional trauma" as common factors for needing to leave home (p. 1). Furthermore, the study highlights the strength of youth working in the sex trade through their creativity in building safety and social support networks. By including reports from the Urban Instiute, SW1 helps students to consider how LGBTQ young people are impacted by intersectional oppression and are active survivors.

A different report titled, "Locked In: Interactions With the Criminal Justice and Child Welfare System for LGBTQ Youth, YMSM, YWSW who Engage in Survival Sex Trade," found in SW1's course syllabus gives social work students the opportunity to learn more about the vulnerability of LGBTQ youth to becoming criminalized. Dank and colleagues (2015) report that law enforcement and child welfare workers perceive LGBTQ youth in the sex trades to be more likely than straight youth in the sex trades to engage in criminal behavior and as such consider that arresting them serves as a way to prevent further crime. The perception of LGBTQ youth as being on a track of criminality 
harshly illuminates systemic oppression based on intersections of race, class, sexuality, and gender. Moreover, Dank and colleagues (2015) remind readers that this is a "startling" comparison to larger public narratives of women and girls (assumed to be white, cis, and straight) as passive, innocent, and more victim-like. Table 8 represents the content used to construct this sub-theme.

\section{Table 8}

\section{"LGBTQ people in the sex trades"}

\begin{tabular}{|l|l|l|}
\hline \multicolumn{1}{|c|}{ Title } & \multicolumn{1}{|c|}{ Author } & \multicolumn{1}{c|}{ Type of Content } \\
\hline $\begin{array}{l}\text { Let Girls Be Girls: How Coercive Sexual } \\
\text { Environments Affect Girls Who Live in } \\
\text { Disadvantaged Communities }\end{array}$ & Andrea Nichols & $\begin{array}{l}\text { Chapter in edited } \\
\text { book }\end{array}$ \\
\hline $\begin{array}{l}\text { Surviving the Streets of NY: Experiences of } \\
\text { LGBTQ Youth, YMSM, and YWSW } \\
\text { Engaged in Survival Sex, }\end{array}$ & $\begin{array}{l}\text { Meredith Dank and the } \\
\text { Urban Institute }\end{array}$ & Report \\
\hline $\begin{array}{l}\text { Locked In: Interactions With the Criminal } \\
\text { Justice and Child Welfare Systems for } \\
\text { LGBTQ Youth, YMSM, YWSW }\end{array}$ & $\begin{array}{l}\text { Meredith Dank and the } \\
\text { Urban Institute }\end{array}$ & Report \\
\hline $\begin{array}{l}\text { Lecture on Practice \& Programmatic Design: } \\
\text { Implications for Working With } \\
\text { Trafficked/CSE/LGBTQ Populations }\end{array}$ & Lara Gerassi & Guest Lecture \\
\hline
\end{tabular}

Content that represents people in the sex trades as complex and multifaceted does not ignore victimization of people in the sex trades. Rather, the complexity of experiences may include experiences of violence in addition to other experiences of joy, frustration, empowerment, apathy, and beyond. However, when people in the sex trades are represented as having a wide range of experiences that cross choice, survival, circumstance, and coercion, social work students may find ample opportunities for advocacy and social action related to the sex trades on micro, mezzo, and macro levels. The content represented throughout this section illuminates the importance of social 
workers engaged with a wide array of sex trade representations to critically think about means of helping that truly advocate for the human rights of people in the sex trades. As such, course materials that include themes of decriminalization of prostitution, access to safety while working, sexual agency, non-judgmental health and social services, and employment opportunities that provide a living wage, are imperative.

\section{Good Intentions and Carceral Feminisms in Social Work}

As a profession, social work is rooted in helping vulnerable communities and working toward social justice. Throughout their social work course work, students encounter a range of content on social work practices, modalities, theoretical frameworks, and social welfare policies that span micro, mezzo, and macro approaches to social work. As people intent on helping, good intentions often lead students towards specific types of "helping interventions." Depending on how students learn to examine the differences between help and harm, good intentions may lead social workers to participate in interventions that further harm the vulnerable communities they aim to help.

Earlier in the dissertation, I discussed the harm imposed upon Black, queer, trans, and/or non-binary sex workers via rescue interventions set on helping victims of sex trafficking escape exploitation. Such interventions are rooted in carceral logics that depend on law enforcement working with social workers to identify victims of sex trafficking. Carceral feminism is rooted in liberal feminism, and has been critiqued by intersectional feminists because it harms communities that have historical trauma with law enforcement and incarceration. Carceral feminist activism ignores the historical trauma and contemporary consequences of incarceration on marginalized communities, in particular Black, indigenous, trans, Latina and immigrant women, queer and non-binary 
people, youth in the sex trades, drug users, and poor people. Therefore, the ways that students are taught to think about the vulnerable communities they aim to work with, and advocate for, may impact their intentions for how they work to help, and whether their help leads to liberation or further harm.

I found a great deal of content that focused on how to help people in the sex trades. Primarily, content focused on the importance of collaborating with social, medical, and legal systems to help people in the sex trades recover from their experiences of trauma, experienced both in and out of the sex industry. Additionally, content spoke to the importance of social workers being able to recognize, prevent, combat, and stop trafficking. Emphasis was also placed on collaborating with Christian-based antitrafficking activists and NGOs and law enforcement to rescue and help those victimized in the sex trade.

Collaborations between evangelical activists, NGOs, social service providers, feminists, and law enforcement have been encouraged in many social work syllabi, while critiqued as rooted in good intentions and carceral consequences in the content of others (Agustín, 2007; Bernstein, 2012; Flaherty, 2016; Law, 2016; Whalley \& Hackett, 2017). In content that portrayed the importance of social workers becoming a part of multidisciplinary teams, there are numerous interventions that focus on comprehensive services that help people in the sex trades understand their exploitative circumstances and recover from the trauma they've experienced.

Interventions intended to address trauma. Importantly, how the experiences of people in the sex trades are represented informs the interventions used by social workers to advocate with and on behalf of their clients. One way that instructors teach students to 
engage with people in the sex trades is through individual-level interventions that help clients recover from the impact of sexual and psychological trauma. First, teachings suggest that social workers need to learn the markers of human trafficking and characteristics that make people vulnerable to being trafficked. Then, social workers should participate in multi-system collaborations to rescue victims of sexual exploitation and help them recover from trauma. Next, social workers can provide case management to help survivors access the legal system, housing, food stamps, welfare assistance, employment programs, healthcare, and educational opportunities. Further, social workers can build their clinical skills by honing their knowledge of sex and substance use addiction and the impact of childhood sexual abuse and psychological trauma on trafficking and abuse survivors. Finally, content included self-identified survivors of the sex trade as guest speakers, and sex trafficking prevention curricula developed by survivors.

There was a range of foci on micro practice including spiritual healing, addressing the needs of female immigrants who have been trafficked, performance art, and prevention education curricula presented by guest speakers. The delivery of content came from guest lecture, academic literature on intervention models, class session titles, book chapters, and journal articles. One chapter was found in an anthology titled, Social Work Practice with Survivors of Sex Trafficking and Commercial Sexual Exploitation, and explores how social workers can learn to respond to sex trafficking among immigrant women by examining trafficking within a landscape of violence against immigrant women (Cook, 2018). Likewise, one interview participant brought up the importance of teaching students about the complex intersections of migration and sex trade. SW12 said, 
I think it's important to understand how fuzzy it all is. The systemic oppression someone might be experiencing while trying to leave domestic violence and poverty. Think about the decisions people might make to keep themselves and families safe. That could be along a various continuum of choice. What does it mean to make decisions under these circumstances? What's in your or out of your control?

This idea of stash houses or whatever, human trafficking [activists] don't want to look at those houses; it is seen as human smuggling, even though women are often held back to cook, clean, engage in commercial sex trade. (Interview, SW12, June 2017)

SW12 mentioned that learning how to articulate the complicated experiences of immigrant women engaged in sex trade has taken years of working with immigrants and refugees, participating in local anti-trafficking activism, and bridging practice, research, and activism.

Possibly one of the most unique forms of content used to teach about the sex trades found in social work syllabi was a performance art piece created by a local dramaturge to tell the story of a prostitution diversion program in a major east coast city. SW11 described her decision-making process for inviting the artist to her graduate-level Foundations of Practice social work course in the following quote,

They were coming at it from this angle of these are prostitutes, $[\ldots]$ who have had three or so arrests for prostitution and are given this opportunity to get involved in D\&A and mental health services and if they succeed in adhering to some of these programmatic requirements then they can avoid 
jail. And in my mind as a social worker that's kind of a coercive arrangement $[\ldots]$ and is just another way of punishing women in sex work. I'm not down with diversion programs, but what I decided to do was have $[\ldots]$ this reading with parts of the play which depicted different women, different characters and the judge who is...well it's this kind of very patriarchal program, and we contrasted it with the Sonagachi Project in India. (Interview, July 2017, SW11)

SW11 continued on to explain that the performance included content that students were able to then ask questions about regarding social work ethics, values, and the benefits versus the consequences of diversion programs.

In another class, one guest speaker talked to students about a "survivor-led" intervention model, My Life My Choice, a ten-session curriculum specifically targeted to girls 12-18 years old aimed at preventing the commercial sexual exploitation of children (2003). The curriculum uses a public health model to prevent behaviors related to sex, relationships, and substance use through shifting participant attitudes, knowledge, and skills (Preventing the Exploitation of Girls: A Ground-Breaking Curriculum, 2016). One goal of the curriculum focused on shifting attitudes states, "Challenge girls' ideas about commercial sexual exploitation (including prostitution) emphasizing that the commercial sex industry is dangerous and debilitating, not glamorous" (My Life My Choice, 2016).

There is ample evidence of social workers engaging in rescue interventions or interventions meant to help people in the sex trades "recover" or "heal" from some kind of health issue. A common assertion is that people in the sex trades were sexually abused as children. A music video featuring GEMS founder Rachel Lloyd titled, The Making of a 
Girl, flashes the statistic, " $80-90 \%$ of [sex trafficking] victims were sexually abused as children” (Buckley, 2011, 3:01) amidst a poetic monologue about the mindset of young women entering sex work. Other course content espousing the idea that most women in the sex trade were sexually abused as children included guest speakers such as Annie Lorber from the organization, Hookers for Jesus and of training material from the My Life, My Choice curriculum that says, "youth who are at higher risk of engaging in sex trade are those with a history of abuse, neglect, and exposure to family violence and addiction." In other words, engagement in the sex trade may be viewed as a consequence of trauma from adverse childhood experiences.

Kari Lerum has explained the emphasis on the victimization of people in the sex trades as a way of deeming them worthy of help or rescue (1999). Lerum specifically draws attention to the treatment of addiction as a disease, so that instead of labeling people as deviant due to their drug use, instead they are viewed as having a sickness. On the one hand, this can facilitate helping people access supportive services should they want them, but on the other, it justifies help only when what has traditionally been labeled "deviant behavior" is caused by a sickness.

Table 9 below shares the cumulative content found in social work syllabi to create this theme. 


\section{Table 9}

"Interventions intended to address trauma"

\begin{tabular}{|c|c|c|}
\hline Title of Content & Author & Type \\
\hline $\begin{array}{l}\text { Examining Service Needs of Trafficked Women From the } \\
\text { Former Eastern Bloc: The Canadian Case }\end{array}$ & $\begin{array}{l}\text { McDonald \& } \\
\text { Timoshkina (2004) }\end{array}$ & Article \\
\hline $\begin{array}{l}\text { Importance of Supportive Relationships Among Women } \\
\text { Leaving Prostitution. }\end{array}$ & Melissa Farley & $\begin{array}{l}\text { Book } \\
\text { Chapter }\end{array}$ \\
\hline Providing Services to African-American Prostituted Women & Melissa Farley & $\begin{array}{l}\text { Book } \\
\text { Chapter }\end{array}$ \\
\hline $\begin{array}{l}\text { Social Justice and Spiritual Healing: Using Micro \& Macro } \\
\text { SW practice to reduce DMST }\end{array}$ & $\begin{array}{l}\text { Perdue, Prior, } \\
\text { Williams, \& } \\
\text { Sherman }\end{array}$ & $\begin{array}{l}\text { Journal } \\
\text { Article }\end{array}$ \\
\hline $\begin{array}{l}\text { Sex Trafficking Among Immigrant Women in the United } \\
\text { States: Exploring Social Work Response Within a Landscape } \\
\text { of Violence Against Immigrant Women }\end{array}$ & $\begin{array}{l}\text { Laurie Heffron } \\
\text { Cook }\end{array}$ & $\begin{array}{l}\text { Book } \\
\text { Chapter }\end{array}$ \\
\hline $\begin{array}{l}\text { Change is a Process: Using the Transtheoretical Model with } \\
\text { CSE \& Trafficked Youth and Adults. }\end{array}$ & Rachel Lloyd & $\begin{array}{l}\text { Book } \\
\text { Chapter }\end{array}$ \\
\hline Dissociation Among Women in Prostitution & Melissa Farley & $\begin{array}{l}\text { Book } \\
\text { Chapter }\end{array}$ \\
\hline Emotional Experiences of Performing Prostitution & Melissa Farley & $\begin{array}{l}\text { Book } \\
\text { Chapter }\end{array}$ \\
\hline Prostitution, Trafficking, and Traumatic Stress & Melissa Farley & Book \\
\hline $\begin{array}{l}\text { Living in Longing: Prostitution, Trauma, Recovery, and Public } \\
\text { Assistance }\end{array}$ & $\begin{array}{l}\text { Margaret Baldwin, } \\
2008\end{array}$ & $\begin{array}{l}\text { Journal } \\
\text { Article }\end{array}$ \\
\hline $\begin{array}{l}\text { Ch. 3: Safety Planning with Survivors of Sex Trafficking \& } \\
\text { CSE }\end{array}$ & $\begin{array}{l}\text { Abby Howard \& } \\
\text { Amber Sutton }\end{array}$ & $\begin{array}{l}\text { Book } \\
\text { Chapter }\end{array}$ \\
\hline Survivors Speak Out About Long Term Needs & $\begin{array}{l}\text { Noel Busch- } \\
\text { Armendariz }\end{array}$ & $\begin{array}{l}\text { News } \\
\text { Article }\end{array}$ \\
\hline
\end{tabular}




\begin{tabular}{|l|l|l|}
\hline Preventing the CSEC: The My Life My Choice Model & $\begin{array}{l}\text { Social service } \\
\text { provider }\end{array}$ & $\begin{array}{l}\text { Guest } \\
\text { Speaker }\end{array}$ \\
\hline Survivor-Led Advocacy and Survivor Entrepreneurship & & $\begin{array}{l}\text { Guest } \\
\text { Speaker }\end{array}$ \\
\hline Benefits of Survivor Leadership, Peer Support Models & Instructor & $\begin{array}{l}\text { Mini- } \\
\text { Lecture }\end{array}$ \\
\hline Play about Project DAWN & Dramaturge & $\begin{array}{l}\text { Guest } \\
\text { speaker }\end{array}$ \\
\hline $\begin{array}{l}\text { Sex Trafficking and Commercial Sexual Exploitation: } \\
\text { Prevention, Identification, Trauma Informed Practice and } \\
\text { Advocacy }\end{array}$ & $\begin{array}{l}\text { Gerassi, L. \& } \\
\text { Nichols A. (2017) }\end{array}$ & Book \\
\hline
\end{tabular}

Federal and state policies. Social workers are encouraged to work toward ending social injustices through policy development and implementation, research and evaluation, social and political action, and community organizing (NASW, 2017, Preamble). To meet this charge related to the sex trades, syllabi included content on federal and state policies with a prominent focus on violence against women, prostitution, the rights of children, and trafficking in persons. For example, two instructors discussed teaching students about policies through debate specifically focused on the legalization of prostitution. Another syllabus included multiple sections on the Polaris Project's website including a link to "report cards" that rate states on their enforcement of prostitutionrelated laws and summaries of state and federal laws in the United States. Furthermore, three specific policies that address human trafficking were included in most syllabi: "The United Nations Protocol to Prevent, Suppress and Punish Trafficking in Persons, Especially Women and Children," "The Victims of Trafficking and Violence Protection Act of 2000," and “The Violence Against Women Act of 2005 and 2013." In addition, 
some policy content explored state laws on prostitution, and provided legal analyses for how states could better respond to the needs of trafficking victims.

Each of these policies, rooted in the good intentions of helping victims of abuse, is focused on protection of women and girls from violence and trafficking. Yet these recommendations for helping victims depend on the threat of incarceration and upholding hegemonic masculinity (Capous, 2007). Carceral solutions are based on increased funding for law enforcement efforts to combat trafficking and prosecute third parties. Further emphasizing tenets of carceral feminism is the focus within the Victims of Trafficking and Violence Protection Act of 2000 on preventing trafficking from occurring, protecting victims of trafficking, and prosecuting traffickers. Preventing human trafficking relies on the neoliberal framework of governmentality in which victims and criminals are constructed by the state, particularly through monitoring specific demographics of people who are "likely" to commit crimes. Protection is meant to come from the state via incarceration of third parties and government funding that supports shelters for victims of trafficking to escape violence. Lastly, prosecution necessitates cooperation between law enforcement, the court system, social workers, and the "victim" to ensure the third party is sent to jail (Smith, 2006).

In a legislative hearing in which the testimonies of Irina Veselykh \& Masha Gnezdilova, two Russian women trafficked into Germany during the World Cup Championship were included, the Honorable Christopher H. Smith (author of the TVPA 2000) gave a briefing on the importance of improving both domestic and international responses toward combating human trafficking. Smith (2006) stated the following to demonstrate the government's commitment to combating human trafficking domestically: 
The new law [TVPA of 2005] requires both the Secretary of Health and Human Services and the Attorney General to prepare reports on best practices to reduce demand. For the first time the new law also authorizes \$20 million for HHS [Health and Human Services] grants programs for U.S. victims, \$10 million for long-term residential treatment facilities, and provides $\$ 50$ million for a new grants program for state and local law enforcement. (Serial No.109-188)

Furthermore, Smith comments on the importance of carceral consequences for those who traffic human beings, and of using profits from exploitation to provide social supports for victims:

The traffickers who use and abuse human beings as commodities to be bought and sold must be tracked down, their nefarious operations crushed, and the individuals who commit these heinous crimes sent to jail for a long, long time. All profits derived from selling women and children into slavery must be seized and put to good use, like providing some semblance of restitution to the victims, or for the construction of shelters.

The speech given by Smith continues to praise the United Nations Protocol to Prevent, Suppress and Punish Trafficking in Persons, Especially Women and Children, which 111 countries have signed onto and committed to combating sex trafficking in their own countries as well as internationally. Smith reflects on the work being done around the world and praises the efforts of law enforcement in some countries, while he reprimands other countries such as India for not working with law enforcement to effectively address 
sex trafficking. In the excerpt above, Smith vilifies traffickers and indicates imperialist expectations that justice will be served through very long prison sentences.

Following the U.N. protocol, the United States passed the Victims of Trafficking and Violence Protection Act of 2000 to fight human trafficking, "especially in the form of sex trade, slavery, and involuntary servitude." Additionally, the passage of the act reauthorized the Violence Against Women Act passed in 1994. In an attempt to assess how effectively the United States is preventing trafficking, protecting women and children from trafficking, and prosecuting those responsible for sex trafficking, the Polaris Project developed a system of state and federal report cards. The report cards assign a grade to states according to a formula based on the number of laws in place to fight child sex trafficking, the enforcement of such laws, and the number of prosecuted traffickers. After assigning a grade, the Polaris Project develops legal analyses and criminal justice recommendations for how to improve the grade. The Polaris Project works to help trafficking victims through a carceral feminist approach - relying on the threat of criminality to deter third parties from facilitating sex slavery.

Even with the attention to prosecuting trafficking and helping victims by providing them social supports, an article by Roby, Turley, and Garrick (2008) asks the question (in its title), "U.S. Response to Human Trafficking: Is it Enough?" The article acknowledges that, as of publication, there was no empirical data on the prevalence and severity of human trafficking taking place in the United States. This is concerning to the authors given the federal commitment to invest in rigorous and quality research that will lead to eradicating demand. They recount that with the passage of the TVPA there were promises of increased funding for law enforcement, yet the rates of victims continue to 
increase. Roby and others (2008) note that even among human service professionals there are many perspectives on how to address the needs of human trafficking victims which leads to an ambivalence on how to address the topic.

Multiple perspectives on how to address the legal tensions related to the sex trade were present in syllabi. Some courses included classroom debates on the "pros and cons" of legalizing prostitution, and one interview participant who used debate mentioned that many students who had initially been against legalizing prostitution switched sides by the end. Students realized that that legalizing prostitution would actually be more beneficial and supportive to those experiencing abuse, violence, and trafficking (Interview, SW20, August 2017).

The documentary I am Jane Doe (2017) appeared in two syllabi and follows the journey of mothers and teens who were kidnapped in middle school and coerced into sex trade. Once reunited with their families, they collectively sued Backpage.com for helping facilitate the trafficking of minors. Following years of organizing, garnering legal and legislative support, and acquiring the support of anti-trafficking advocates and activists across the country, they won the case and shut the Adult Services section of www.BackPage.com down. The legal victory against Backpage.com was an affirmation of justice for the families devastated and traumatized by the kidnapping of their children. In multi-system collaborations, social workers depend on international, federal, state, and local policies implemented to stop the sex trade and protect the vulnerable by advocating the carceral punishment of third parties who violate human rights. The Violence Against Women Act (1991) is one of the policies that has served many survivors of violence by aiding them with housing and employment opportunities by 
increasing the amount of funding allocated to and by the criminal justice system. By criminalizing domestic violence, survivors were meant to feel protected knowing that their abuser may be deterred by the threat of serving prison time.

Other content included in syllabi focused federal policies are outlined in Table 10. 


\section{Table 10}

\section{"Federal and state policies"}

\begin{tabular}{|c|c|c|}
\hline Title of Content & Author & Type \\
\hline I Am Jane Doe & Mary Mazzio & Film \\
\hline $\begin{array}{l}\text { Sexual Trafficking in the United States: A } \\
\text { Domestic Problem with Transnational } \\
\text { Dimensions }\end{array}$ & David Hodge (2005) & Article \\
\hline Report Cards & $\begin{array}{l}\text { Shared Hope } \\
\text { http://sharedhope.org/reportcar } \\
\text { ds }\end{array}$ & State Laws \\
\hline State and Federal Laws & $\begin{array}{l}\text { Polaris } \\
\text { http://www.polarisproject.org/r } \\
\text { esources/state-and federal-laws }\end{array}$ & $\begin{array}{l}\text { Organizational } \\
\text { website }\end{array}$ \\
\hline The Economics of HT, Verite Report & www.verite.org & Weekly Topic \\
\hline $\begin{array}{l}\text { Criminal Justice System \& Legislative } \\
\text { Responses (Sex Trafficking \& CSE) }\end{array}$ & Ch. 9 in Nichols & Chapter \\
\hline $\begin{array}{l}\text { Violence Against Women and Dept of } \\
\text { Justice Reauthorization Act of } 2005\end{array}$ & $\begin{array}{l}\text { H.R. } 3402 \\
\text { Sponsor: Rep. James } \\
\text { Sensenbrenner }\end{array}$ & Policy document \\
\hline $\begin{array}{l}\text { Council of Europe Convention on Action } \\
\text { Against Trafficking in Human Beings } 2008\end{array}$ & United Nations & Document \\
\hline Violence Against Women Act 2013 & $\begin{array}{l}\text { S. } 47 \text { Sponsored by: Senator } \\
\text { Patrick Leahy }\end{array}$ & Policy document \\
\hline $\begin{array}{l}\text { Victims of Trafficking and Violence } \\
\text { Protection Act } 2000\end{array}$ & $\begin{array}{l}\text { Sponsored by: Rep. Christoper } \\
\text { H. Smith }\end{array}$ & $\begin{array}{l}\text { Policy } \\
\text { Document }\end{array}$ \\
\hline $\begin{array}{l}\text { United Nations Convention Against } \\
\text { Transnational Organized Crime } 2000\end{array}$ & United Nations & $\begin{array}{l}\text { Policy } \\
\text { Document }\end{array}$ \\
\hline Mann Act of 1910 & James Robert Mann & $\begin{array}{l}\text { Policy } \\
\text { Document }\end{array}$ \\
\hline
\end{tabular}




\begin{tabular}{|c|c|c|}
\hline $\begin{array}{l}\text { The violence of Silence: Survivor } \\
\text { Testimony in Political Struggle }\end{array}$ & Catherine Mackinnon & Book Chapter \\
\hline Protocol on the 'Sale of Children' & United Nations & $\begin{array}{l}\text { Policy } \\
\text { Document }\end{array}$ \\
\hline Prostitution and Trauma in U.S. Rape Law & Michelle J. Anderson (2004) & Journal Article \\
\hline $\begin{array}{l}\text { U.S. Response to Human Trafficking: Is it } \\
\text { Enough? }\end{array}$ & $\begin{array}{l}\text { Roby, Turley, and Garrick } \\
(2008)\end{array}$ & Journal Article \\
\hline $\begin{array}{l}\text { United Nations Protocol to Prevent, } \\
\text { Suppress and Punish Trafficking in } \\
\text { Persons, Especially Women and Children }\end{array}$ & United Nations & $\begin{array}{l}\text { Policy } \\
\text { Document }\end{array}$ \\
\hline $\begin{array}{l}\text { Women and Children in the Global Sex } \\
\text { Trade: Toward More Effective Policy }\end{array}$ & Roby, J. (2005) & Book Chapter \\
\hline $\begin{array}{l}\text { CEDAW Convention on the Elimination of } \\
\text { all Forms of Discrimination Against } \\
\text { Women (International Bill of Rights for } \\
\text { Women) }\end{array}$ & CEDAW & $\begin{array}{l}\text { Policy } \\
\text { Document }\end{array}$ \\
\hline $\begin{array}{l}100 \text { Countries and Their Prostitution } \\
\text { Policies }\end{array}$ & $\begin{array}{l}\underline{\mathrm{http}: / / \text { prostitution.procon.org } / \mathrm{v}} \\
\underline{\text { iew.resource.php?resourceID }=} \\
\underline{000772}\end{array}$ & $\begin{array}{l}\text { Organizational } \\
\text { website }\end{array}$ \\
\hline $\begin{array}{l}\text { Victim testimonies of Irina Veselykh \& } \\
\text { Masha Gnezdilova (trafficked into } \\
\text { Germany to work as prostitutes during the } \\
\text { World Cup). }\end{array}$ & $\begin{array}{l}\text { Hon. Christopher H. Smith, } \\
2006\end{array}$ & Testimony \\
\hline
\end{tabular}

\section{Instructors Socialize Students to Grasp the Experiences of People in the Sex Trades}

Ample content addressed the role of social workers in meeting the needs of people in the sex trades. Students are oriented to understand the psychological trauma experienced by survivors of human trafficking, the role of professional intervention, and the need to critically engage with research, policy, theoretical debates, and social work practices. Further, human trafficking is regarded as "modern-day slavery," and thus social 
workers are encouraged to work with law enforcement, domestic and international NGOs, and evangelical anti-trafficking activists to prevent trafficking and rescue women and girls in the sex trades from slavery. Finally, feminist abolitionist theory is used in course content to underscore the necessity of eradicating all sex trade as a form of gender-based violence under patriarchy.

"Vigilante Rescue" will help end global sex trade. Throughout the data, one mission is clear: social workers, other helping professionals, NGOs, and street outreach workers must be part of stopping the global sex trade. Tips for identifying victims and pimps - both domestically and transnationally - appear in syllabi in the form of articles, organizational literature, and documentaries. Elena Shih uses the term "vigilante rescue ${ }^{11}$ " to describe organizing "concerned citizens" to rescue victims of sex trafficking. Social work engage in vigilante rescue as they teach students to be on the lookout for someone who exhibits signs victimization of trafficking.

Although Carole Vance is not included in the sample of course content for this study, her analyses of anti-sex trafficking documentaries prove useful for examining multiple types of content found in this project. Vance (2012) discusses the melodramatic expression of anti-sex trafficking documentaries meant to invoke fear, panic, and action with the term "melomentary." Examples of melodramatic films include, "Selling of Innocents: Fight to End Sex Trafficking in India", and "Fields of Mudan," both of which show up repeatedly in syllabi and portray the young and innocent victims of sex

\footnotetext{
${ }^{11}$ Elena Shih uses the term "Vigilante Rescue" to describe the ways that "concerned citizens" learn that human trafficking is everywhere, yet they can't see it because it is criminal behavior and takes place in the illicit economy. Therefore, the public is taught to look for various markers of trafficking that are also markers of poverty, recent immigration status, sexualized femininity, and racial and ethnic differences.
} 
trafficking and sex slavery in the Global South. These films inspire a sense of urgency to stop the sexual exploitation of women and children globally. Other content titles in syllabi include, "Halting the Trafficking of Women \& Children in Thailand for the Sex Trade: Progress and Challenges" (Engstrom, Minas, Espinoza, \& Jones, 2004), and "Blazing Trails, Confronting Challenges: The Sexual Exploitation of Women and Girls in the Philippines" (Hughes, 2000). Further, titles such as, "Mail order Brides in a Global World" (Belleau, 2003), "Prostitution and Trafficking of Women and Children from Mexico to the United States (Ugarte, Zarate, Farley, 2004)”, and “From Duty to Despair: Brothel Prostitution in Cambodia" (Freed, 2004) remind social workers just how vulnerable women and children are to becoming caught in the global sex trade for life. Students can simply glance over content titles on the syllabus to gain a sense of issues that plague the sex trade.

Vance (2012) remarks that casting women and children in the sex trades draws on narratives of vulnerability, blamelessness, and innocence to rationalize the need for rescuing and restoring them to family and communities. Melodramatic discourse causes an emotional experience by encouraging viewers or readers to imagine the vulnerable, realize that they could be your daughter, sister, or wife, and acknowledge that trafficking could happen in your own backyard.

The narrative of vulnerability, innocence, and helplessness has proved powerful in pushing social workers, NGOs, celebrities, policy makers, and missionaries into action and work with victims of sex trafficking. Consequently, because such narratives depend on exaggerated and one-dimensional realities to define victim experiences, social workers subscribing to these narratives may inadvertently harm people in the sex trades. 
Additionally, should a victim of trafficking not present to law enforcement or social workers as fitting the typical "victim" profile, they could be overlooked, arrested, or not provided services or support. People working in the sex trades who do work with third parties to acquire customers rarely disclose that they feel victimized and forced to engage in prostitution, despite how outsiders perceive their experience (Dank, 2012; Lutnick, 2016).

For further content used to construct this theme and section, see Table 11.

\section{Table 11}

“'Vigilante Rescue’ will help end global sex trade"

\begin{tabular}{|l|l|l|}
\hline \multicolumn{1}{|c|}{ Title of Content } & \multicolumn{1}{|c|}{ Author } & \multicolumn{1}{|c|}{ Type } \\
\hline $\begin{array}{l}\text { Selling of Innocents: Fight to End Sex } \\
\text { Trafficking in India }\end{array}$ & $\begin{array}{l}\text { Aapne Aap Women } \\
\text { Worldwide Foundation }\end{array}$ & Film \\
\hline Natasha Trade & Donna Hughes & $\begin{array}{l}\text { Journal } \\
\text { Article }\end{array}$ \\
\hline Fields of Mudan & Michael Wagner, 2004 & Film \\
\hline $\begin{array}{l}\text { Prostitutes of God, "Religious Prostitution in } \\
\text { Southern India Dating Back to the 6 }\end{array}$ & VICE staff & Film \\
\hline $\begin{array}{l}\text { From Duty to Despair: Brothel Prostitution in } \\
\text { Cambodia }\end{array}$ & Melissa Farley & $\begin{array}{l}\text { Journal } \\
\text { Article }\end{array}$ \\
\hline $\begin{array}{l}\text { Halting the Trafficking of Women \& Children in } \\
\text { Thailand for the Sex Trade: Progress and } \\
\text { Challenges }\end{array}$ & $\begin{array}{l}\text { Engstrom, Minas, } \\
\text { Espinoza, \& Jones (2004). }\end{array}$ & $\begin{array}{l}\text { Journal } \\
\text { Article }\end{array}$ \\
\hline $\begin{array}{l}\text { Blazing Trails, Confronting Challenges: The } \\
\text { Sexual Exploitation of Women and Girls in the } \\
\text { Philippines. }\end{array}$ & $\begin{array}{l}\text { Santos, AF in Hughes, D } \\
\text { \& Roche, C. }\end{array}$ & $\begin{array}{l}\text { Chapter in } \\
\text { CATW } \\
\text { collection }\end{array}$ \\
\hline $\begin{array}{l}\text { Prostitution and Trafficking of Women and } \\
\text { Children from Mexico to the United States. }\end{array}$ & $\begin{array}{l}\text { Marisa Ugarte, Laura } \\
\text { Zarate, \& Melissa Farley } \\
\text { (2008) }\end{array}$ & $\begin{array}{l}\text { Journal } \\
\text { Article }\end{array}$ \\
\hline
\end{tabular}




\begin{tabular}{|l|l|l|}
\hline Sex Workers of Havana: The Lure of Things. & G.D Hodge (2007) & $\begin{array}{l}\text { Online } \\
\text { magazine }\end{array}$ \\
\hline $\begin{array}{l}\text { Sex Trafficking: The Global Market of Women } \\
\text { and Children }\end{array}$ & Farr, K. (2004) & Book \\
\hline $\begin{array}{l}\text { Discussion of the politics of prostitution in India } \\
\text { to a student group from Indiana on study abroad } \\
1-2 \text { week trip }\end{array}$ & $\begin{array}{l}\text { Lalit Khandare \& Haresh } \\
\text { Dalvi }\end{array}$ & $\begin{array}{l}\text { Guest } \\
\text { Speakers }\end{array}$ \\
\hline $\begin{array}{l}\text { International Sex Trafficking: Understanding the } \\
\text { Global Epidemic }\end{array}$ & $\begin{array}{l}\text { Leonard Territo \& George } \\
\text { Kirkham, 2010. }\end{array}$ & $\begin{array}{l}\text { Journal } \\
\text { Article }\end{array}$ \\
\hline Mail Order Brides in a Global World & Marie-Claire Belleau & Text \\
\hline
\end{tabular}

Feminist abolitionism. Feminist abolitionism developed out of radical feminist theory and focuses on abolishing the patriarchy and eradicating sites of violence against women perpetuated by men. Feminist abolitionists (along with other radical feminists) believe that pornography and prostitution are venues of violence against women and as such should be outlawed and abolished (Bryson, 1992; Rudy, 2001). From a feminist abolitionist lens, eradicating the sex trade is the only way to save women from being enticed into the sex industry. Vigilante rescue groups are informed by the radical framing of prostitution as site for perpetuating violence against women and therefore strive to identify potential victims of sex trafficking to rescue them from a life of sexual violence.

Feminist abolitionist content was included in some syllabi as one strand among other feminist theories to explore the sex trades, while in other syllabi it was the only feminist theory used to represent "the feminist perspective." SW12 emphasized that she includes multiple theoretical perspectives in her course so that students have enough 
information to critically think about how race, class, and gender impact people in the sex trades. SW12 said,

And I have all the feminist perspectives in there too. The radical feminists, who look at the whole patriarchal aspect of pornography and prostitution, and those who look at the rights of individual to decide what to do with their body and earn their living. [...] I also bring in the specific vulnerabilities of the LGBTQ population. (Interview, SW12, August 2017)

Feminist abolitionist theory and writings in syllabi such as, "In Defense of Feminist Abolitionism" (Madden \& Dempsey, 2011) and, "Towards an Abolitionist Approach to Prostitution and Trafficking" (Hughes, 2004) help construct the importance of criminalization to stop sex trafficking and prostitution as well as prevent the violence attached to the sex trade via prostitution, coercion, choice, survival, or circumstance.

Furthermore, pornography, visible prostitution, and participation in the sex industry were named in course content as factors that allow violence to occur against people in the sex trades. In her speech that titled "Demand and Debate," the CoExecutive Director of the Coalition Against the Trafficking in Women (CATW) Dorchen Leidholdt acknowledges the different perspectives among feminist activists related to the sex industry, but argues that prostitution has led to severe violence against women and should be eradicated.

When used in isolation, feminist abolitionism can be dangerous to the clients of social workers. By relying solely on this theoretical tradition, social workers could unintentionally make their clients vulnerable to violence, incarceration, and further 
poverty by advocating for policy and services that limit access to financial resources and clandestine sex trade. Most recently, the Stop Enabling Sex Traffickers Act and Allow States and Victims to Fight Online Sex Trafficking Act (FOSTA/SESTA) was passed in both the House and Senate, nominally to eliminate violence against women (Cole, 2018). This act targets the Internet's role in the sex trade, thereby forcing sex workers to find more conspicuous venues for engaging in sex work, in turn making them more vulnerable to being criminalized for offenses like public sex and loitering. Moreover, people in the sex trades face the further likelihood of violence because perpetrators know that the law will not protect the sex worker (who is breaking the law). For some people sex trade is the most viable way to make a living, particularly trans or cisgender women of color, LGBQ, youth and minors living on the street, using drugs, undocumented immigrants and others who are systematically excluded from the employment force (Dank, 2012). With carceral consequences for those found guilty of pimping, trafficking, pandering, or prostitution, carceral feminist activism and feminist abolitionism contribute to the mass incarceration and enslavement of communities of color.

Table 12 shows the content used to develop the sub-theme, "Feminist abolitionism" for this section.

\section{Table 12}

\section{"Feminist abolitionism"}

\begin{tabular}{|l|l|c|}
\hline \multicolumn{1}{|c|}{ Title of Content } & \multicolumn{1}{|c|}{ Author } & \multicolumn{1}{c|}{ Type } \\
\hline $\begin{array}{l}\text { In Defense of Feminist } \\
\text { Abolitionism }\end{array}$ & M. Madden-Dempsey (2011) & Law Review Journal \\
\hline
\end{tabular}




\begin{tabular}{|l|l|l|}
\hline $\begin{array}{l}\text { Feminism in the } 21^{\text {st }} \\
\text { Century }\end{array}$ & Chesler, P. \& Donna Hughes, 2004 & Online Newspaper Article \\
\hline $\begin{array}{l}\text { Towards an } \\
\text { Abolitionist Approach } \\
\text { to Prostitution and } \\
\text { Trafficking }\end{array}$ & Donna Hughes & $\begin{array}{l}\text { Speech to Czech Republic } \\
\text { Parliament }\end{array}$ \\
\hline $\begin{array}{l}\text { Prostitution is Sexual } \\
\text { Violence in Psychiatric } \\
\text { Times, XXI(12) }\end{array}$ & Melissa Farley (2004) & Journal Article \\
\hline $\begin{array}{l}\text { Is Prostitution } \\
\text { Empowering If You } \\
\text { Choose to Do It? }\end{array}$ & $\begin{array}{l}\text { Megan Murphy. (2016). } \\
\text { https://verilymag.com/2016/04/new- } \\
\text { york-magazine-prostitution-porn- } \\
\text { feminism-news-1204 }\end{array}$ & Online magazine \\
\hline
\end{tabular}

Social workers need to collaborate. Professional partnerships and collaborations with the adult and juvenile criminal justice systems, politicians, medical providers, legal advocates, and other social services are deemed paramount by social workers to help people in the sex trades. In particular, film, guest speakers, articles, and book chapters found in syllabi emphasize the importance of collaboration across multiple systems to rescue victims of sex trafficking. One article on social justice and spiritual healing discusses collaboration between faith-based services, social workers, and law enforcement to help prostitution survivors recover from trauma (Perdue, Prior, Williamson, \& Sherman, 2012). The article draws on the work of a program (RISE) housed within the Salvation Army ${ }^{12}$ in Northeast Ohio that recognizes human trafficking as modern slavery. RISE believes that building a coalition of social service providers, law

\footnotetext{
${ }^{12}$ An international movement out of an evangelical part of the universal Christian church, whose message is based on the Bible and ministry motivated by the love of God.
} 
enforcement, and legal advocates and prosecutors can aid victims in accessing services to help them recover from trauma (RISE, 2018).

An example of video content that captured multi-institutional collaboration was a short news documentary titled, "CNN Trafficking Raid in India," which documented investigative journalists from $\mathrm{CNN}$ entering a brothel in India with local law enforcement to remove victims of sexual exploitation. Sex worker activists around the globe have critiqued the use of raids to remove sex workers from their places of employment, specifically because such removal makes sex workers more vulnerable to violence. These raids bring together violent and corrupt law enforcement, social workers from NGOs, and missionaries to remove many people from their sole source of income; yet the media represents the rescuers as heroes.

Rescue operations like the $\mathrm{CNN}$ raids are supported by international NGOs that have developed in the Global South to rescue women and girls from sex slavery by giving them a place to live and teaching them a trade through their agency. NGOs such as the International Justice Mission (IJM), Sari Bari, $8^{\text {th }}$ day Café, UNICEF, ECPAT, and Effect International were highlighted in course syllabi as examples of social entrepreneurship models to "rescue and restore" women to their homes and families by teaching them a skill or trade that can be used to earn an income. For example, one syllabus for a two-week study abroad course specifically stated that the students would be travelling to India to learn more about the partnerships between law enforcement, International Justice Mission, and a survivor entrepreneurship program called Sari Bari. The mission statement on Sari Bari's website says that the company employs survivors of "Kolkata's red light areas who have taken brave steps into new life, freedom, and hope" 
to hand-make products out of recycled saris. On Sari Bari's website, products are marketed by telling buyers that, "each Sari Bari product is marked with the name of the woman who made it and with your purchase you become a part of her freedom story" (Sari Bari, 2018). I interviewed SW11, who taught the study abroad course, and she explained that Sari Bari is able to sell their products in the U.S. and make a large profit based on the appeal of helping survivors of sex trafficking.

Additionally, Sari Bari collaborates with other NGOs that aim to help survivors of sex trafficking by employing them and helping them learn a trade and sell products. They collaborate with $8^{\text {th }}$ Day Café ${ }^{13}$ (http://8thdaycafe.com/), Rahab's Rope ${ }^{14}$ (https://www.rahabsrope.com/), and The Loyal Workshop ${ }^{15}$ (https://www.theloyalworkshop.com/). From my interview with SW11, who led the trip to "learn about culture and trafficking in India," I was told that these NGOs collaborate by selling goods in the café, and the leather making company provides handles for Sari Bari satchels; this collaboration allows cross-promotion among NGOs. Each of these organizations works closely with one another and with the International Justice Mission (IJM) to identify human trafficking survivors and provide them with services.

IJM works with INTERPOL ${ }^{16}$ to conduct brothel raids and rescue women and girls assumed to be victims of trafficking based on their participation in the sex trade. After the rescue intervention, IJM attempts to place the rescued with organizations to help them with their social, physical, emotional, housing, and employment needs.

\footnotetext{
13 8th Day Cafe is an American-style bakery and cafe in Kolkata

${ }^{14}$ Rahab's Rope is a mission-based NGO that serves to give hope and opportunity to the women and girls at risk of or who have been forced into the commercial sex trade of India

15 The Loyal Workshop is a small ethical leather-making company that provides employment alternatives to survivors of human trafficking in India.

${ }^{16}$ INTERPOL: International Criminal Police Organization
} 
Organizations like IJM, Sari Bari, Rahab’s Rope, and The Loyal Workshop purport to empower survivors of trafficking by teaching them a trade and providing them with services to meet their daily needs. At the same time, these rescue- and empowermentbased agencies generate profit off of the labor of the exploited they claim to help (Chaudry, 2016).

Survivor entrepreneurship opportunities continue to develop in the United States as well. Each of the NGOs named above has partner organizations located in the United States and some are used as examples for others to develop upon. Annie Lorber, a guest speaker for one of the courses in my data sample and founder of Hookers for Jesus, started a safehouse for "lady" survivors of the commercial sex industry, "after surviving her own experience working in Las Vegas, overdosing on drugs, and coming to an epiphany with God" (Lorber, 2014). Lorber's organization provides 6-12 month housing, counseling, life-skills training, nutritional education, spiritual guidance, fitness instruction, and other educational opportunities.

Additional content found in course syllabi on "how to recognize" trafficking victims and "how to protect" children is intrinsic to the work of the aforementioned international and domestic NGOs. For instance, a report from the United States Department of State, "How Can I Recognize Trafficking Victims," The Handbook to Combat Trafficking in Children: Chapter for Religious Leaders produced by UNICEF, and the proposal from the Office of Juvenile Justice and Delinquency Prevention, "Protecting our Children: Working Together to End Child Prostitution" (2002), assist organizations in recognizing the physical, emotional, and geographical characteristics of 
those who are at risk of or likely to be found engaging in sex trade, and the importance of rescue from a life of sexual exploitation.

Table 13 includes additional content used to construct the theme covered in this section.

\section{Table 13}

\section{"Social workers need to collaborate"}

\begin{tabular}{|l|l|l|}
\hline \multicolumn{1}{|c|}{ Title of Content } & \multicolumn{1}{|c|}{ Author } & \multicolumn{1}{|c|}{ Type } \\
\hline CNN Trafficking Raid in India & CNN & Video \\
\hline Half the Sky & Kristof \& WuDunn (2010) & Text \\
\hline Hands that Heal Curriculum & $\begin{array}{l}\text { Faith Alliance Against } \\
\text { Slavery and Trafficking }\end{array}$ & Organizational Website \\
\hline Hookers for Jesus & Annie Lobert & Guest Speaker \\
\hline $\begin{array}{l}\text { The Challenges of Fighting Sex } \\
\text { Trafficking in the Legalized } \\
\text { Market of the Netherlands }\end{array}$ & http://prostitution.procon.org & Text \\
\hline $\begin{array}{l}\text { How Can I Recognize Trafficking } \\
\text { Victims }\end{array}$ & U.S. Dept of State & Document \\
\hline $\begin{array}{l}\text { Trafficking of Children for } \\
\text { Prostitution: Protecting Our } \\
\text { Children: Working Together to } \\
\text { End Child Prostitution. }\end{array}$ & Donna Hughes & Conference Speech \\
\hline $\begin{array}{l}\text { Handbook to Combat Trafficking } \\
\text { in Children: Chapter for Religious } \\
\text { Leaders }\end{array}$ & UNICEF & Website/NGO \\
\hline
\end{tabular}




\begin{tabular}{|c|c|c|}
\hline $\begin{array}{l}\text { ECPAT (based in Thailand, has } \\
\text { mission to fight CSE of children) }\end{array}$ & www.ecpat.net & Website \\
\hline $\begin{array}{l}\text { Process of working with local law } \\
\text { enforcement to do raids on brothels } \\
\text { and undercover rescues for under- } \\
\text { aged girls sold into prostitution }\end{array}$ & Biju Matthew, IJM Director & Discussion \\
\hline $\begin{array}{l}\text { Discussion about work with } \\
\text { SariBari }\end{array}$ & Course co-facilitator & Guest Speaker \\
\hline History and Mission of SariBari & www.saribari.com & Text \\
\hline International Justice Mission & www.ijm.org/ & Website \\
\hline The Loyal Workshop & $\begin{array}{l}\text { www.theloyalworkshop.com } \\
\text { / }\end{array}$ & Website \\
\hline Rahab's Rope & www.rahabsrope.com & Website \\
\hline $8^{\text {th }}$ Day Cafe & $\begin{array}{l}\text { http://8thdaycafe.com/missio } \\
\mathrm{n}\end{array}$ & Website \\
\hline Sari Bari & www.saribari.com & $\mathrm{NGO}$ \\
\hline
\end{tabular}

Research. Both syllabus content and interviews with faculty focused on the necessity for social workers to engage in research, identify policy opportunities, and implement innovative services. Nestled within the syllabus content were texts arguing for theoretical frameworks that help students understand how changing migration patterns, labor conditions, and neoliberal policies have created the conditions that facilitate the sex trade. For example, an MSW class on human development includes the article, "New Directions in Research on Human Trafficking" (Weitzer, 2014), which acknowledges that 190 
anti-trafficking discourse and enforcement of sex trafficking has relied on anecdotal claims that have gone unsubstantiated by rigorous academic research. Such claims highlight discrepancies in statistics that describe the magnitude of sex trafficking across the world, but almost uniformly publicize the issue as one on the rise. While labor trafficking crosses many economic sectors and exploits workers through long hours, reduced wages, physical beatings and sexual assault, it has consistently been ignored in public discourse. Weitzer (2014) bridges concerns about migration policies, labor policies, and the overarching neoliberal discourse that perpetuates the criminalization and enforcement of those assumed to be trafficking young women, while those benefitting off of the exploitation of migrant laborers go unnoticed.

One of my interview participants further addressed politics inherent to the sex industry. SW2 says,

That differentiation [of prostitution and sex work] is very political. Isn't even sex work labor? Why do we separate those out in the protocols? The United States had a vested interest in criminalizing prostitution and a specific intention in separating Sex Trafficking (ST) from Labor Trafficking (LT). They had federal money that couldn't go to anything that supported prostitution-related work. The political decision to talk about trafficking and separate ST and LT was not about exploitation, it was about political expediency. And the US being able to further their agenda and their assumptions about prostitution being criminal. (Interview, SW2, June 2017) 
SW2's comments expose the influence of capitalist politics on implementing policies confined to sex trafficking while ignoring labor trafficking.

When asked what social work students need to know about working with people in the sex trades, SW13 spoke to the importance of being able to apply various theories to the behaviors of people in the sex trades. Additionally, she commented that these theories can be applied in the context of research opportunities and questions posed by community-based social service agencies. Further, SW13 remarked that social workers should not have an agenda when engaging in community-based research. She goes on to say, $[\ldots]$ they need to participate with researchers and not push us away because they think we are giving them more work to do and [that] it's irrelevant. Granted research takes a long time to do and disseminate so I can see the disconnect--you do all this stuff and then there is no reward [...] We need to help them do their job and not be agenda-driven, help policy makers make better policies and not be ideologically driven. (Interview, SW13, June 2017)

Most of the syllabi included content that demonstrated the need for social work engagement with practice, research, and theory. Examples of such texts found in syllabi included, Human Trafficking: Applying Research, Theory, and Case Studies (BuschArmendariz, Nsonwu, \& Heffron, 2018), Sex Trafficking in the U.S.: Theory, Research, Policy, and Practice (Nichols, 2016), and "Sex Trafficking \& Commercial Sexual Exploitation of LGBTQ People: Implications for Practice" (Dank, 2012). Each of the above references offers a nod to understanding that harsh criminal consequences people 
engaged in sex trade despite their experiences of choice, empowerment, force, coercion or exploitation.

An analysis of a world without carceral institutions used for rehabilitation purposes is missing from these texts. In situating many experiences within the sex trade as complicated and facilitated through neoliberal social policies, one interview participant in my study disclosed that at the end of her book she recommends to establish Universal Health Care in the U.S., expand social safety nets, address inequality in social institutions such as education, healthcare, poverty, wage inequality, and mass incarceration. (Interview, SW1, June 2017, SW1)

SW1's recommendations do not rely on the use of rescue interventions to effectively help people in the sex trades, rather they engage with the structural systems that serve to shape the experiences of people in the sex trades, and reinforce the need to make money through underground economic opportunities.

SW1 focuses on structural recommendations at the macro level as a way of highlighting the consequences of interventions simply focused on rescue. For example, youth and adults in the sex trades face consequences when they are arrested by law enforcement under the guise of help. Consequences like being held in detention when deemed a victim of sex trade, losing parental rights to children, being returned to abusive home conditions, and being turned into welfare case managers set up barriers in the lives of young people trying to survive by engaging in sex trade. Such consequences are important for social workers to pay close attention to, particularly as they relate to criminal consequences such as felony records that prevent access to housing, educational 
opportunities, and living wage jobs, that may await youth in the sex trades who are already marginalized.

See Table 14 for content found in syllabi that I used to develop the theme for this section. 


\section{Table 14}

\section{"Research"}

\begin{tabular}{|c|c|c|}
\hline Title of Content & Author & Type \\
\hline $\begin{array}{l}\text { Social Work Practice With Survivors } \\
\text { of Sex Trafficking and Commercial } \\
\text { Sexual Exploitation }\end{array}$ & $\begin{array}{l}\text { Nichols, A, Edmond, } \\
\text { T, Heil } \\
\text { 2017) }\end{array}$ & Book Chapter \\
\hline $\begin{array}{l}\text { Sex Trafficking \& Commercial } \\
\text { Sexual Exploitation of LGBTQ } \\
\text { People: Implications for Practice }\end{array}$ & $\begin{array}{l}\text { Ch. } 10 \text { A. Nichols SW } \\
\text { Practice within... }\end{array}$ & Book Chapter \\
\hline $\begin{array}{l}\text { Sex Trafficking in the U.S.: Theory, } \\
\text { Research, Policy and Practice }\end{array}$ & Nichols, A. (2016). & Book Chapter \\
\hline Discussion of Findings & $\begin{array}{l}\text { Shared Hope } \\
\text { International Research }\end{array}$ & Organizational Website \\
\hline $\begin{array}{l}\text { Human Trafficking: Applying } \\
\text { Research, Theory and Case Studies. }\end{array}$ & $\begin{array}{l}\text { Busch-Armendariz, } \\
\text { Nsonwu, Heffron } \\
(2017)\end{array}$ & Book \\
\hline $\begin{array}{l}\text { New Directions in Research on } \\
\text { Human Trafficking }\end{array}$ & Weitzer, R. (2014). & Journal Article \\
\hline Prostitution in 9 Countries & $\begin{array}{l}\text { NYMag.com } \\
\text { verilymag.com }\end{array}$ & Web-based magazine \\
\hline
\end{tabular}

Talk about sex. Not only can social workers employ an anti-oppressive praxis in their work with sex trade workers, they can and in some states are required to engage with issues related to sex and sexuality. Of the twenty syllabi, four courses were specifically focused on the intersections of sexuality and social work, and included topics and texts related to the sex trade. The content for these courses specifically used the language of "sex work." The use of the term "sex work" in content used for sexuality and 
social work courses suggests that social workers should recognize the constellation of experiences within the sex trades that may include, but extends beyond victimization. For example, articles and conversations about sex work were included in class sessions titled, "Sex and Power," "Cross-Cultural Issues," and "Concepts of Normalcy."

In a sexuality and social work class, one journal article and one book chapter demonstrateed the need for social workers to be comfortable talking about sex, sexuality, sexual trauma, sexual empowerment and sexual grief across the diverse communities they will work with. In "Imag(in)ing Possibilities: The Psycho-Therapeutic Potential of Queer Pornography," Keiko Lane (2013) shares her professional therapeutic reflexive process around the possibilities of pornography. To begin the chapter, Lane draws on an early career moment in which the influence of "pornography as violence" led to her betraying a client who struggled with shame around desiring consensual sexual power. Lane further shares her development as a psycho-somatic therapist teaching graduate students to seek out as much explicit sexual information as possible for the benefit of themselves and their clients. Central to their book chapter, Lane acknowledges that pornography can be an avenue for learning about and exploring both desire and grief particularly at the intersections of sexuality, desire, shame, gender identity, racism, trauma, and grief (2013). A journal article, in the same course syllabus, titled "Gay-for-Pay: Straight Men and the Making of Gay Pornography (Escoffer, 2003) draws on the term "situational homosexuality" (Kunzel, 1999 as cited in Escoffer, 2003) to analyze the contexts in which men engage in sexual behavior with other men in which they reap a reward. The article steps outside of sexual identity, and examines sexual behavior as socially, culturally, socio-structurally, and economically situated. Escoffer draws on examples of 
"homosexuality" in historically same-sex institutional settings (like prisons, boarding schools, and military barracks) where people who do not identify as gay in other settings draw on "sexual scripts" (Gagnon \& Simon, 1973 as cited in Escoffer, 2003, p. 33) to engage in sex. Sex workers, homeless youth, and porn actors are named as those who must draw on economically situated sexualities to do their work and get their needs met. This article introduces a range of entry points for social work students to engage with. As readers interrogate the non-normative and hegemonic ideas asserted in the article, they essentially build skill in theorizing, applying, and discussing topics of sex and sexuality in a social work context.

Other sex work content in syllabi included a chapter on sex work and social work practice (Ingersoll \& Satterly, 2014), a discussion led by a former sex worker about how macro issues like economic inequality and educational inequality impact people in the sex trades, and a class debate on legalizing prostitution within a class session titled, "Paraphilias, Sexual Addictions, Pornography."

Overall, lessons about the importance of developing a comfort with conversations about sex and sexuality are threaded throughout syllabi intersecting social work and sexuality studies. Content within these courses focused on micro and macro topics related to sex and sexuality. For instance, class material covered topics such as sex therapy, exploring sexual reflexivity, and journaling about one's own sexual journey. Macro issues spanned topics related to sex work and the sex trade to cover the intersections of social inequality and the sex trade, social movements and organizing on sexual justice, legalization, and expanding ideas of "sexual normalcy." 
The sex trade content found in social work and sexuality syllabi included topics of sexual history, sexuality, and sexual relationships. The social work faculty I interviewed teaching these courses felt it was important that these classes provided space for exploring sex work through moral, legal, and political lenses, given that the sex lives of people students will work with are political and intersect economic, racial, social, disability, housing, and sexual justice. In fact, when I asked one interview participant about what she thinks social workers most need to know to work with sex workers, she expanded on the importance of understanding moral, faith-based, and feminist arguments related to sex work,

They need to know about the hierarchy of johns and prostitutes. Understand how brothels work. Understand how policy defines prostitution and who gets hurt when there is an arrest. [...] I think they need to understand the moral argument, the religious literacy around it, particularly for people of faith - it is an historic profession--it is in the Bible. They need to understand feminist theory to get it. (Interview, SW2, August 2017)

SW2 and other social work faculty teaching courses that address sexuality in social work include policy debates around prostitution and human trafficking in class sessions on sex work. Faculty found these class sessions to be particularly informative for students as they learned that people in the sex trades interact with many social systems that both implicitly and explicitly regulate and monitor sex and sexuality. 
One instructor (SW1) described the sexuality class as a good venue to include sex trades content as it provided an opportunity to help students learn about themselves, their values, biases, and assumptions. In the interview, SW1 said,

Social workers should know the historical legacy of social work as a profession rescuing fallen women. They need to know the ways in which even today some social workers will remove children from care of parents, particularly if mom is involved in any type of sex work. (Interview, SW1, June 2017)

The sex trades content included in social work and sexuality classes demonstrates the temporal realities of sex work intersecting individuals, families, and communities that social workers engage.

In chapter 2 of this dissertation, I quoted Carly Kalish, a social worker who said that social workers working with young people trading sex have to be able to stomach that young people are having sex for money. Because much of the literature is on how sex trafficking impacts children, discussing minors and sex/sexuality becomes a contentious topic for some.

Below you will find Table 15, that outlines the content used to develop the section theme. 


\section{Table 15}

"Talk about Sex"

\begin{tabular}{|c|c|c|}
\hline Title of Content & Author & Type \\
\hline Sex \& Power & Instructor & Class Topic \\
\hline Cross-Cultural Issues & Instructor & Class Topic \\
\hline Sex Work and Social Work Practice & Ingersoll \& Satterly & $\begin{array}{l}\text { Chapter in } \\
\text { Textbook }\end{array}$ \\
\hline $\begin{array}{l}\text { Where's the Justice? Sex Workers' Rights in } \\
\text { Hungary }\end{array}$ & $\begin{array}{l}\text { Association of Hungarian } \\
\text { Sex Workers (SZEXE \& } \\
\text { HCLU) }\end{array}$ & Film \\
\hline $\begin{array}{l}\text { Discussion of macro issues, like economic } \\
\text { inequality and inequality in access to } \\
\text { education }\end{array}$ & Former sex worker & Guest Speaker \\
\hline The Danger of Coming Out as a Sex Worker & www.fusion.net & Web-blog \\
\hline $\begin{array}{l}\text { Stripclubs According to Strippers: Exposing } \\
\text { Workplace Sexual Violence }\end{array}$ & Holsopple, K. (1998). & Report \\
\hline $\begin{array}{l}\text { "Paraphilias, Sexual Addictions, } \\
\text { Pornography" }\end{array}$ & $\begin{array}{l}\text { Macro policy debate: } \\
\text { Legalization of } \\
\text { Prostitution }\end{array}$ & Class Session \\
\hline $\begin{array}{l}\text { Ch. } 9 \text { Special Topics, "Sex Work and Social } \\
\text { Work Practice }\end{array}$ & $\begin{array}{l}\text { Class Session: The } \\
\text { Concepts of Normalcy }\end{array}$ & Weekly Topic \\
\hline $\begin{array}{l}\text { Imag(in)ing Possibilities: The Psycho- } \\
\text { Therapeutic Potential of Queer Pornography }\end{array}$ & Lane, K. (2013) & Journal Article \\
\hline $\begin{array}{l}\text { Gay-for-Pay: Straight Men and the Making } \\
\text { of Gay Pornography }\end{array}$ & Escoffer, J. (2003) & Journal Article \\
\hline Sex Work & Instructor & Class Topic \\
\hline
\end{tabular}


Interrogate structural violence. The last theme speaks to an urgency to examine the ethics, harm, and violence of anti-trafficking interventions on those already vulnerable to criminalization. Importantly, content associated with this theme is rooted in critical feminist theories that illustrate how most people engaged in the sex trade will not benefit from rescue interventions, but rather would benefit from the dismantling of carceral institutions governed by neoliberalism and built upon the interconnectedness of racism, classism, sexism, cissexism, heterosexism, ableism, ethnocentrism.

Within this content, faculty incorporated articles titled, "Now You See Her, Now You Don't: Sex workers at the U.N. Trafficking Protocol Negotiations” (Doezema, 2005) to discuss the complexity and sanctions that result from the dramatization of narratives like, "trafficking is hidden in plain sight." Additionally, one course used our article, "Ethical and Human Rights Issues in Coercive Investigations With Sex Workers (Wahab \& Panichelli, 2013), which examines the ethical implications of social workers' participation in interventions that arrest sex workers in order to help them. One syllabus included a class session titled, "Erasure of People of Color in Anti-Trafficking Responses" and used an article titled, "Reclaiming their Lives and Breaking Free: An Afrocentric Approach to Recovery from Prostitution” (Valandra, 2007). Valandra's article focuses on a culturally specific agency that views prostitution as systematic violence against African-American women; the agency responds to the driving forces in the sex trade of poverty, violence, racism, classism, and sexism as they provide services to women in their program. An article found in syllabus content that acknowledges antitrafficking activism as nuanced, asks the question (as the title for their article), "Antitrafficking campaigns: Decent? Honest? Truthful?" (Andrijasevice \& Anderson, 2011). 
Further, the article, "The Myth of White Slavery in Contemporary Discourses of Trafficking in Women" (Doezema, 2005) potentially answers the question of deceit and the repercussions of anti-trafficking campaigns focused specifically on rescuing women and children from sex trafficking.

Content that breaks down binary narratives of people in the sex trade can help social work education examine various ways the sex trade shows up in the lives of people we work with. For example, Limoncelli’s (2009) article, “The Trouble with Trafficking: Conceptualizing Women's Labor and EconomicHuman Rights" reminds social workers to use a macro lens to consider how the experiences of people in the sex trades are shaped.

Additionally, Alexandra Lutnick's (2016) book Domestic Minor Sex Trafficking: Beyond Victims and Villains was included in two course syllabi. Lutnick interviewed case managers and social workers who worked with youth in the sex trades and found that almost uniformly, social service workers explained that the youth don't see themselves as victims. This finding contradicts the social work value of self-determination by using rescue and arrest-based interventions with youth in the sex trades.

Please refer to Table 16 to see the syllabi content used to construct the final theme of this chapter. 


\section{Table 16}

\section{"Interrogate structural violence"}

\begin{tabular}{|c|c|c|}
\hline Title of Content & Author & Type \\
\hline $\begin{array}{l}\text { Now You See Her, Now You Don't: Sex Workers at } \\
\text { the U.N. Trafficking Protocol Negotiations }\end{array}$ & Jo Doezema (2005) & Journal Article \\
\hline $\begin{array}{l}\text { Loose Women or Lost Women? The Re-emergence } \\
\text { of the Myth of White Slavery in Contemporary } \\
\text { Discourses of Trafficking in Women }\end{array}$ & Jo Doezema & Journal Article \\
\hline $\begin{array}{l}\text { Anti-Trafficking Campaigns: Decent? Honest? } \\
\text { Truthful? }\end{array}$ & $\begin{array}{l}\text { Andrijasevic and } \\
\text { Anderson }\end{array}$ & Journal Article \\
\hline Running from the Rescuers & Soderlund & Journal Article \\
\hline $\begin{array}{l}\text { Beyond Rescue: The Campaign Against Forced } \\
\text { Prostitution Works When it Addresses the Needs of } \\
\text { Victims }\end{array}$ & Thrupkaew & Journal Article \\
\hline $\begin{array}{l}\text { Trafficking and Prostitution Reconsidered New } \\
\text { Perspectives on Migration, sex work, and human } \\
\text { rights. }\end{array}$ & $\begin{array}{l}\text { Kamala Kempadoo } \\
\text { (2011) }\end{array}$ & Book \\
\hline $\begin{array}{l}\text { Domestic Minor Sex Trafficking: Beyond Victims } \\
\text { and Villains. }\end{array}$ & $\begin{array}{l}\text { Alexandra Lutnick } \\
(2016)\end{array}$ & Book \\
\hline $\begin{array}{l}\text { Ethical and Human Rights Issues in Coercive } \\
\text { Investigations With Sex Workers. }\end{array}$ & $\begin{array}{l}\text { Wahab \& } \\
\text { Panichelli (2013) }\end{array}$ & Editorial \\
\hline $\begin{array}{l}\text { A Perfect Storm: The U.S. Anti-Trafficking of } \\
\text { American Indian Women and Girls }\end{array}$ & Johnson, A. & $\begin{array}{l}\text { Human Rights } \\
\text { Law Review }\end{array}$ \\
\hline $\begin{array}{l}\text { Traffic Violations: Determining the Meaning of } \\
\text { Violence in Sexual Trafficking vs. Sex Work. }\end{array}$ & Penelope Saunders & Journal Article \\
\hline $\begin{array}{l}\text { The Trouble with Trafficking: Conceptualizing } \\
\text { Women's Sexual Labor and Economic Human } \\
\text { Rights. }\end{array}$ & Limoncelli & Journal Article \\
\hline
\end{tabular}




\section{Conclusion}

Overall, the opportunity to engage with critical-minded and well-intended scholars has been humbling and educational. Initially, the interviews felt regenerative and inspiring. Upon reviewing my research journal, I found myself surprised time and again at how frequently participants centered the goal of social justice and intersectionality in relation to the sex trades during interviews. The themes I've identified in this chapter demonstrate that people in the sex trades are represented in multiple ways, with a greater tendency towards a victim-based representation overall. However, content that complicates victimization was minimally present in my data sample. The findings illuminate vast perspectives and approaches to the sex trades.

During immersion in course content and interview transcripts I have experienced a wide array of emotions, existential crises, and frustration about the deep-seated influence that feminist abolitionist theory has held on social work. I remain puzzled by conversations with research participants who critiqued the role of structural racism, xenophobia, and issues of poverty in creating demand for sex trade and human trafficking, while including content in their course syllabus that emphasized the importance of working with law enforcement to incarcerate third parties. Interview participants were also honest about not knowing certain types of content or subjects and emphasized that they aim to stay open-minded to diverging perspectives. For example, SW4 reflected that a local anti-trafficking coalition she was involved with did not include sex worker rights activism, and felt that was problematic.

Throughout the analysis of course syllabi and interviews I found many contradictions between conversations, course descriptions and objectives, and the content 
used to teach students about the sex trades. Although social justice and intersectionality were named as foci of many courses, interview participants and syllabi represented the path to social justice and intersectional social work differently. For some incarceration was an important component to seeking justice for people in the sex trades. One interview participant, who teaches a class on race relations and advocates for inclusion of sexuality education in social work programs, reflected that "sex workers are always the ones to be criminalized, and instead it should be the pimps" (SW13, July 2017). When applying an anti-carceral feminist lens to sex trades content, the goal of social justice and intersectional praxis are contradicted by the indication that "pimps" should be incarcerated in addition to or instead of the sex worker.

In the next chapter, I focus on the anti-carceral feminist implications of study findings presented in this chapter for social work education in pursuit of ameliorating systemic barriers and institutional oppression. Informed by anti-violence and transformative justice movements centering the voices of queer and trans women activists and scholars of color, I offer suggestions for social work research, practice, and education related to the sex trades rooted in visions for social justice. 


\section{Chapter V: Analysis \& Implications for Social Work}

Students are taught about an array of experiences in the sex trades that include experiences of agency, choice, survival, coercion, and force. Multiple conceptual frameworks are represented in course syllabi to both teach social work students about client experiences in the sex trades and to teach the strategies social work students should utilize when working with those involved with the sex trades. Discourses of coercion and survival dominate the teachings about the sex trades, but some social work students, particularly those learning about the sex trades in sexuality courses, are being exposed to multiple and more complex narratives about the experiences of people taking part in sex trade.

Instructors seem to be primarily teaching about "sex trafficking" and consequently focused on coercion and violence as a framework for understanding the sex trades. These types of courses relied on theories of victimology, feminist abolitionism, and carceral logics. Overwhelmingly, this content on sex trafficking focused on 1) human trafficking as modern day slavery, 2) human rights violations and federal/state law, treaties, and policies intended to address such abuses, 3) sexual violence and slavery, 4) victimization, and 5) the necessity for social workers to collaborate with law enforcement to criminalize third parties responsible for facilitating sex trade as the solution to ending violence against cisgender women and girls in the sex trades.

The five classes with "sex or sexuality" in the title (four of which were social work and sexuality classes and one was titled "sex trafficking") added the experiences of LGBTQ people who trade sex for money, in-class debates on the legalization of prostitution, a documentary on sex worker rights, the experiences of college students 
working as escorts, and the nuances of both enjoying and disliking sex work simultaneously. Additionally, two of the sexuality and social work courses drew on content that explored how social workers could ethically support people in the sex trades without being coercive and participating in criminalization.

Overall, the syllabi indicate that feminist abolitionist theories have deeply influenced social work perspectives on sex trades. It seems that any mention of "sex trade" within social work is instantly understood as sexual abuse or violence and that other factors, such as those related to sex and sexuality, are somehow dismissed as outside the purview of social work. Such a conclusion seems logical when returning to the roots of American social work, a time in which the sexual expression of adolescent females was criminalized and policed by morality politics. When assigned "delinquency" status, young white women were sent to homes for wayward girls to preserve (or regain) their sexual innocence, develop skills in domesticity, and receive protection from the evils of urban life (Abrams, 2000; Dozema, 1999; Saunders, 2005). Motivated by the panic inducing fear of "white slavery," social workers attempted to prevent vulnerable white women from encountering the persuasion of illustrious and insatiable men—often imagined as dangerous black, brown, Jewish, and immigrant men (Doezema, 1999). However, if white women were lured into prostitution, they were seen as "fallen" to a life of sexual promiscuity. By regulating sexuality as criminal and worthy of rehabilitation, over time the focus of sex and sexuality in social work became relegated to a "victimbased status" that drew on the helping skills of social workers.

In short, social work syllabi in the data set reveal problematic ideas about how people in the sex trades can best be supported by social work practices. As such, a 
nuanced and critical investigation of how people in the sex trades are currently represented with social work syllabi is necessary as a first step in improving the learning outcomes for students of social work who then become active in the field. Indeed, questioning how and why various representations of people in the sex trades exist may help social workers to engage more critically and deeply with the range of experiences in the sex trades and as a result positively impact the profession and our clients.

\section{The Anti-carceral Feminist Politics of Using Racialized Imagery to Teach About Sex Trade}

Each of the social work courses focused on human trafficking state in their syllabi that human trafficking is "Modern Day Slavery." Without further diving into the histories of slavery around the world, students are thereby taught that all sex trade is sex trafficking, not forced or coerced labor, even though human trafficking has been framed as "modern day slavery" or "sexual slavery." Students therefore learn to conflate all sex work as trafficking/slavery and by doing so learn that it is acceptable to appropriate what has largely been the experience of black people in the United States. The discourse of "modern day slavery" as related to sex trafficking appropriates black suffering and ignores racialized and sexualized labor in relationship to mass incarceration.

While not all enslaved people (past and present) are African American, it is the historical image of African American slavery in the United States that is implied and evoked without consideration for the racialization and sexualization of labor both past and present. Teaching students that those who are active in the sex trades are slaves, in other words, is reductive and problematic in terms of histories of race, gender, sex, sexuality, and labor politics. Instead of invoking the racialized imagery of the pre- 
Emancipation African American slave, it might be more useful to view sex trade as work that can be chosen, forced, unpaid, and/or coerced. It is also important to recognize sex work as a criminalized form of labor, which is also a very real problem that impacts clients who choose this type of employment for myriad reasons, including its flexibility, availability, accessibility, wage rate, and/or skill set qualifications.

In addition to invoking legacies of African American slavery in their syllabi, social work instructors suggest that the solution to the problem of trafficking is to support federal legislation that advocates the "three P's" (Prevent, Protect, and Prosecute). One lesson that students then receive is that arresting and criminalizing those assumed to be a third party responsible for facilitating sex trade of the "identified" victim helps people working in the sex trades. This perspective, however seemingly common sense it is to arrest the "bad guys," is problematic in terms of widespread racism within the criminal legal system where people of color are disproportionately arrested and imprisoned. For instance, social work students might be surprised to learn, and yet need to be aware, that some scholars and activists refer to the prison system itself as "modern day slavery" (Alexander, 2010; Davis, 2007; Love \& Das, 2015).

If we use a wider critical context and more intersectional lens for the discussion of sex trafficking and incarceration, it is apparent that there are damaging consequences to using "slavery" as a metaphor and prosecution as a method. For instance, Black women and women of color of any age (cis and trans) have been harmed through their involvement in the sex trade as a result of the interlocking conditions of racism and sexism. This harm is distinctly related to historical experiences of dehumanization through chattel slavery, where they were forced to provide unpaid sexual, reproductive, 
manual, and domestic labor for white men and their families. Asking questions about how violence is carried out via the State, systems, and institutions with the implementation of such carceral policies is imperative. Racial bias within the criminal legal system has led to the incarceration of black women as young as 13-14 active in sex trade. These young people should have been protected by the law, but instead will possess criminal records, thereby impacting access to employment, a living wage, housing, and opportunities structured by racial and economic injustice.

A research study on the adultification of Black girls, out of the Poverty Inequality Center at Georgetown University, found that through adultification black girls as young as five years old are perceived to be less innocent than white girls of the same age (Epstein, Blake, \& Gonzalez, 2017). The denial of their innocence leads to perceptions of them as uncontrollable and unable to regulate their developing emotions and bodies (Epstein, Blake, and Gonzalez, 2017). Common behaviors among children, like throwing a tantrum, is labeled as threatening and dangerous, bwhich has been cause for physical restraint by school resource officers (Ritchie, 2017). This adultification of Black girls becomes a weapon of the state used to justify criminalizing them as adults before they turn 18 years old. If we truly wish to work towards an anti-violent, equitable, and antioppressive world, social workers must utilize intersectional and anti-carceral feminism to interrogate the implications of incarceration throughout the lifespan and its impact at micro, mezzo, and macro levels.

Many forms of sex work are currently criminalized which makes anyone who works in the sex trade subject to arrest if caught. The criminalization of sex trade poses a risk to those who have been forced into trading sex by a third party and often prevents 
them from accessing legal, medical, or social services. They fear not being believed, particularly if they don't resemble the "ideal survivor" image, and know that if they are not believed they could be arrested, deported, or sent back to abusive living conditions.

Social work instructors need to teach about the devastating impacts of the criminal justice system and mass incarceration, especially upon disenfranchised communities. For instance, if arrested while living and working on the street, the impact of incarceration and criminal history reduce the feasibility of finding living wage employment. If eligible, state assistance does not provide enough income to meet basic needs and therefore those who have criminal records are required to work in underground economies such as the sex trade to meet their immediate and long-term needs. Lastly, instructors should acknowledge that rescuing people from the sex trade because it has been deemed dangerous by outsiders is conjecture and does not dismantle the proven structural violence of white supremacy, classism, cissexism, ableism, and mass incarceration.

One potential anti-carceral strategy for social work students to consider is the decriminalization of sex trade. Decriminalization means removing legal penalties associated with prostitution. Although not the solution to ending all systemic and interpersonal violence, it has the potential to reduce workplace violence and allow people working in the sex trades more agency in their work. When sex trade is recognized as labor and the threat of incarceration for working is taken out of the equation, the potential for exploitation and sexual violence is minimized. It also allows people who are harmed during sex trade to more easily access the services they want and need without the fear of arrest, stigma, and shame. 


\section{Use an Intersectional Lens to Examine Concepts and Values About Sex(uality)}

It seems that teaching about sexuality in social work facilitates a more complex understanding of the sex trades that is useful. However, in the data set, only four course syllabi used sexuality as a focus to engage a broad range of experiences, behaviors, and therapeutic possibilities for people in the sex trades (inclusive of sex trafficking and sexual violence as experiences that occur in the sex trade). In these courses that focus on sexuality in relationship to social work, students are taught to critically think through concepts of normalcy in relation to sex and sexuality and to examine their own values through an intersectional lens when engaging with sex trade content.

In addition to covering content that contested concepts of "normalcy" when it comes to sex and sexuality, these types of courses incorporated intersectional theories of oppression to highlight the complex entanglement of imperialism, the policing of sexuality, and prostitution legislation. When talking about sex, sexuality, and sexual violence, it is imperative to examine the intersections of race, class, (dis)ability, sex, gender, nation, migration, sexuality, indigeneity, body size, faith, age, and beyond. These enmeshed social categories impact how people access social institutions, and ultimately, the ability to access their human rights and needs.

Although the following interview excerpt was not found in the data analyzed for this study, it does provide context for the lack of sexuality-based intersectional content found in social work syllabi used in this study. When interviewed about Project ROSE, Dr. Roe-Sepowitz, faculty member at Arizona State University School of Social Work and founder of Project ROSE says, “... having that many body parts in your body parts-having that many body fluids near you, doing things that are freaky and weird really 
messes up your ideas of what a relationship looks like and intimacy" (Roe-Sepowitz, 2013). This quote from Roe-Sepowitz attests to highly normative assumptions about sex and sexuality wherein multiple partners and certain sexual behaviors have a traumatic and pathological impact upon all intimate relationships. Roe-Sepowitz, perhaps not surprisingly, also asserts that it is difficult to determine whether participation in sex trade is voluntary or forced and therefore broadly concludes that all sex trade is trafficking (2014). Although her use of "freaky" and "weird" to discuss sexuality is extreme in its judgmental tone, Roe-Sepowitz is not an outlier in terms of social work perspectives on the sex trades.

Recognizing the complex situated-ness of those involved in the sex trades necessitates an intersectional lens, which in this study has been found most often in sexuality-based courses. Barring the sexuality-based courses in social work, there is sparse critical analysis of the social, geographic, and historical events that construct the sexual deviance of people active in sex trade. Instead, the epistemological weight of radical feminist influence, rather than intersectional feminism, on social work takes over. Radical feminist ideologies are evident through specific well-known feminist abolitionist scholars who show up in syllabi as well as the common themes in course content, such as the ubiquitous focus on all sex trade as modern day slavery and violence.

Yet, in the second chapter, I addressed how the logic of "sickness," "innocence," and "compulsory victimization" fell short when black women and girls like Monica Jones, Bresha Meadows, Latesha Clay, Alisha Walker, and Cyntoia Brown were incarcerated under laws that were intended to help them even though, by such laws, they would be defined as victims. Because black women and youth in the sex trades don't 
conform to notions of femininity rooted in heteropatriarchal standards of whiteness, they are frequently seen as hypersexual, sexual deviants, already sexualized, and sexual agents, despite how they themselves contextualize their experiences. A wider critical context and intersectional lens makes these conditions more intelligible.

Indeed, social work instructors would improve the quality of learning outcomes regarding the sex trades by including a range of feminist theoretical frameworks in their courses. In particular, critical feminisms inclusive of intersectional feminisms, transnational feminisms, anti-carceral feminisms, and transfeminisms would help social work students engage with a range of discourses and experiences related to the sex trades. One instructor among interview participants, SW1, taught her students about "liberal feminist" and "transnational feminist" perspectives on the sex trades so that students are able to use different lenses to contemplate the experiences of people who trade sex.

\section{The Exclusion of Transgender Women of Color (TWOC) and Lesbian, Gay, Bisexual, Transgender, Queer (LGBTQ) People}

In my interviews with social work instructors, I learned that many students who take their courses wish to work with victims of sex trafficking once they graduate. Given that instructors acknowledge the intention of their students to work with trafficking victims (defined by federal law) in the United States, they must teach students to understand the complex systemic factors that facilitate sex trade by young people under 18. For example, due to racism, homophobia, transphobia, adultism, and violence across systems, LGBTQ young people may be forced onto the street and need to trade sex to make money, shelter, food, and safety. Transgender or "trans" women, and in particular 
TWOC, may face barriers to accessing employment due to the intersections of heterosexism, cissexism, and racism.

Hegemonic processes of racialization and gendering result in excluding TWOC and LGBTQ people from formal sector economy and make the sex economy an accessible option for work. Yet, content discussing LGBTQ youth and TWOC is minimally present in the data sample. When included, these populations are positioned in proximity to being "at-risk" of engaging in survival sex and as vulnerable to being criminalized. Interestingly, content inclusive of LGBTQ youth do not discuss their vulnerability to third party persuasion into the sex trade. Instead, the majority of courses teach that it is presumably heterosexual cisgender women and girls who are presumably being coerced into sex trade by heterosexual cisgender men.

Representations that construct TWOC and LGBTQ people of color as violent, uncontrollable, hypersexual, physically strong, and outspoken (or as subverting hegemonic femininity), position them at increased vulnerability of being criminalized when working in the sex trades (Ritchie, 2017). In other words, their cisgender, white, heterosexual counterparts who conform to hegemonic gender norms are more likely to be perceived as innocent. As a result, social work students are taught that Black women and other women of color are criminals who choose to trade sex and are undeserving of their help, whereas white women are deserving victims forced into the sex industry.

\section{Cultivating Empathy For "Good Victims"}

Social work students are taught to cultivate empathy towards those perceived to be victims. "Survivor leadership" or "survivor-led interventions" are frequently framed as empowerment-based and feminist oriented techniques that center the voices of those on 
the margins. However, social work instructors must be extremely reflexive when teaching about these types of sex trafficking interventions. I am particularly concerned with of the ways in which survivor led interventions are deployed as universally trauma-informed and socially just.

First, not all people who are exploited in the sex trades stop trading sex for money and identify themselves as a victim of exploitation or as surviving anything. While the term "survivor" is meant to recognize the strength of those who experience violence, this term has a restrictive history. "Survivor" is not considered a label that can be applied to just anyone, namely if someone does not experience their time trading sex as victimizing. Second, not all survivor stories are the same. And, as such, while the framing of survivor leadership may sound empowering, for example, that sometimes survivors harm other survivors. All people who participate in the sex trades have different experiences, needs, and goals. If one story is constructed as the universal experience, others that diverge may be pushed to the margins. Using an intersectional feminist lens highlights how internalized oppression might be present in the behaviors and narratives of those involved in the sex trades. Third, upholding "survivor-led" programs may unintentionally construct the image of an "ideal" or "good" survivor. The "ideal survivor" narrative suggests that survivors experience and respond to sexual trauma and systemic violence in the same way.

Instead, students should learn that part of their role in advocating for people who have current or former experience in the sex trades should be to help navigate systemic barriers when their clients try to access healthcare, housing, welfare assistance, substance use treatment, the legal system, and formal sector employment. The "survivor leader" 
represents a publicly relatable experience of sex trafficking and is able to reach a broad audience of concerned citizens and potential donors to support the cause. The focus on victimization, simply put, tugs at heartstrings and recruits helpers. It is much more simple and clear to align with a mission that focuses on individuals as victims or criminals rather than structural oppression as the ultimate danger.

Anti-carceral feminist logic rejects the term "innocent" as connected to human rights due to its discursive employment and instead focuses on the potential human rights violations inherent to carceral policies. For example, given the failure of poor, queer, trans, youth on the street, drug users, people of color, and those without U.S. citizenship to conform to notions of hegemonic whiteness through femininity, masculinity, sexuality, and purity, they are significantly likely to experience violations of their human rights through incarceration based upon the intersections of oppression. Therefore, anti-carceral feminism takes criminalization and criminal consequence out of the equation and instead advocates for transformative justice--in other words, institutional change and elimination of system violence, advantage, and oppression. Furthermore, the voices of current and former sex workers are centered, and they are recognized as the experts of their own lives and needs. Policies that allow poverty to exist would be overhauled and everyone would be able to meet their basic needs and thrive without fear of criminalization.

\section{Impact of Feminist Imperialism on Cisgender Women and Girls in the Global South}

Students are taught that cisgender women and young girls in the Global South are especially vulnerable to being trafficked into sex trade. The focus on women in the Global South as the main subject for understanding sex trade aligns itself with an imperialist feminist strategy (Amos \& Parmar, 1984; Baker, 2018; Kempadoo, 2015) 
whereby white women and men from the Global North are motivated by racist and imperialist logics to rescue and protect brown women in the Global South from dangerous, animalistic brown men (Spivak, 1988). The trope of the "third world woman as victim" creates a problematic narrative (but one that easily becomes dramatized) of what sex trade looks like in the United States and how social workers can support people in the sex trades. In actuality, global capitalism has ensured that the material realities of people in the sex trades in the Global North and Global South are quite different. Social workers must thereby realize that one size social work does not fit all, especially within the sex trades.

When working with individuals, communities, and systems, social workers must grapple with the deep complexities of cultural imperialism, colonization, and global power as related to the cultural and colonial histories that have shaped the understanding of sexual agency and the constraining choices of women participating in sex work (Kempadoo, 2001). In short, the inclination to "rescue" women from the Global South should raise a red flag to social workers and signal the potential for social work to reinforce and contribute to culturally oppressive legacies.

\section{Rescue Work is Paramount}

Students are taught that rescue work is paramount to help cisgender or "cis" women and girls in the sex trades. Within the findings of the study, there has been a compulsory focus on victimization. Although, five out of twenty syllabi do provide examples of content that complicates the priority of rescue work, students are overwhelmingly taught that their primary role in terms of working with people in the sex trades is to "help" by rescuing victims from violent conditions. However, when social 
workers, and medical service providers, citizen vigilantes, and law enforcement draw on socially constructed ideas of what it looks like to be a victim of sex trafficking, they risk contributing to the harm already embedded within disenfranchised communities. When rescue interventions occur and people are arrested as a means of protection, violence and re-traumatization at the hands of police and within the prison system is likely, regardless of age or experience of victimization (Carlton, 2016; Whalley \& Hackett).

Furthermore, law enforcement continues to work with social service agencies and legal advocates to conduct undercover operations with the intent of "rescuing" victims (the person trading sex) and arresting the client or the trafficker associated with them. The rescue typically involves an arrest of the victim as a form of protection and removal from the dangerous third party. These rescue interventions are tied to controlling images of Black women as "jezebels" and promiscuous (less innocent than their white counterparts) and Black men as dangerous, threatening perpetrators. Even if the rescue was helping someone who identified as a victim of sexual exploitation, ample evidences suggests arrest and detainment is re-traumatizing and dehumanizing.

If governmentality influences our gendered and racialized understandings of who participates in sex trade voluntarily and who is forced or coerced into sex trade, it becomes clear that rescuing the vulnerable is a complicated process full of value judgments. Oftentimes, we problematically criminalize those who have already been sexualized and deemed to represent criminalized or deviant behavior. For instance, Monica Jones, Marissa Alexander, Bresha Meadows, and Latesha Clay are people who should have been protected, but due to how legislation has impacted police presence in the world of social services, were instead incarcerated and judged as criminal. 
Instead of complacently teaching about rescue work, and effectively harming those we should help, social work instructors can find examples of intersectional content and incorporate them into the classroom. These materials are often already present in courses focused on sexuality and social work content and can be easily borrowed and adapted. Intersectional content helps contextualize the ethical dimensions of the social work profession, namely those that support rescue-interventions, and intersectional content also diversifies representations of people who work in the sex trades to be more reflective of actual populations.

For instance, one class in the data sample titled "Sex Trafficking" reviews reports based off research from the Urban Institute with LGBTQ youth living on the street. This is an example of a report that brings LGBTQ communities into social work conversations about the sex trades and complicates their experiences. Dank and colleagues (2015) demonstrate the vulnerability of LGBTQ youth in the sex trades to being criminalized, while at the same time demonstrating the dependence of their survival on the sex economy. This report serves social workers well, as it allows us to enter from multiple points. Rescue cannot be easily proposed as a solution that will help these communities, particularly as their experiences of racism, ageism, oppression, homophobia, and transphobia are highlighted in their abilities to access employment as well as to find social and medical services that are not traumatizing and that legitimate their experiences.

Additionally, it is important that social work instructors are able to discuss the politics of sex and sexuality in their courses and ask students to engage in their own reflexive process around sexuality. Within the study, sexuality-based courses have included content in their courses that allow students to apply various feminist 
perspectives, read about the history of prostitution, practice journaling about sex and sexuality, examine the benefits and consequences of legalizing prostitution, and witness the powerful activism of sex workers fighting for their rights. These courses provide a good example of intersectional pedagogy within social work that would benefit the discipline, if more widely implemented.

\section{Conclusion}

Within social work, there remains a dominant focus on the victimization of those within the sex trades that is based on statistics that have been largely debunked and widely misused. This study has illuminated potential opportunities for social work education to better educate students about the sex trades and socialize them to understand their role in relation to working with people engaged in the sex trade. It is my contention that social workers should actively embrace both intersectional and anti-carceral feminist approaches to teach social work students about multifarious experiences in the sex trades. While there are a few sexuality and social work classes teaching intersectional content and providing students with material to stretch beyond binary thinking, social work needs to integrate intersectional sex trades content throughout the curriculum.

When attention to sex trade is diverted towards rescue, harm, and interpersonal violence, we miss the opportunity to address systemic violence and oppression that perpetuates abuse, exploitation, and coercion among TWOC, LGBTQ youth, youth of color, undocumented immigrants, drug users, youth in foster care, and youth living on the streets. Furthermore, instead of being recognized for the skill it takes to overcome the barriers they face when they try to access basic resources, those involved in the sex trades are instead frequently discriminated against by social service providers and also 
criminalized by law enforcement, which is even more damaging. If social work must stay focused on experiences of violence, perhaps that focus could address the micro, mezzo, and macro systems that perpetuate violence on the very communities we claim to help. Ideally though, we need to engage in critical thinking activities with the content we draw on in classes and consider the myriad experiences within the sex trades that blur choice, coercion, survival, and exploitation.

Furthermore, when social work education invokes intersectionality as a lens through which to teach about the sex trades, we must be explicit about which social group categories we are looking at intersectionally. Ultimately, we must at a minimum engage the intersections and interlocking categories of race, ethnicity, class, gender identity, sexuality, migration, nation of origin, (dis)ability, age, religion, body size, and indigeneity (Collins, 1990; Crenshaw, 1991; de Vries, 2015; McCall, 2005; Mehrotra, 2010). In addition to intersectionality as applied to the identities of our clients, intersectional thinking is also useful for thinking about the varied cultural contexts of social work itself and its historical treatment of those involved in the sex trades.

The praxis of intersectionality requires that social work instructors deploy content that necessitates critical reflection on how social workers become agents of racialized state control. Social work instructors must thereby rethink their use of content that reinforces problematic historical legacies of social work that are racialized. It is especially important that we think critically about false narratives of "white slavery" whereby white women are positioned as innocent victims of prostitution and women of color are agentic criminals when active in the very same endeavor of trading sex for money. For instance, content on sex trade in the Global South is frequently and 
problematically used to teach about the needs of people active in the sex trades in the United States without consideration of geopolitical dynamics that differently situate those involved in sex trade. As such, it would be useful if instructors centralized transnational feminist content that acknowledges the role the United States plays in maintaining and benefiting from global capitalism through institutions that perpetuate violence, oppression, and poverty in the Global South. Even certain manifestations of feminism with the Global North have contributed to the harmful imperialist belief that women of the Global South are more oppressed, without agency, and therefore in need of rescuing from the atrocious acts of men in their own culture or nation.

Moreover, one of the first ways social work educators can strengthen engagement with the sex trades is to actively embrace anti-carceral feminist approaches to social work. An anti-carceral feminist approach to teaching and researching the sex trades prioritizes alternatives to criminal punishment. While anti-carceral literally means "against incarceration," the framework extends to include not just the period of being locked up but also the effects of incarceration over a lifetime on an individual, their family, communities, and beyond (Rodriguez, 2018).

Incarceration has a lifetime of effects on those current and former youth and adults who have served time in juvenile detention centers and adult prisons. After release from detention, finding a job is difficult if not impossible; re-entering family and community can be disorienting and traumatic; safe and affordable housing that allows people with criminal records to live in their facilities are difficult to access; PTSD is common; and in general, reintegrating into society is challenging on many levels. Additionally, after release in many states, people are unable to vote, lose rights to 
citizenship, and are confined to certain jurisdictions based upon the conditions of their release. It is paramount that social work instructors and their students understand that those most impacted by the effects of incarceration are those already vulnerable to poverty, criminalization, and intersectional oppression. To the degree that social justice is the underpinning of social work values by addressing the impact of poverty and oppression on the "vulnerable," an anti-carceral feminist approach that addresses the systemic factors that perpetuate poverty and oppression upon disadvantaged and "vulnerable" communities is more supportive of the values that underwrite social work education, research, and education.

I contend that an anti-carceral feminist approach would better serve social work, but it is unfortunately more common that carceral punishment and the related concept of governmentality is asserted as a foundational concept in our work, especially when we situate cisgender women and girls as victims. I argue, along with other critical sex worker scholars, that we must engage in intersectional thinking about the complex conditions of sex trade workers; interrogate melodramatic and racialized narratives of the sex industry as slavery; and focus on the many ways we can help people without carceral consequences and contributing to mass incarceration of already disenfranchised and marginalized people working in the sex trades.

Simply put, instructors play an instrumental role in socializing their students on how to work with people in the sex trades. To truly understand the complexity of where those we aim to help are situated, we must draw on intersectionality as an epistemological and ontological tool. As educators who have the power to shape the future of the practice of social work, we must likewise think through the epistemological 
implications of where our knowledge comes from and how we disseminate that knowledge to the students who will work with people who trade sex for material gain. Social work educators must acknowledge that we don't always have the answers and thus we can teach our students to both ask questions and not have all the answers. It is important to slow down, stay curious, and consider where our knowledge is derived.

These are lessons that I have tried to cultivate in my own work. For instance, while re-reading the interview transcript with SW17, I was confronted with the realization that not all social workers understand concepts such as "social justice, structural oppression, human rights, and critical thinking" the same way. These terms were used throughout interviews with instructors and syllabi used in the analysis, yet I did not probe for further clarification in the meaning attached to them. To some participants in the study, social justice meant working with law enforcement to help women and children victims of sex trafficking, while my own lens sees that collaboration as directly perpetuating social injustice. Moreover, when I asked study interview participants about what they hoped students took away from their courses, there was an overwhelming focus on prioritizing "critical thinking." Although the instructors I connected with had various theoretical backgrounds that informed their teaching about the sex trades, they all hoped that students would think critically about the information they were learning. And, again no one offered a definition of critical thinking, nor did I probe further to understand. There was an assumption that we shared a common understanding. It is in retrospect that I realize this lack of clarification and assumption of shared understanding is both a limitation of this study and an area of growth for social work educators, particularly as the consequences fall on the communities we work with. 
When I initiated data collection, I anticipated arriving at a specific set of findings and analyses. While some of my initial expectations have come to light, the depth of complexity surrounding study findings offers much to the discussion on sex trades within social work education and research. This study draws on a small sample size, which could also be considered a limitation. However, the study findings, including the small sample size itself emphasize both strengths and weaknesses of social work education related to teaching about the sex trades. Ultimately, the small sample size shows how minimal discussions of sex trades are occurring within social work education. The lack of attention to the sex trades within our courses must change given the widespread engagement with sex work and its various implications upon our multifaceted clients.

\section{Study Limitations}

Although I conclude that social work educators must more wisely use content that promotes intersectional and anti-carceral frameworks in their teaching about the sex trades, there is ample room to expand my recommendations. In fact, one limitation to this study is that I did not interview social work students to find out what they learned in their classes about the sex trades. Important gaps in teaching and learning may have been identified by comparing student interviews about their learning outcomes with instructor interviews about intended learning outcomes. Furthermore, given the depth of conversations I had with interview participants, there is a lot of data that has gone unused in this study. I only minimally used interview analysis to provide context for the content analysis. The study may have been strengthened by incorporating additional themes and quotes from interview participants in addition to following up with interview participants after the content analysis to learn more about how participants drew on specific examples 
of course content in the classroom. Member-checking - a qualitative strategy for demonstrating the credibility of the study — with the study participants whose words were used to support content analyses, would have farther bolstered the findings of the study. Member-checking would have added the benefit of being able to engage with where and how interpretations of the data both converged and diverged.

Other potential limitations include, the study sample itself - the language used to recruit study participants as well as the strategies used to identify syllabi and interview paticipants. For example, had I ask for participation from social work instructors who taught about either "sex work," "sex industry," "sex trafficking," "domestic minor sexual exploitation,” or "Commercial Sexual Exploitation of Children," as opposed to using "sex trade" as a way to emphasize the trading of sex due to a variety of needs and circumstances, I may have arrived at a vastly different sample. While I stand by my use of "sex trade" for the purposes of this study, it could be valuable to conduct further study that recruited participation by using just one of the above named terms.

One last limitation important to mention, is that although I knew it may be a barrier to connect with study participants, I chose to collect data over the summer, when many social work faculty are not on contract and may not be checking email as frequently as they might during the traditional academic year. This led me to collect course syllabi as quickly as possible, almost half of the sample gathered through Google searches, rather than taking more time to connect individually with each instructor who taught from a syllabus used in the sample. 


\section{Future Directions for Social Work}

Given the recommendations within this study, one future possibility for further social work research is a project with social work students about the explicit and implicit messages they receive from their social work instructors about the sex trades. A research project focused on what students are learning, regardless of instructor intention, would complement the findings and analyses of this project, which focuses specifically on how instructors can control content and shape learning outcomes. It would be useful to understand the knowledge students enter the field with, particularly if they encounter clients who trade sex or if they have the opportunity to address structural violence towards people in the sex trades.

Furthermore, because a key recommendation of the study is to use an intersectional lens when engaging sexuality related content, another opportunity for social work research is to explore how social work educators currently incorporate intersectional sexuality-based content into their social work courses. This would help to identify the range of ways that intersectional content shows up in social work courses that provide students the chance to engage with sexuality related material across many identities, histories, politics, and geographies while rejecting the idea of a normative sexual identity and history.

Finally, it is notable that there are barriers to engaging in research related to the sex industry within social work due to conflicting perspectives about the experiences and needs of those who work in the sex trades. Because of such conflicts within social work practice, research, and education, statistics on human trafficking have frequently been constructed through individual social service provider reports of their clients. For 
example, a study on the number of trafficking victims in Texas drew on social service provider reports of how many of their clients are victims of trafficking (BuschArmendariz, Nale, Kammer-Kerwick, Kellison, Torres, Cook Heffron, Nehme, 2016). The Texas study does not describe how providers determine who is a victim of trafficking and who is not. The reports made by providers are based on how the social service provider or social worker perceives the experience of their client who may trade sex for money or who may be "at-risk" — as determined by the social worker—of being coerced into the sex industry. Importantly, social worker perceptions do not always match up with how clients identify with their experience (Lutnick, 2016).

There is great disparity in how we define the experiences of clients who work in the sex trades, and this lack of consensus signals a crucial opportunity for further research. It is this definitional conflict that ends up providing confusing information about the experiences of people in the sex trades whereby some people may be getting their needs met, while others may not and might be further harmed. Assuming that people in the sex trades qualify as victims of sex trafficking, when they do not, may actually put them closer to harm. This negative consequence warrants further study into how agencies screen their clients for human trafficking, where and how their screening tools are developed, the action steps taken by agencies when those assigned victim status don't conform, and follow up on the experiences of such clients. Additionally, more research should focus on specific communities that are disenfranchised and traumatized as they navigate systemic resources to access their health, housing, welfare, and safety.

Considering the needs for research related to the sex trades, it is imperative that social work educators equip students with a constellation of perspectives in the course 
content they provide to students. Students, who then become social workers, are deeply influenced by the social work education they receive and can have a lasting influence on their approach to learning about the marginalized communities they work with. As students venture into the professional world, they deserve to go prepared and poised to ask questions about the practices, procedures, and screening tools their agencies use with their clients. If they have the prior knowledge to help them engage deeper with harmful social work interventions, they can ultimately serve as advocates for the diverse backgrounds of people, experiences, and needs in the sex trades. In the end, students who are educated in anti-carceral and intersectional strategies are our best hope for truly fulfilling the purpose that our profession envisions for itself. 


\section{References}

Abel, G., \& Wahab, S. (2017). "Build a friendship with them": The discourse of "at-risk" as a barrier to relationship building between young people who trade sex and social workers. Child \& Family Social Work, 22(4), 1391-1398.

Abrams, L. S. (2000). Guardians of virtue: The social reformers and the "girl problem," 1890-1920. Social Service Review, 74(3), 436-452.

Abramovitz, M. (1998). Social work and social reform: An arena of struggle. Social Work, 43(6), 512-526.

Addams, J. \& Joslin, K. (2002). A new conscience and an ancient evil. Urbana, IL: University of Illinois Press, Chicago.

Agar, J. (2016, January 11). Retrieved on 9/21/2016 from: http://www.mlive.com/news/grandrapids/index.ssf/2016/01/girl_15_sent_to_priso n_for_lur.html

Agustín, L. M. (2007). Sex at the margins: Migration, labour markets and the rescue industry. Zed Books.

Alexander, M. (2012). The new Jim Crow: Mass incarceration in the age of colorblindness. The New Press.

Alvarez, M. B., \& Alessi, E. J. (2012). Human trafficking is more than sex trafficking and prostitution implications for social work. Affilia, 27(2), 142-152.

Amber, J. (2015, March 4). In her own words: Marissa Alexander tells her story. Retrieved from: http://www.essence.com/2015/03/04/marissa-alexander-exclusive 
Amos, V. \& Parmar, P. (1984). Challenging imperial feminism. Feminist review, (17), 319.

Anzaldúa, G. (2002). Now let us shift... the path of conocimiento... inner work, public acts. In G. Anzaldúa \& A. Keating (Eds.), This bridge we call home: Radical visions for transformation, (540-578). New York City: Routledge.

ASU School of Social Work News. (2012, April). ASU, Phoenix Police team up to help victims of prostitution. Retrieved from: https://asunews.asu.edu/20120426_social_work.

Attia, A. (2016). Explicit Equality: The Need for Statutory Protection Against AntiTransgender Employment Discrimination. Southern California Interdisciplinary Law Journal, 25, 151.

Bader, E. (2016, July). National Organization of Women turns 50: Building towards an Intersectional feminist future. Retrieved from: http://www.truthout.org/news/item/36818-national-organization-for-women-turns-50-building-anintersectional-feminist-future

Baker, C. N. (2013). Moving Beyond 'Slaves, Sinners, and Saviors': An intersectional feminist analysis of US sex-trafficking discourses, law and policy. Journal of Feminist Scholarship, 4(Spring 2013), 1-23.

Baker, C. N. (2014). An intersectional analysis of sex trafficking films. Meridians: feminism, race, transnationalism, 12(1), 208-226.

Barton, B. (2006). Stripped: Stories from Exotic Dancers. NYC: NYU Press. 
Becerrill, C. (2017, February 16). Why is this sex worker in jail for surviving? Retrieved from: http://www.thefader.com/2017/02/16/alisha-walker-sex-worker-murdersupport

Berg, H. (2015). Trafficking policy, meaning making and state violence. Social Policy and Society, 14(1), 145-155.

Brock, D. R. (1998). Making work, making trouble: Prostitution as a social problem. Toronto, BC: University of Toronto Press.

Bernstein, E. (2014). Militarized humanitarianism meets carceral feminism: The politics of sex, rights, and freedom in contemporary antitrafficking campaigns. Signs, 40(1) $46-71$.

Bernstein, E. (2012). Carceral politics as gender justice? The "traffic in women" and neoliberal circuits of crime, sex, and rights. Theory and Society, 41(3), 233-259.

Bierria, A \& Communities Against Rape and Abuse. (2007). Pursuing a radical antiviolence agenda inside/outside a non-profit structure. In INCITE! Women of Color Against Violence (Eds.), The Revolution Will Not Be Funded (pp. 151-163). Cambridge, MA: South End Press.

Blair, C. (2010). I've got to make my livin': Black women's sex work in turn-of-thecentury Chicago. Chicago: The University of Chicago.

Boyer, P. S. (1992). Urban masses and moral order in America, 1820-1920. Harvard University Press.

Bradford, J., Reisner, S. L., Honnold, J. A., \& Xavier, J. (2013). Experiences of transgender-related discrimination and implications for health: results from the 
Virginia Transgender Health Initiative Study. American Journal of Public Health, 103(10), 1820-1829.

Braun, V. \& Clarke, C. (2006). Using thematic analyses in psychology. Qualitative Psychology, 3(2), 77-101.

Brennan, D. (2008). Competing claims of victimhood? Foreign and domestic victims of trafficking in the United States. Sexuality Research \& Social Policy, 5(4), 45-61.

Brennan, D. (2014). Life interrupted: Trafficking into forced labor in the United States. Durham, NC: Duke University Press.

Bromfield, N. F., \& Capous-Desyllas, M. (2012). Underlying motives, moral agendas and unlikely partnerships: The formulation of the US Trafficking in victims protection act through the data and voices of key policy players.Advances in Social Work, 13(2), 243-261.

Bruxvoort, D. (2014). Raids, rescues, and rehabilitation: Rethinking anti-trafficking interventions. Human Trafficking Center. Retrieved from: http://humantraffickingcenter.org/wp-content/uploads/2013/10/Raids-RescuesandRehabilitation-Rethinking-Anti-Trafficking-Interventions.pdf

Bryson, S. (2015). A credit check of maternal assets: 'Care Capital and the Construction of the 'Good Enough Family' by Child Welfare Caseworkers and Courts. British Journal of Social Work, (bcv128) 1-18.

Busch-Armendariz, N.B., Nale, N.L., Kammer-Kerwick, M., Kellison, B., Torres, M.I.M., Cook Heffron, L., Nehme, J. (2016). Human Trafficking by the Numbers: The Initial Benchmark of Prevalence and Economic Impact for Texas. Austin, 
TX: Institute on Domestic Violence \& Sexual Assault, The University of Texas at Austin.

Bumiller, K. (2013). Feminist Collaboration with the State in Response to Sexual Violence: Lessons from the American Experience. In Tripp A., Ferree M., \& Ewig C. (Eds.), Gender, Violence, and Human Security: Critical Feminist Perspectives (pp. 191-213). New York City: NYU Press.

Burman, T. (2015). The land of smiles: Sex tourism in Thailand. Asian Journal of Multidisciplinary Studies, 3(7), 10-19.

Capous-Desyllas, M. (2007). A critique of the global trafficking discourse and US policy. Journal of Sociology \& Social Welfare, 34, 57.

Carlton, B. (2016). Penal reform, anti-carceral feminist campaigns and the politics of change in women's prisons, Victoria, Australia. Punishment \& Society, 1462474516680205

Carmon, I. (2015, January 27). Marissa Alexander released from jail. Retrieved from: http://www.msnbc.com/msnbc/marissa-alexander-may-be-released

Chang, G. (2016). Disposable Domestics: Immigrant women workers in the global economy. Haymarket Books.

Chapkis, W. (1997). Live Sex Acts: Women Performing Erotic Labour. NYC: Routledge.

Chaudry, V. (2016). Living at the edge: Disability, gender, and neoliberal debtscapes of microfinance in India. Affilia, 81(2), 177-191.

Cheng, S., \& Kim, E. (2014). The paradoxes of neoliberalism: Migrant Korean sex workers in the United States and "sex trafficking." Social Politics, 21(3), 355381. 
Chen, C-I., \& Dulani, J., \& Lakshmi Piepzna-Samarasinha. (2011). The revolution starts at home: Confronting intimate violence within activist communities. Boston: South End Press.

City of Phoenix, AZ. (2014, April). Article IV. Offenses involving morals. Retrieved from:

http://www.codepublishing.com/az/phoenix/frameless/index.pl?path=../html/Phoe nix23/Phoenix2352.html.

Collins, P. H. (2000). Black feminist thought: Knowledge, consciousness, and the politics of empowerment. New York: Routledge.

Collins, P.H. (2005) Black sexual politics. New York: Routledge.

Crenshaw, K. (1991). Mapping the margins: Intersectionality, identity politics, and violence against women of color. Stanford law review, 1241-1299.

Crenshaw, K. (2011). From private violence to mass incarceration: Thinking intersectionally about women, race, and social control. UCLA Law Review, 59, 1418

Critical Resistance \& INCITE! Women of color Against Violence. (2006). Gender violence and the Prison-Industrial Complex. In INCITE! Women of Color Against Violence (Eds.), Color of Violence: the incite! anthology, (pp. 223-226). Cambridge, MA: South End Press.

Daley, A. (2010). Reflections on reflexivity and critical reflection as critical research practices. Affilia, 25(1), 68-82.

Dank, M., Yahner, J., Madden, K., Banuelos, I., Yu, Y., Ritchie, A., Mora, M., \& Conner, B. (2015). Surviving the streets of New York: Experiences of LGBTQ 
youth, YMSM, and YWSW engaged in survival sex. Report of the Urban Institute. Retrieved from: https://www.urban.org/research/publication/survivingstreets-new-york-experiences-lgbtq-youth-ymsm-and-ywsw-engaged-survival-sex

Dank, M., Yu, L., Yahner, J., Pelletier, E., Mora, M., \& Conner, B. (2015). Locked In: Interactions with the Criminal Justice and Child Welfare Systems for LGBTQ Youth, YMSM, and YWSW Who Engage in Survival Sex. Report of the Urban Institute Retrieved from: https:/www.urban.org/research/publication/lockedinteractions-criminal-justice-and-child-welfare-systems-lgbtq-youth-ymsm-andywsw-who-engage-survival-sex

Davis, A. Y. (2003). Race and criminalization: Black Americans and the punishment industry. Criminological perspectives: Essential readings, 284.

Dejanova, T. E., \& Raghavan, C. (2013). Report from the field: evaluating an alternative to incarceration program for "highly probable trafficking victims." Dialectical anthropology, 37(2), 291-298.

DeBoise, C. (2014). Human Trafficking and Sex Work: Foundational Social-Work Principles. Meridians: feminism, race, transnationalism, 12(1), 227-233.

Dewey, S. (2011). Neon wasteland: On love, motherhood, and sex work in a rust belt town. Berkeley: University of California Press.

Ditmore, M. (2009). The use of raids to fight trafficking in persons. New York, NY: Urban Justice Center.

Doezema, J. (1999). Loose women or lost women? The re-emergence of the myth of white slavery in contemporary discourses of trafficking in women. Gender issues, $18(1), 23-50$. 
Doezema, J. (2002). Who gets to choose? Coercion, consent, and the UN Trafficking Protocol. Gender \& Development, 10(1), 20-27.

Duggan, L. (1993). The trials of Alice Mitchell: Sensationalism, sexology, and the lesbian subject in turn-of-the-century America. Signs, 18(4), 791-814.

Duggan \& Hunter. (2006). Sex wars: Sexual dissent and political culture. New York: Routledge.

Elliott, D. E., Bjelajac, P., Fallot, R. D., Markoff, L. S., \& Reed, B. G. (2005). Traumainformed or trauma-denied: principles and implementation of trauma-informed services for women. Journal of Community Psychology, 33(4), 461-477.

Epstein, R., Blake, J., \& González, T. (2017). Girlhood interrupted: The erasure of Black girls' childhood. Report of The Center on Poverty Inequality at Georgetown University Law School. Retrieved from: https://www.law.georgetown.edu/poverty-inequality-center/

Faderman, L. (1978). The morbidification of love between women by 19th-century sexologists. Journal of Homosexuality, 4(1), 73-90.

Falcon, S. (2006). The Color of Violence: The INCITE! Anthology.

Farrell, A., \& Cronin, S. (2015). Policing prostitution in an era of human trafficking enforcement. Crime, Law and Social Change, 64(4-5), 211-228.

FBI. (2014, July 23). 168 Juveniles Recovered in Nationwide Operation Targeting Commercial Child Sex Trafficking. Retrieved from: https://www.fbi.gov/news/pressrel/press-releases/168-juveniles-recovered-innationwide-operation-targeting-commercial-child-sex-trafficking 
\#FreeBresha (2017, January 3 ). Join us on January $19^{\text {th }}$ for a national day of action to \#FreeBresha. Retrieved from: www.freebresha.wordpress.com/blog.

Farrell, A., McDevitt, J., \& Fahy, S. (2010). Where are all the victims? Criminology \& Public Policy, 9(2), 201-233.

Farrell, A., McDevitt, J., \& Fahy, S. (2008, April). Understanding and improving law enforcement responses to human trafficking: Final Report. Retrieved from: https://www.ncjrs.gov/pdffiles1/nij/grants/222752.pdf

Flaherty, J. (2016). No More Heroes: Grassroots Challenges to the Savior Mentality. AK Press.

Francis, Halcyon, "Educating Students About the Social Constructs of Sex Work: Integrating a Course Focused on Prostitution into the Social Work Curriculum" (2015). Doctorate in Social Work (DSW) Dissertations. Paper 63.

Galazia, J. (2007). Staged. In A. Oakley (ed), Working Sex: Sex Workers Write about a Changing Industry (pp. 86-90), Berkeley: Seal Press.

Garland, D. (1997). Governmentality' and the problem of crime: Foucault, criminology, sociology. Theoretical criminology, 1(2), 173-214.

Grbich, C. (2007). Qualitative data analysis: An introduction. Thousand Oaks, CA: SAGE.

Gringeri, C. E., Wahab, S., \& Anderson-Nathe, B. (2010). What makes it feminist?: Mapping the landscape of feminist social work research. Affilia, 25(4), 390-405.

Guest, G., Bunce, A., \& Johnson, L. (2006). How many interviews are enough? An experiment with data saturation and variability. Field methods, 18(1), 59-82.

Hall, L. (2004). Hauling down the double standard: Feminism, social purity and sexual 
science in late nineteenth century Britain. Gender \& History, 16(1), 36-56.

Haraway, D. (1988). Situated knowledges: The science question in feminism and the privilege of partial perspectives. Feminist Studies, 14, 575-699.

Harding, S. (1993). Rethinking standpoint epistemology: What is "strong objectivity?" In L. Alcoff, \& E. Potter (Eds.), Feminist Epistemologies (pp. 49-82). New York: Routledge.

Hayes, K. (2016, April 10). On sex work and survival: Why we must stand with Alicia Walker. Retrieved from: https://transformativespaces.org/2016/04/10/on-sexwork-survival-why-we-must-stand-with-alisha-walker-2/

Heineman, J., MacFarlane, R. T., \& Brents, B. G. (2012). Sex industry and sex workers in Nevada.

Hollibaugh, A. (2000). My dangerous desires: A queer girl dreaming her way home. Durham, NC: Duke University Press.

Hooker, S. (2016, December 16). A round table on police violence against sex workers of color: Part 1. Retrieved from: http:/titsandsass.com/a-round-table-on-police-violence-against-sex-workers-ofcolor-part-i/

Hulko, W. (2014). Operationalizing Intersectionality in Feminist Social Work Research: Reflections and techniques from research with Equity-Seeking groups. In Wahab, S., Anderson-Nathe, B., \& Gringeri, C (Eds.), Feminisms in Social Work Research: Promise and Possibilities for Justice-based Knowledge (69-89). New York: Routledge.

Hunter, N. (2006). Contextualizing the sexuality debates: A chronology. In Sex wars: 
Sexual dissent and political culture. New York: Routledge.

Human Rights Watch. (2012, July 19). Sex workers at risk: Condoms of evidence of prostitution in four cities. Retrieved from:

https://www.hrw.org/report/2012/07/19/sex-workers-risk/condoms-evidenceprostitution-four-us-cities

Illich, I. (1968, April). To hell with good intentions. In Conference on Inter-American Student Projects. Cuernavaca, Mexico. Retrieved from http://www. swaraj. org/illich_hell. Htm.

INCITE! affiliate and collective of radical women of color, queer people of color, and Indigenous people who identify as people in the sex trades. (2011, April). No Simple Solutions: State Violence and the Sex Trades. Retrieved from: http://inciteblog.wordpress.com/2011/04/22/no-simple-solutions-state-violenceand-the-sex-trades/

Institute on Domestic Violence and Sexual Assault, University of Texas Austin, School of Social Work. (2016, December). Human Trafficking by the Numbers: The initial benchmark of prevalence and economic impact for Texas. Retrieved from: http://sites.utexas.edu/idvsa/files/2017/02/Human-Trafficking-by-the-Numbers2016.pdf

Jackson, C. (2016). Framing Sex Worker Rights: How US Sex Worker Rights Activists Perceive and Respond to Mainstream Anti-Sex Trafficking Advocacy. Sociological Perspectives, 59(1), 27-45.

Johnston, A., Friedman, B., \& Shafer, A. (2014). Framing the problem of sex trafficking: Whose problem? What remedy? Feminist Media Studies, 14(3), 419-436. 
Jordan, J., Patel, B., \& Rapp, L. (2013). Domestic minor sex trafficking: A social work perspective on misidentification, victims, buyers, traffickers, treatment, and reform of current practice. Journal of Human Behavior in the Social Environment, 23(3), 356-369.

Kempadoo, K. (2001). Women of color and the global sex trade: Transnational feminist perspectives. Meridians, 1(2), 28-51.

Kempadoo, K. (2017). Sex workers' rights organizations and anti-trafficking campaigns. In Trafficking and Prostitution Reconsidered (pp. 183-190). Routledge.

Kesler, K. (2002). Is a feminist stance in support of prostitution possible? An exploration of current trends. Sexualities, 5(2), 219-235.

Kessler, G. (2015, March 24). Loretta Lynch’s False Claim on Sex Trafficking Arrests. Retrieved from: https://www.washingtonpost.com/news/factchecker/wp/2015/11/24/loretta-lynchs-false-claim-on-sex-traffickingarrests/?utm_term $=.24 \mathrm{a} 1 \mathrm{c} 778 \mathrm{~d} 175$

Kinney, E. (2015). Victims, villains, and valiant rescuers: Unpacking Sociolegal constructions of human trafficking and crimmigration in popular culture. The Illegal Business of Human Trafficking, 87-108.

Knight, K. R. (2015). Addicted. pregnant. poor. Duke University Press.

Kotrla, K. (2010). Domestic minor sex trafficking in the United States. Social Work, $55(2), 181-187$.

Koyama, E. (2006). Disloyal to feminism: Abuse of survivors within the domestic 
violence shelter system. In INCITE! Women of Color Against Violence (Eds.), Color of Violence: the incite! anthology, (pp. 208-222). Cambridge, MA: South End Press.

Koyama, E. (2013). Rescue is for kittens: 10 things everyone needs to know about "rescues" of youth in the sex trade. Can be retrieved from: http://eminism.org/blog/entry/400.

KSU Freedom Alliance. (2013, April 5). Kansas on brink of enacting human trafficking law inspired by Wichita programs. Retrieved from: http://www.ksufreedomalliance.org/human-trafficking-in-kansas.html

Law, V. (2015, January $28^{\text {th }}$ ). Why is Marissa Alexander still being punished for fighting back? Retrieved from: https://www.thenation.com/article/why-marissa-alexander-still-being-punishedfighting-back/

Lee, V. (2013, July 30). What happens to children rescued in sex sweep? Retrieved from: http://abc7.com/archive/9190535/

Legal Momentum. (n.d). History of VAWA. Retrieved from: http://www.legalmomentum.org/history-vawa.

Lerum, K. (1999). Twelve-step feminism makes sex workers sick: How the State and recovery model turn women into victims. Sexuality and Culture, 2(1), 7-36.

Lerum, K., \& Brents, B. G. (2016). Sociological perspectives on sex work and human trafficking. Sociological Perspectives, 59(1), 17-26.

Lerum, K., McCurtis, K., Saunders, P., \& Wahab, S. (2012). Using human rights to hold 
the US accountable for its anti-sex trafficking agenda: the Universal Periodic Review and new directions for US policy. Anti-Trafficking Review, (1), 80.

Lerum, K., \& Dworkin, S. L. (2015). Sexual agency is not a problem of neoliberalism: Feminism, sexual justice, \& the carceral turn. Sex Roles, 73(7-8), 319-331.

Limoncelli, S. (2009). The trouble with trafficking: Conceptualizing women's sexual labor and economic human rights. Women's studies international forum, 32(4), 261-269).

Limoncelli, S. A. (2016). What in the world are anti-trafficking NGOs doing? findings from a global study. Journal of Human Trafficking, 2(4), 316-328.

Lobasz, J. K. (2012). Victims, villains, and the virtuous constructing the problems of "human trafficking." (Doctoral dissertation, University of Minnesota).

Love, D. \& Das, V. (2017, September 9). Slavery in the US Prison System. Retrieved from: https://www.aljazeera.com/indepth/opinion/2017/09/slavery-prison-system170901082522072.html

Lundblad, K. S. (1995). Jane Addams and social reform: A role model for the 1990s. Social Work, 661-669.

Lutnick, A. (2016). Domestic Minor Sex Trafficking: Beyond Victims and Villains. New York City: Columbia University Press.

MacKinnon, C. A. (1993). Prostitution and civil rights. Michigan Journal of Gender \& Law, 1, 13.

Majic, S. (2013). Sex Work Politics: From Protest to Service Provision. Philadelphia, PA: University of Pennsylvania Press.

Majic, S. (2014). Teaching equality?;“John Schools,” Gender, and Institutional 
Reform. Polity, 46(1), 5-30.

de Vries, K. M. (2015). Transgender people of color at the center: Conceptualizing a new intersectional model. Ethnicities, 15(1), 3-27.

McArdle, A. \& Erzen, T. (2001). Zero Tolerance: Quality of life and the new police brutality in New York City. NYC: NYU Press.

McCall, L. (2005). The complexity of intersectionality. Signs: Journal of women in culture and society, 30(3), 1771-1800.

Mehrotra, G. (2010). Toward a continuum of intersectionality theorizing for feminist social work scholarship. Affilia, 25(4), 417-430.

Meyers, D. T. (2014). Feminism and sex trafficking: Rethinking some aspects of autonomy and paternalism. Ethical Theory and Moral Practice, 17(3), 427-441.

Miller, H. L. (2000). Sexologists Examine Lesbians and Prostitutes in the United States, 1840-1940. NWSA Journal, 12(3), 67-91.

Mogul, J., Ritchie, A., \& Whitlock, K. (2011). Queer (In)Justice: The criminalization of LGBT People in the United States. Boston, MA: Beacon Press.

Mohanty, C. T. (2003). "Under Western eyes" revisited: feminist solidarity through anticapitalist struggles. Signs: Journal of Women in culture and Society, 28(2), 499-535.

Monbiot, G. (2016, April 15). Neoliberalism-the ideology at the root of all our problems. Retrieved from: https://www.theguardian.com/books/2016/apr/15/neoliberalismideology-problem-george-monbiot

Morgaine, K., \& Capous-Desyllas, M. (2014). Anti-Oppressive Social Work Practice. Sage. 
Nadal, K. L., Davidoff, K. C., \& Fujii-Doe, W. (2014). Transgender women and the sex work industry: roots in systemic, institutional, and interpersonal discrimination. Journal of Trauma \& Dissociation, 15(2), 169-183.

Nader, L. (1972). Up the anthropologist: Perspectives gained from studying up. In D. Hymes (ed), Reinventing Anthropology (pp.284-311). NYC: Pantheon Books.

Nagoshi, J. L. (2010). Transgender theory: Embodying research and practice. Affilia, $25(4), 431-443$.

Nawyn, S. Birdal, N., \& Glogower, N. (2013). Estimating the extent of sex trafficking: Problems in Definition and Methodology. International Journal of Sociology, $43(3), 55-71$.

National Association of Social Workers. (2008). Preamble to the Code of Ethics.

Retrieved from: https://www.socialworkers.org/pubs/code/code.asp

NCAVP. (2016, June 26). National Report on Hate Violence Against Lesbian, Gay, Bisexual, Transgender, Queer and HIV-Affected Communities Released Today. Retrieved from: http://avp.org/wpcontent/uploads/2017/05/2015_NCAVP_HVReport_MR.pdf

O’Brien, E. (2012). Ideal victims in trafficking awareness campaigns'. In Crime, Justice and Social Democracy (pp. 315-326), (Eds) Carrington, K., Ball, M., O’Brien, E., and Tauri, J. United Kingdom, Palgrave Macmillan.

Office on Women's Health. (2015, September 30). The Violence Against Women Act. Retrieved From: https://www.womenshealth.gov/violence-against-women/lawson-violence-against-women/\#a 
O’hara, M. (2016, January 27). Teen sent to prison after appearing as bait in Backpage ad used for robbery. Retrieved from: https:/www.dailydot.com/irl/michigan-childsex-trafficking-victim-prison/

Ortega, M. (2006). Being lovingly, knowingly ignorant: White feminism and women of color. Hypatia, 21(3), 56-74.

Ortega, M. (2011). “To live in the borderlands means you.” In A. Keating \& G. Gonzalez-Lopez (Eds.), Bridging: How Gloria Anzaldúa's Life and Work Transformed Our Own (pp. 155-157). Austin, TX: University of Texas Press.

Parreñas, R. (2011). Illicit flirtations: Labor, migration, and sex trafficking in Tokyo. Palo Alto: Stanford University Press.

Reardon, C. (2016, March 22). Fighting youth sex trafficking: The social worker's role. Retrieved from: http://www.socialworktoday.com/archive/032216p10.shtml

Reisch, M. (2013). What is the future of social work?. Critical and Radical Social Work, $1(1), 67-85$.

Rich, A. (1980). Compulsory heterosexuality and lesbian existence. Signs, 5(4), 631-660.

Richie, B. E. (2000). A Black feminist reflection on the antiviolence movement. Signs: Journal of Women in Culture and Society, 25(4), 1133-1137.

Richie, B. E. (2001). Challenges incarcerated women face as they return to their communities: Findings from life history interviews. Crime \& Delinquency,47(3), 368-389.

Richie, B. (2012). Arrested justice: Black women, violence, and America's prison nation. NYU Press.

Ritchie, A. J. (2017). Invisible no more: Police violence against Black women and 
women of color. Boston: Beacon Press.

Roberts, D. E. (1991). Punishing drug addicts who have babies: Women of color, equality, and the right of privacy. Harvard Law Review, 1419-1482.

Roberts, D. E. (2004). The social and moral cost of mass incarceration in African American communities. Stanford Law Review, 1271-1305.

Rodriguez, D. (2018). Scholars for Social Justice Blog: To define "incarceration" as against "Mass Incarceration." Retrieved from: http://scholarsforsocialjustice.com/ssj-blog-to-define-incarceration-against-massincarceration-by-dylan-rodriguez/

Roe-Sepowitz, D. E., Gallagher, J., Hickle, K. E., Pérez Loubert, M., \& Tutelman, J. (2014). Project ROSE: An arrest alternative for victims of sex trafficking and prostitution. Journal of Offender Rehabilitation, 53(1), 57-74.

Ross, L. (2006). The color of choice: White supremacy and reproductive justice. In INCITE! Women of Color Against Violence (Eds.), Color of Violence: the incite! anthology, (pp. 53-65). Cambridge, MA: South End Press.

Rossiter, A. (2001). Innocence lost and suspicion found: Do we educate for or against social work. Critical Social Work, 2(1), 1-6.

Rubin, G. (1984). Thinking sex: Notes for a radical theory of the politics of sexuality. In Social perspectives in Lesbian and Gay Studies; A reader, pp. 100-133.

Ryan, J. (2013, October 23). Protecting vulnerable children worldwide: Preventing and addressing sex trafficking of youth in foster care. Retrieved from: http://www.missingkids.org/Testimony/10-23-13

Saleebey, D. (2000). Power in the people: Strengths and hope. Advances in social work, 
l(2), 127-136.

Sallmann, J. (2010). Living with stigma: Women's experiences of prostitution and substance use. Affilia, 25(2), 146-159.

Saunders, P. (2005). Traffic violations: Determining the meaning of violence in sexual trafficking versus sex work. Journal of Interpersonal Violence, 20(3), 343-360.

Schreter, L.D., Jewers. M.M. \& Sastrawidjaja, S. (2007). The danger of conflating trafficking and sex work: A position paper of the Sex Workers Project at the Urban Justice Center. Retrieved from: http://www.sexworkersproject.org/mediatoolkit/downloads/20070330BriefingPaperOnConflationOfTraffickingAndSexWork.pdf

Segrave, M., \& Carlton, B. (2010). Women, trauma, criminalisation and imprisonment. Current Issues in Criminal Justice, 22(2), 287-305.

Shanahan, R. (2013). Youth Engaging in Prostitution: An examination of race, gender, and their intersections. (Doctoral Dissertation, University of Maryland, College Park).

Shawl, O. (2016, July 20). Gaylord woman charged for online prostitution, failing to inform partners of HIV. Retrieved from: http://www.petoskeynews.com/gaylord/gaylord-woman-charged-for-onlineprostitution-failing-to-inform-partners/article_21 eeda5a-4e9d-11e6-91b4$5 \mathrm{~b} 86 \mathrm{~b} 855308 \mathrm{c} . \mathrm{html})$

Shdaimah, C. S., \& Leon, C. (2015). "First and Foremost They're Survivors" Selective Manipulation, Resilience, and Assertion Among Prostitute Women. Feminist criminology, 10(4), 326-347. 
Shih, E. (2016). Not in My "Backyard Abolitionism” Vigilante Rescue against American Sex Trafficking. Sociological Perspectives, 59(1), 66-90.

Silver, C. (2013, August 13). Shocking numbers of sex trafficking victims come out of fostercare. Retrieved from: http://www.alternet.org/civil-liberties/shockingnumbers-sex-trafficking-victims-come-out-foster-care.

Sloan, L., \& Wahab, S. (2000). Feminist voices on sex work: Implications for social work. Affilia, 15(4), 457-479.

Smith, A. (2005). Beyond pro-choice versus pro-life: Women of color and reproductive justice. NWSA journal, 17(1), 119-140.

Smith, A. (2006). Dismantling the master's tools with the master's house: Native feminist liberation theologies. Journal of Feminist Studies in Religion, 22(2), 85-97.

Soderlund, G. (2005). Running from the rescuers: New US crusades against sex trafficking and the rhetoric of abolition. National Women's Studies Association Journal, 17(3), 64-87.

Sokoloff, N. J., \& Dupont, I. (2005). Domestic violence at the intersections of race, class, and gender challenges and contributions to understanding violence against marginalized women in diverse communities. Violence against women, 11(1), 3864.

Sokoloff, N. J., \& Pratt, C. (2005). Domestic violence at the margins: Readings on race, class, gender, and culture. Rutgers University Press.

Spade, D. (2013). Intersectional resistance and law reform.Signs: Journal of Women in Culture and Society, 38(4), 1031-1055.

Spade, D. (2015). Normal life: Administrative violence, critical trans politics, and the 
limits of law. Duke University Press.

Sprague, J. (2016). Feminist methodologies for critical researchers: Bridging differences. Lanham, MD: Rowman \& Littlefield.

Stransky, M. \& Finkelhor, D. (2008). How many juveniles are involved in prostitution in the U.S.? Retrieved from: http://www.unh.edu/ccrc/prostitution/Juvenile_Prostitution_factsheet.pdf

Stern, J. (2011/2012). This is what pride looks like: Miss Major and the violence, poverty, and incarceration of low-income transgender women. A New Queer Agenda, 10.1-10.2.

Strangio, C. (2014). Arrested for Walking While Trans: An Interview with Monica Jones. ACLU: Blog of Rights, April, 2.

Sudbury, J. (2006). Rethinking antiviolence strategies: Lessons from the Black Women's Movement in Britain. In INCITE! Women of Color Against Violence (Eds.), Color of Violence: the incite! anthology, (pp. 13-24). Cambridge, MA: South End Press.

Sudbury, J. (2014). Global lockdown: Race, gender, and the prison-industrial complex. Routledge.

Sutherland, K. (2004). Work, sex, and sex-work: Competing feminist discourses on the international sex trade. Osgoode Hall Law Journal, 42, 139.

Thuma, E. (2014). Against the "Prison/Psychiatric State": Anti-violence feminisms and the politics of confinement in the 1970s. Feminist Formations, 26(2), 26-51.

Thuma, E. (2015). Lessons in self-defense: Gender violence, racial criminalization, and anti-carceral feminism. Women's Studies Quarterly, 43(3), 52-71. 
Tomkinson, S. (2012). The Multiplicity of truths about human trafficking: Beyond "The sex slave" discourse. Central European University Political Science Journal, (01), 50-67.

Uy, R. (2011). Blinded by Red Lights: Why Trafficking Discourse Should Shift Away from Sex and the Perfect Victim Paradigm. Berkeley Journal of Gender Law \& Justice, 26(1), 204-219.

Vance, C. S. (2012). Innocence and experience: Melodramatic narratives of sex trafficking and their consequences for law and policy. History of the Present, 2(2), 200-218.

Violence Against Women Reauthorization Act of 2013, Enhancing judicial and law enforcement tools to combat violence against women is in Title 1 of the U.S.C. $\S 102$ (2013). Retrieved from: https://www.congress.gov/bill/113thcongress/senate-bill/47

Wahab, S. (2002). "For Their Own Good?": Sex work, social control and social workers, a Historical Perspective. Journal of Sociology and Social Welfare, 29(4), 39-57.

Wahab, S. (2004). Tricks of the Trade: What social workers can learn about female sex workers through dialogue. Qualitative social work, 3(2), 139-160.

Weitzer, R. (2010). The mythology of prostitution: Advocacy research and public policy. Sexuality Research and Social Policy, 7(1), 15-29.

Wahab, S., \& Panichelli, M. (2013). Ethical and human rights issues in coercive interventions with sex workers. Affilia, 28(4), 344-349.

Weitzer, R. (2007). The social construction of sex trafficking: Ideology and institutionalization of a moral crusade. Politics \& Society, 35(3), 447-475. 
Whalley, E., \& Hackett, C. (2017). Carceral feminisms: the abolitionist project and undoing dominant feminisms. Contemporary Justice Review, 20(4), 456-473.

White, P. (2015, October 5). A thank you note to carceral sex negative feminists.

Retrieved from:

http://www.feministcurrent.com/2015/10/05/a-thank-you-note-to-carceralsexnegative-feminists/

Whittier, N. (2016). Carceral and Intersectional Feminism in Congress The Violence Against Women Act, Discourse, and Policy. Gender \& Society, 30(5), 791-818. World Bank Group. (2018). What we do. Retrieved from: http://www.worldbank.org/en/about/what-we-do. 


\section{Appendices}

Appendix A: Template used for Analyzing Syllabi

\begin{tabular}{|c|c|c|}
\hline \multicolumn{3}{|c|}{ Social Work Sex Trades Syllabi Analysis Template } \\
\hline \multicolumn{3}{|c|}{ Title \& Description of Class: } \\
\hline \multicolumn{3}{|c|}{ Key Messages and/or Learning Goals of the course: } \\
\hline $\begin{array}{l}\text { How does syllabus discuss the } \\
\text { role of social work in relation to } \\
\text { the sex trades }\end{array}$ & Example 1: & Example 2: \\
\hline $\begin{array}{l}\text { What ideologies, values, } \\
\text { theoretical perspectives shape } \\
\text { course content? }\end{array}$ & \multicolumn{2}{|l|}{$\begin{array}{l}\text { Example 1: } \\
\text { Example 2: }\end{array}$} \\
\hline $\begin{array}{l}\text { How does the syllabus address } \\
\text { criminalization, law } \\
\text { enforcement, carcerality, } \\
\text { criminal justice system? }\end{array}$ & Example 1: & Example 2: \\
\hline $\begin{array}{l}\text { How does content reflect the } \\
\text { needs and experiences of people } \\
\text { in the sex trades? }\end{array}$ & \multicolumn{2}{|l|}{ Examples: } \\
\hline \multicolumn{3}{|c|}{ How does the syllabus address feminism, if at all? } \\
\hline \multicolumn{3}{|c|}{ Presence of U.S. based narratives of people in the sex trades } \\
\hline $\begin{array}{l}\text { Perpetuate Dominant Narrative } \\
\square \text { Addicted to drugs } \\
\square \text { Survivors of abuse (pathology) } \\
\square \text { Innocent/Victim/criminal/ Expl } \\
\square \text { High rates of STI's and HIV } \\
\square \text { Other, describe }\end{array}$ & ted/trafficked & $\begin{array}{l}\text { Resist Dominant Narratives } \\
\square \text { Addicted to drugs } \\
\square \text { Survivors of childhood sexual abuse } \\
\text { (pathology) } \\
\square \text { Innocent/victim/criminal/ exploited/trafficked } \\
\square \text { Other, describe: }\end{array}$ \\
\hline
\end{tabular}


Appendix B: Recruitment Letter to Faculty to share syllabi and/or be interviewed

Dear Social Work Faculty Member,

Hello, I hope this inquiry finds you well! My name is Meg Panichelli and I am currently embarking on my dissertation research project as a doctoral student in the School of Social Work at Portland State University. I'd like to invite you to be a participant in the project that explores the question: what are students learning about the sex trades in social work coursework?

I am seeking data collection through:

- Social work syllabi related to the sex trades

- Interviews with faculty member teaching courses related to the sex trades

A little about my background: I am using an anti-carceral feminist framework to analyze the data that I receive from syllabi and through interviews. I believe in supporting people who work in the sex trades, without the use of law enforcement whether they entered by choice, force, coercion, or circumstance. I recognize that social workers have the ability to help and support sex workers in a variety of ways and I am very curious about how this appears in course content. Given differences in approach or perspective there is a chance that we do not share the same strategies for teaching about the sex trades. I want to be upfront about how I approach this project, because it may deter you from participating.

If your interest has been sparked, please allow me to invite you to review the following eligibility criteria, and to share your syllabi/participate in an interview if you answer 'yes' to any of the following:

- Do you teach a course that specifically focuses on any of these terms: sex work, prostitution, sex trafficking, sex trades, sex industry, adult entertainment, sexual economies, sexual exploitation, pornography?

- Do you teach a course in which you have one or more class sessions is specifically focused on: sex trafficking, prostitution, sex trades, sex industry, sex and/or underground economies, sex industry, commercial sex work, sexual exploitation, pornography?

- Do you teach a course in which you have class material (readings, lectures notes, videos, websites, etc.) related to: sex work, sex trades, sex trafficking, sex economies, sexual exploitation, prostitution, adult entertainment, porn industry?

NOTE: If you read any of the preceding criteria and thought, "That sounds like something I teach or include in my classes, but not the language I use," please also inquire about participating.

Additionally, any participation in this project will be kept confidential and all data will be stored in a secure location and confidential location. Each interview will last between 30-60 minutes, depending on how much we have to talk about. Please contact me at the email address below if you would like to provide a syllabus, participate in an interview, or have other questions!

Best,

Meg Panichelli

mpanic2@pdx.edu

Portland State University

Doctoral Student/Adjunct Instructor 


\section{Appendix C: Original Interview Guide for Instructors}

1. Why do you teach about the sex trades?

2. What are some of your favorite methods to teach about the sex trades (material, articles, community based practice, guest lectures, class activities)?

3. When you teach about the sex trades, what are some of the lessons you hope for students to take away?

4. What do you believe that social workers roles are as related to the sex trades?

5. What is an example of social work with sex trade workers that you are inspired by or felt supportive of?

6. How do you (or do you not) incorporate an intersectional lens or incorporate issues of discussion of race, class, gender identity, sexuality, ethnicity, and nationality when teaching about the sex trades?

7. What do you think social justice with people in the sex trades looks like?

8. What else would you like to share about your experience of teaching social work students about the sex trades? 
Appendix D: Final Interview Guide (Revised on June 23, 2017)

1. How do you decide what to include in your course related to the sex trades?

2. What are some of your favorite teaching tools/strategies for teaching social work students about the sex trades?

3. When you teach about the sex trades, what are some of the lessons you hope that students to take away?

4. What is an example of social work with sex trade workers that you are inspired by or feel that social work students should know about?

5. In your class, what are some specific ways you discuss social justice related to the sex trades?

6. How does the social, political, religious, or geographic climate associated with the university impact how and what you teach related to the sex trades?

7. What are the prominent needs of people in the sex trades?

8. What do social workers most need to:

a. Know to work with folks in the sex trades?

b. To be able to do to work with folks in the sex trades?

9. What else would you like to share about your experience of teaching social work students about the sex trades? 
Appendix E: Raw data for organizing and coding content ( $1^{\text {st }}$ step after collecting all syllabi)

\begin{tabular}{|c|c|c|}
\hline $\begin{array}{l}\text { Template Section/Deductive } \\
\text { Code }\end{array}$ & SW 12 (Interview \& Syllabus) & (Syllabus only) \\
\hline $\begin{array}{l}\text { Title \& } \\
\text { Description of Class }\end{array}$ & $\begin{array}{l}\text { Title: Human Trafficking \& } \\
\text { Social Work Practice } \\
\text { Desc: Intro to HT (labor \& sex) } \\
\text { examining multi-level scope; } \\
\text { greatest human rights challenge } \\
\text { of all time. Explore laws \& } \\
\text { protocol, learn how to help in } \\
\text { efforts to combat ST/HT (online } \\
\text { class). }\end{array}$ & $\begin{array}{l}\text { Title: Issues in the Treatment of } \\
\text { Women (Adv clinical social work } \\
\text { elective). } \\
\text { Desc: Identify and apply } \\
\text { assessment and intervention } \\
\text { relevant to practice w/women. }\end{array}$ \\
\hline $\begin{array}{l}\text { Key Messages and/or } \\
\text { Learning Goals of the course }\end{array}$ & $\begin{array}{l}\text {--Define, identify types, } \\
\text { understand scope of HT. } \\
\text {--Analyze supply chains \& areas } \\
\text { of vulnerability. } \\
\text {--Gain knowledge of available } \\
\text { resources (LE, NGO, Service } \\
\text { Providers, Aftercare, legal and } \\
\text { immigration, academia) } \\
\text {--Understand key provisions of } \\
\text { laws protocols, agreements. } \\
\text {--Learn proper, effective, and safe } \\
\text { methods of citizen investigation. } \\
\text {--Apply learning to combat } \\
\text { trafficking. }\end{array}$ & $\begin{array}{l}\text { General topics covered: } \\
\text {--Family \& other relationships } \\
\text {--Sexuality, mental health illness, } \\
\text { poverty \& oppression. } \\
\text {--Practice Issues include: } \\
\text { Battering, wife abuse, alcohol } \\
\text { abuse, sexual abuse, severe \& } \\
\text { persistent mental illness, eating } \\
\text { disorders }\end{array}$ \\
\hline $\begin{array}{l}\text { How syllabus discusses the } \\
\text { role of social work in relation } \\
\text { to sex trades }\end{array}$ & $\begin{array}{l}\text { 1)Apply knowledge to combat } \\
\text { HT } \\
\text { 2) Be able to proerply identify \& } \\
\text { investigate (safely) HT }\end{array}$ & $\begin{array}{l}\text { 1)Assessment } \& \text { Intervention by } \\
\text { default of course purpose. }\end{array}$ \\
\hline $\begin{array}{l}\text { Ideologies, values, theoretical } \\
\text { perspectives that shape } \\
\text { content? } \\
\text {--Use } 2 \text { Examples }\end{array}$ & $\begin{array}{l}\text { It is complex, Youth are } \\
\text { vulenerable, It's a thing that } \\
\text { needs to stop. } \\
\text { Ex. } 1 \text { Walking Prey, How } \\
\text { America's Youth are Vulnerable } \\
\text { to Sex Slavery } \\
\text { Ex. } 2 \text { Typology of Modern Day } \\
\text { Slavery } \\
\text { Ex. } 3 \text { Slavery Footprint } \\
\text { Ex. } 4 \text { Amnesty Intl Proposal on } \\
\text { Decrim }\end{array}$ & $\begin{array}{l}\text { 1) Girls Like Us (Rachel } \\
\text { Lloyd's Memoir } \\
\text { 2) Unit on "women and } \\
\text { poverty" that covers: } \\
\text { homelessness, AIDS, } \\
\text { Prostitution }\end{array}$ \\
\hline $\begin{array}{l}\text { Content for Criminalization \& } \\
\text { Criminal Justice System }\end{array}$ & $\begin{array}{ll}\text { TIP Report, Palermo } \\
\text { Protocol, Current } \\
\text { Federal Laws, Shared } \\
\text { Hope (What We Do) } \\
\text { I am Jane Doe, Polaris } \\
\text { \& Shared Hope: Report } \\
\text { cards on Prostitution } \\
\text { State Laws \& Policies }\end{array}$ & ○ Girls Like Us \\
\hline $\begin{array}{l}\text { Content that reflects the needs } \\
\text { and Experiences of people in } \\
\text { the sex trades }\end{array}$ & $\begin{array}{ll} & \begin{array}{l}\text { Prostitution in } 9 \\
\text { countries }\end{array} \\
\text { Challenges of fighting } \\
\text { legalized prostitution }\end{array}$ & $\begin{array}{l}\text { Still a difficult issue for feminists } \\
\text { in Sex Work: Writing by Women } \\
\text { in the Sex Industry (Delacoste \& } \\
\text { Alexander) }\end{array}$ \\
\hline
\end{tabular}




\begin{tabular}{|c|c|c|}
\hline & $\begin{array}{ll} & \text { market in Netherlands, } \\
\circ & \text { Procon.org } \\
\circ & \text { Survivor perspectives } \\
\circ & \text { Walking Prey }\end{array}$ & \\
\hline $\begin{array}{l}\text { How does syllabus address } \\
\text { feminisms, if at all? }\end{array}$ & $\begin{array}{l}--1 \text { article shows there } \\
\text { multiple feminist perspectives } \\
\text {--Documentary film on sex } \\
\text { worker rights/empowerment }\end{array}$ & $\begin{array}{l}\text {--Course states that it seeks to } \\
\text { exemplify the classroom principle } \\
\text { of feminist social work. } \\
\text {--Feminism in historical } \\
\text { perspective, feminist sw practice, } \\
\text {--Feminism, Femininity, \& Freud, } \\
\text { by Gilligan, Mahler, Klein, } \\
\text { Erikson }\end{array}$ \\
\hline \multicolumn{3}{|c|}{ Perpetuates or Resists Dominant Narratives } \\
\hline $\begin{array}{l}\square \text { Addicted to drugs } \\
\square \text { Survivors of abuse (pathology) } \\
\square \text { Innocent/Victim/criminal/ } \\
\text { Exploited/trafficked } \\
\square \text { High rates of STI's and HIV } \\
\square \text { Other, describe }\end{array}$ & $\begin{array}{l}\text { Perpetuates: } \\
\text {--Survivors of abuse } \\
\text {--Innocent/victim/criminal/ } \\
\text { exploited/trafficked }\end{array}$ & $\begin{array}{l}\text { Perpetuates: } \\
\text {--High rates of STI's and HIV } \\
\text {--Street-based-connected to } \\
\text { homelessness }\end{array}$ \\
\hline $\begin{array}{l}\square \text { Addicted to drugs } \\
\square \text { Survivors of childhood sexual } \\
\text { abuse (pathology) } \\
\square \text { Innocent/victim/criminal/ } \\
\text { exploited/trafficked } \\
\square \text { Other, describe: }\end{array}$ & $\begin{array}{l}\text { Resists: } \\
\text {--Decriminalization Proposal } \\
\text {--One article shows sex workers } \\
\text { not just in an either/or binary }\end{array}$ & $\begin{array}{l}\text { Resists: } \\
\text {--incorporates multiple feminist } \\
\text { perspectives }\end{array}$ \\
\hline
\end{tabular}

